\title{
Hospital nurse staffing models and patient and staff-related outcomes (Review)
}

Butler M, Collins R, Drennan J, Halligan P, O’Mathúna DP, Schultz TJ, Sheridan A, Vilis E
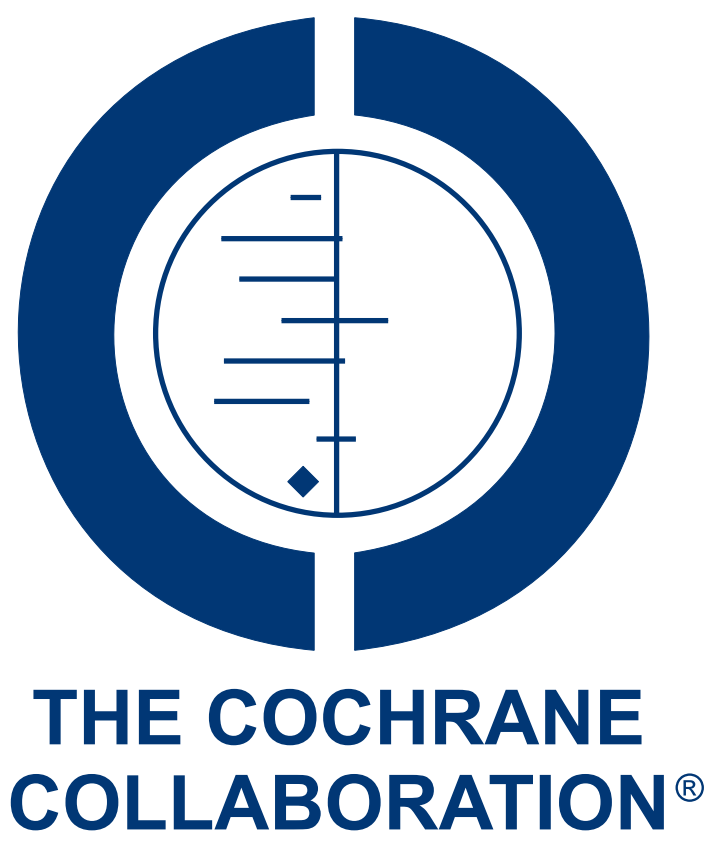

This is a reprint of a Cochrane review, prepared and maintained by The Cochrane Collaboration and published in The Cochrane Library 2011, Issue 7

http://www.thecochranelibrary.com

\section{WILEY}

Hospital nurse staffing models and patient and staff-related outcomes (Review)

Copyright @ 201 I The Cochrane Collaboration. Published by John Wiley \& Sons, Ltd. 
TABLE OF CONTENTS

HEADER . . . . . . . . . . . . . . . . . . . . . . . . . . . . . . . . . . . . . . . . . . . . .

ABSTRACT . . . . . . . . . . . . . . . . . . . . . . . . . . . . . . . . . . . . . . . . . . . . . . 1

PLAIN LANGUAGE SUMMARY . . . . . . . . . . . . . . . . . . . . . . . . . . . . . . . . . . . . . . . . . . . . .

SUMMARY OF FINDINGS FOR THE MAIN COMPARISON ．．．．．．．． . . . . . . . . . . . . . . . 3

BACKGROUND . . . . . . . . . . . . . . . . . . . . . . . . . . . . . . . . . . . . . . . . . . . .

OBJECTIVES . . . . . . . . . . . . . . . . . . . . . . . . . . . . . . . . . . . . . . . . . . . . . . . . .

METHODS . . . . . . . . . . . . . . . . . . . . . . . . . . . . . . . . . . . . . . . .

RESULTS . . . . . . . . . . . . . . . . . . . . . . . . . . . . . . . . . . . . . . . . . . . . .

Figure 1. . . . . . . . . . . . . . . . . . . . . . . . . . . . . . . . . . . . . . . . . . 9

Figure 2. . . . . . . . . . . . . . . . . . . . . . . . . . . . . . . . . . . . . . 11

Figure 3. . . . . . . . . . . . . . . . . . . . . . . . . . . . . . . . . . . . . 12

Figure $4 . \quad$. . . . . . . . . . . . . . . . . . . . . . . . . . . . . . . . . . . . . . . . . . . . . $\quad . \quad 13$

ADDITIONAL SUMMARY OF FINDINGS . . . . . . . . . . . . . . . . . . . . . . . . . . . . . . . . .

DISCUSSION . . . . . . . . . . . . . . . . . . . . . . . . . . . . . . . . . . . . . . . . . . . . . .

AUTHORS' CONCLUSIONS . . . . . . . . . . . . . . . . . . . . . . . . . . . . . . . . . . . .

ACKNOWLEDGEMENTS . . . . . . . . . . . . . . . . . . . . . . . . . . . . . . . . . . . . . .

REFERENCES . . . . . . . . . . . . . . . . . . . . . . . . . . . . . . . . . . . . . . . 20

CHARACTERISTICS OF STUDIES . . . . . . . . . . . . . . . . . . . . . . . . . . . . . . . . . . . . . . . . .

DATA AND ANALYSES . . . . . . . . . . . . . . . . . . . . . . . . . . . . . . . . . . . . . . . . . . 48

Analysis 1.1. Comparison 1 Addition of specialist nursing post to staffing versus standard staffing, Outcome 1 In-hospital mortality.

Analysis 1.2. Comparison 1 Addition of specialist nursing post to staffing versus standard staffing, Outcome 2 Length of stay.

Analysis 1.3. Comparison 1 Addition of specialist nursing post to staffing versus standard staffing, Outcome 3

Analysis 1.4. Comparison 1 Addition of specialist nursing post to staffing versus standard staffing, Outcome 4 Attendance

Analysis 1.5. Comparison 1 Addition of specialist nursing post to staffing versus standard staffing, Outcome 5 Postdischarge admission, ED visit or death.

Analysis 1.6. Comparison 1 Addition of specialist nursing post to staffing versus standard staffing, Outcome 6 Postdischarge adverse events.

Analysis 1.7. Comparison 1 Addition of specialist nursing post to staffing versus standard staffing, Outcome 7 Employment status 6 months post-discharge (of patients previously employed).

Analysis 1.8. Comparison 1 Addition of specialist nursing post to staffing versus standard staffing, Outcome 8 Glycosylated haemoglobin.

Analysis 2.1. Comparison 2 Increasing the proportion of support staff versus usual staffing, Outcome 1 Deaths in trauma unit.

Analysis 2.2. Comparison 2 Increasing the proportion of support staff versus usual staffing, Outcome 2 Deaths in hospital.

Analysis 2.3. Comparison 2 Increasing the proportion of support staff versus usual staffing, Outcome 3 Deaths at 4 months.

Analysis 3.1. Comparison 3 Team midwifery versus standard care, Outcome 1 Perinatal death. . . . . . . . . . 56

Analysis 3.2. Comparison 3 Team midwifery versus standard care, Outcome 2 Length of stay in hospital (days). . . $\quad 56$

Analysis 3.3. Comparison 3 Team midwifery versus standard care, Outcome 3 Length of stay in SCN (days). . . . $\quad 57$

ADDITIONAL TABLES . . . . . . . . . . . . . . . . . . . . . . . . . . . . . . . . . . . . . . . . 5

APPENDICES . . . . . . . . . . . . . . . . . . . . . . . . . . . . . . . . . . . . . 65

HISTORY . . . . . . . . . . . . . . . . . . . . . . . . . . . . . . . . . . . . . . . 70

CONTRIBUTIONS OF AUTHORS . . . . . . . . . . . . . . . . . . . . . . . . . . . . . . . . . . . . . . . . . . . . . .

DECLARATIONS OF INTEREST . . . . . . . . . . . . . . . . . . . . . . . . . . . . . . . . 70

SOURCES OF SUPPORT . . . . . . . . . . . . . . . . . . . . . . . . . . . . . . . . . . . . . . . . . . . .

DIFFERENCES BETWEEN PROTOCOL AND REVIEW . . . . . . . . . . . . . . . . . . . . . . . . . . . . . . .

Hospital nurse staffing models and patient and staff-related outcomes (Review)

Copyright $\odot 20$ II The Cochrane Collaboration. Published by John Wiley \& Sons, Ltd. 
Hospital nurse staffing models and patient and staff-related outcomes (Review)

Copyright $\odot 201$ I The Cochrane Collaboration. Published by John Wiley \& Sons, Ltd. 


\title{
[Intervention Review] \\ Hospital nurse staffing models and patient and staff-related outcomes
}

\author{
Michelle Butler ${ }^{1}$, Rita Collins ${ }^{1}$, Jonathan Drennan ${ }^{1}$, Phil Halligan ${ }^{1}$, Dónal P O’Mathúna ${ }^{2}$, Timothy J Schultz ${ }^{3,4}$, Ann Sheridan ${ }^{1}$, \\ Eileen Vilis ${ }^{5}$ \\ ${ }^{1}$ School of Nursing, Midwifery and Health Systems, University College Dublin, Dublin, Ireland. ${ }^{2}$ School of Nursing, Dublin City \\ University, Dublin, Ireland. ${ }^{3}$ Discipline of Nursing, University of Adelaide, Adelaide, Australia. ${ }^{4}$ Australian Patient Safety Foundation, \\ Adelaide, Australia. ${ }^{5}$ Canadian Cochrane Centre, University of Ottawa, Ottawa, Canada
}

Contact address: Michelle Butler, School of Nursing, Midwifery and Health Systems, University College Dublin, Belfield, Dublin, Dublin 4, Ireland. michelle.butler@ucd.ie.

Editorial group: Cochrane Effective Practice and Organisation of Care Group.

Publication status and date: New, published in Issue 7, 2011.

Review content assessed as up-to-date: 30 May 2010.

Citation: Butler M, Collins R, Drennan J, Halligan P, O’Mathúna DP, Schultz TJ, Sheridan A, Vilis E. Hospital nurse staffing models and patient and staff-related outcomes. Cochrane Database of Systematic Reviews 2011, Issue 7. Art. No.: CD007019. DOI: 10.1002/14651858.CD007019.pub2.

Copyright (C) 2011 The Cochrane Collaboration. Published by John Wiley \& Sons, Ltd.

\begin{abstract}
A B S T R A C T

\section{Background}

Nurse staffing interventions have been introduced across countries in recent years in response to changing patient requirements, developments in patient care, and shortages of qualified nursing staff. These include changes in skill mix, grade mix or qualification mix, staffing levels, nursing shifts or nurses' work patterns. Nurse staffing has been closely linked to patient outcomes, organisational outcomes such as costs, and staff-related outcomes.
\end{abstract}

\section{Objectives}

Our aim was to explore the effect of hospital nurse staffing models on patient and staff-related outcomes.

\section{Search methods}

We searched the following databases from inception through to May 2009: Cochrane/EPOC resources (DARE, CENTRAL, the EPOC Specialised Register), PubMed, EMBASE, CINAHL Plus, CAB Health, Virginia Henderson International Nursing Library, the Joanna Briggs Institute database, the British Library, international theses databases, as well as generic search engines.

\section{Selection criteria}

Randomised control trials, controlled clinical trials, controlled before and after studies and interrupted time series analyses of interventions relating to hospital nurse staffing models. Participants were patients and nursing staff working in hospital settings. We included any objective measure of patient or staff-related outcome.

\section{Data collection and analysis}

Seven reviewers working in pairs independently extracted data from each potentially relevant study and assessed risk of bias.

Hospital nurse staffing models and patient and staff-related outcomes (Review)

Copyright $\odot 201$ I The Cochrane Collaboration. Published by John Wiley \& Sons, Ltd. 


\section{Main results}

We identified 6,202 studies that were potentially relevant to our review. Following detailed examination of each study, we included 15 studies in the review. Despite the number of studies conducted on this topic, the quality of evidence overall was very limited. We found no evidence that the addition of specialist nurses to nursing staff reduces patient death rates, attendance at the emergency department, or readmission rates, but it is likely to result in shorter patient hospital stays, and reductions in pressure ulcers. The evidence in relation to the impact of replacing Registered Nurses with unqualified nursing assistants on patient outcomes is very limited. However, it is suggested that specialist support staff, such as dietary assistants, may have an important impact on patient outcomes. Self-scheduling and primary nursing may reduce staff turnover. The introduction of team midwifery (versus standard care) may reduce medical procedures in labour and result in a shorter length of stay without compromising maternal or perinatal safety. We found no eligible studies of educational interventions, grade mix interventions, or staffing levels and therefore we are unable to draw conclusions in relation to these interventions.

\section{Authors' conclusions}

The findings suggest interventions relating to hospital nurse staffing models may improve some patient outcomes, particularly the addition of specialist nursing and specialist support roles to the nursing workforce. Interventions relating to hospital nurse staffing models may also improve staff-related outcomes, particularly the introduction of primary nursing and self-scheduling. However, these findings should be treated with extreme caution due to the limited evidence available from the research conducted to date.

\section{PLAIN LANGUAGE SUMMARY}

\section{Hospital nurse staffing models and patient and staff-related outcomes}

Many countries have introduced new models for staffing hospital units with nursing staff in response to shortages of qualified nurses and changes in patient care needs. These include changes in the mix of qualified and unqualified nurses within the hospital workforce, the mix of nurses with different qualifications and different levels of experience, and the way in which nursing staff are allocated to hospital units and to individual patients receiving care on each hospital unit. We identified 15 relevant studies that were considered to be of an appropriate design to be included in this review.

It appears that certain changes to hospital nurse staffing, particularly the introduction of specialist nursing roles and specialist support staff, may improve patient outcomes. The introduction of staffing models such as primary nursing and self-scheduling may reduce the number of staff resignations. However, the research in relation to these topics is limited and the findings should be treated with caution.

Hospital nurse staffing models and patient and staff-related outcomes (Review) 


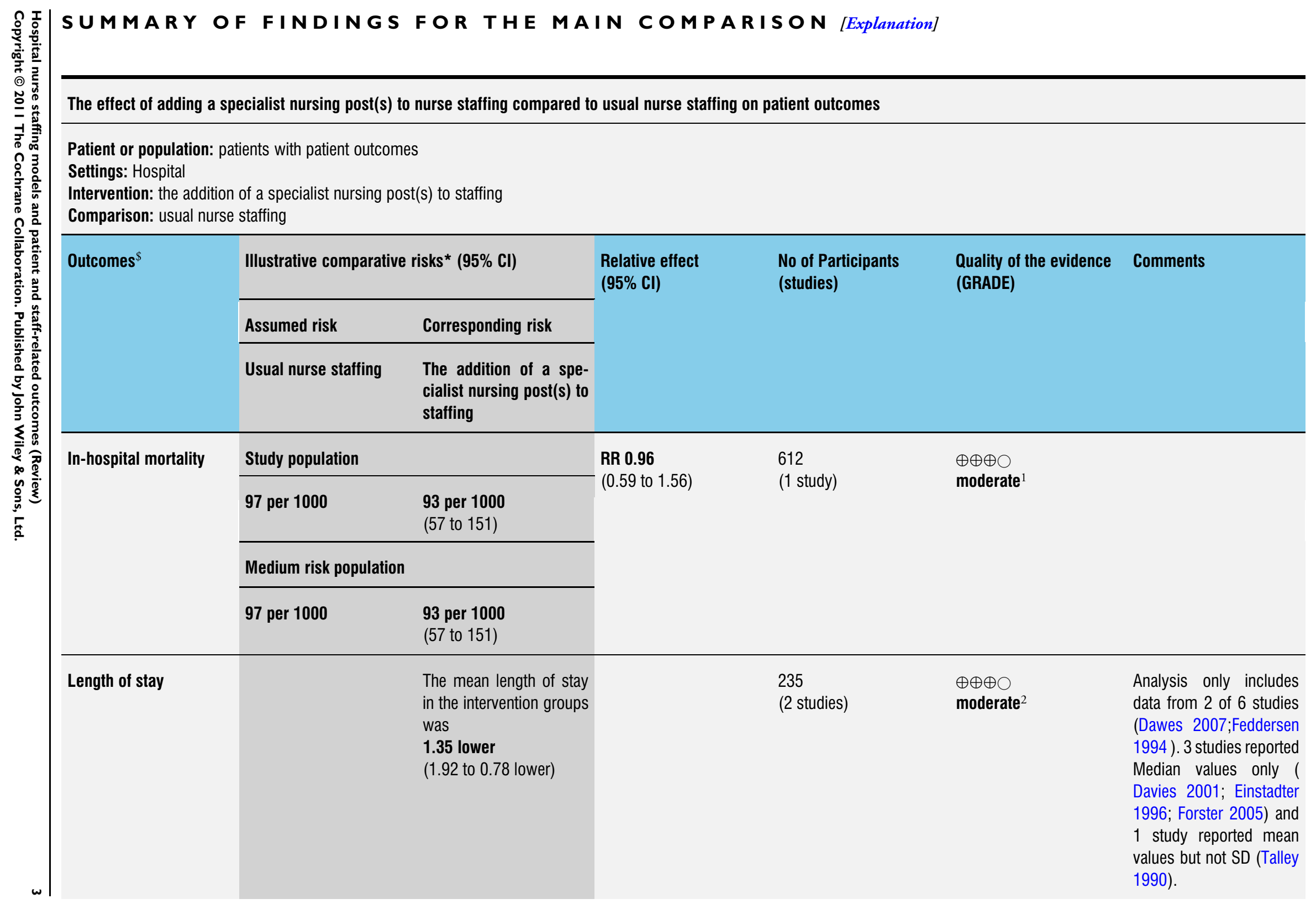




\begin{tabular}{|c|c|c|c|c|c|c|}
\hline \multirow[t]{4}{*}{ Readmission } & \multicolumn{2}{|c|}{ Study population } & \multirow{4}{*}{$\begin{array}{l}\text { RR } 1.15 \\
(0.88 \text { to } 1.52)\end{array}$} & \multirow{4}{*}{$\begin{array}{l}878 \\
\text { (3 studies) }\end{array}$} & \multirow{4}{*}{$\begin{array}{l}\oplus \oplus \oplus \bigcirc \\
\text { moderate }^{2}\end{array}$} & \multirow{4}{*}{$\begin{array}{l}\text { Analysis does not include } \\
\text { data from } 1 \text { study (Forbes } \\
2006 \text { ) as data were re- } \\
\text { ported as the range of } \\
\text { readmission rates over } \\
\text { the three time periods } \\
\text { rather than actual values }\end{array}$} \\
\hline & 174 per 1000 & $\begin{array}{l}200 \text { per } 1000 \\
(153 \text { to } 264)\end{array}$ & & & & \\
\hline & \multicolumn{2}{|c|}{ Medium risk population } & & & & \\
\hline & 144 per 1000 & $\begin{array}{l}166 \text { per } 1000 \\
(127 \text { to } 219)\end{array}$ & & & & \\
\hline \multirow{4}{*}{$\begin{array}{l}\text { Attendance at ED within } \\
30 \text { days }\end{array}$} & Study populati & & \multirow{4}{*}{$\begin{array}{l}\text { RR } 1.14 \\
(0.79 \text { to } 1.62)\end{array}$} & \multirow{4}{*}{$\begin{array}{l}472 \\
\text { (1 study) }\end{array}$} & \multirow{4}{*}{$\begin{array}{l}\oplus \oplus \oplus \bigcirc \\
\text { moderate }^{3}\end{array}$} & \\
\hline & 192 per 1000 & $\begin{array}{l}219 \text { per } 1000 \\
(152 \text { to } 311)\end{array}$ & & & & \\
\hline & \multicolumn{2}{|c|}{ Medium risk population } & & & & \\
\hline & 192 per 1000 & $\begin{array}{l}219 \text { per } 1000 \\
(152 \text { to } 311)\end{array}$ & & & & \\
\hline \multirow{4}{*}{$\begin{array}{l}\text { Post-discharge admis- } \\
\text { sion, ED visit or death }\end{array}$} & \multicolumn{2}{|c|}{ Study population } & \multirow{4}{*}{$\begin{array}{l}\text { RR } 1.33 \\
(0.93 \text { to } 1.91)\end{array}$} & \multirow{4}{*}{$\begin{array}{l}328 \\
\text { (1 study) }\end{array}$} & \multirow{4}{*}{$\begin{array}{l}\oplus \oplus \oplus \bigcirc \\
\text { moderate }^{1}\end{array}$} & \\
\hline & 234 per 1000 & $\begin{array}{l}311 \text { per } 1000 \\
\text { (218 to } 447)\end{array}$ & & & & \\
\hline & \multicolumn{2}{|c|}{ Medium risk population } & & & & \\
\hline & 234 per 1000 & $\begin{array}{l}311 \text { per } 1000 \\
\text { (218 to } 447)\end{array}$ & & & & \\
\hline \multirow{3}{*}{$\begin{array}{l}\text { Post-discharge adverse } \\
\text { events }\end{array}$} & \multicolumn{2}{|c|}{ Study population } & \multirow{3}{*}{$\begin{array}{l}\text { RR } 1.03 \\
(0.7 \text { to } 1.53)\end{array}$} & \multirow{3}{*}{$\begin{array}{l}328 \\
\text { (1 study) }\end{array}$} & \multirow{3}{*}{$\begin{array}{l}\oplus \oplus \oplus \bigcirc \\
\text { moderate }^{1}\end{array}$} & \\
\hline & 228 per 1000 & $\begin{array}{l}235 \text { per } 1000 \\
(160 \text { to } 349)\end{array}$ & & & & \\
\hline & Medium risk p & & & & & \\
\hline
\end{tabular}




\begin{tabular}{|c|c|c|c|}
\hline $\begin{array}{l}\text { Glycosylated haemoglo- } \\
\text { bin }\end{array}$ & $\begin{array}{l}\text { The mean Glycosylated } \\
\text { haemoglobin in the inter- } \\
\text { vention groups was } \\
\mathbf{0 . 5} \text { lower } \\
\text { (1.9 lower to } 0.9 \text { higher) }\end{array}$ & $\begin{array}{l}88 \\
\text { (1 study) }\end{array}$ & $\begin{array}{l}\oplus \oplus \bigcirc \bigcirc \\
\text { low }^{3,4}\end{array}$ \\
\hline
\end{tabular}

*The basis for the assumed risk (e.g. the median control group risk across studies) is provided in footnotes. The corresponding risk (and its $95 \%$ confidence interval) is based on the assumed risk in the comparison group and the relative effect of the intervention (and its $95 \% \mathrm{Cl}$ ).

Cl: Confidence interval; RR: Risk ratio;

GRADE Working Group grades of evidence

High quality: Further research is very unlikely to change our confidence in the estimate of effect.

Moderate quality: Further research is likely to have an important impact on our confidence in the estimate of effect and may change the estimate.

Low quality: Further research is very likely to have an important impact on our confidence in the estimate of effect and is likely to change the estimate.

Very low quality: We are very uncertain about the estimate.

${ }^{\$} \mathrm{~A}$ range of outcomes were included across studies relating to this intervention. In some cases, an outcome may have been included in one study only. Therefore the number of studies per outcome varies considerably.

Differences noted in baseline characteristics of control and intervention groups

2 One study was a CCT - therefore not randomly allocated

${ }^{3}$ CCT study - therefore not randomly allocated

${ }^{4}$ Results reported only for 88/129 patients - no explanation given 


\section{B A C K G R O U N D}

A range of nurse staffing model interventions has been introduced across countries in recent years to address nursing shortages. These include changes to nurse staffing levels, the nursing skill mix, the educational preparation of nurses, staff allocation models, shift patterns, and the use of overtime and agency staff. It is suggested that nurse staffing is closely associated with the quality of care that patients receive and with patient outcomes.

\section{Description of the condition}

Currently there is a shortage of nurses across many countries (Buchan 2005; Buchan 2009; Potempa 2009) which is likely to continue in the coming decade (Potempa 2009; Preston 2009). At the same time, hospitalised patients have become more acutely ill, requiring more intensive nursing time and care (Buerhaus 2000; Lang 2004) and ageing populations are likely to require additional nursing resources (Preston 2009). In addition, the numbers of patients receiving hospital care has increased in many countries (e.g. Australia (AIHW 2006)). The International Council of Nurses reported that "a common challenge facing HR managers is determining the most effective mix of staff and skills needed to deliver quality and cost-effective patient care" in the light of "rising demand for health services, cost containment and shortages of nurses and other health workers" (ICN 2006).

\section{Description of the intervention}

Models of hospital nurse staffing dictate the allocation of nursing resources to meet patient care needs. The numbers of nurses available in a hospital or hospital unit (staffing levels) can be quantified in relation to numbers of patients in that hospital or hospital unit (nurse per patient ratio). Numbers of nurses can also be quantified in terms of hours of nursing care and nurse full time equivalents (FTE) or whole time equivalents (WTE). Currently, one WTE/ FTE is equivalent to 37.5 hours per week in Australia, Canada and Ireland. Mandatory nurse to patient ratios have been introduced in California, USA and in the state of Victoria in Australia in response to concerns about staffing levels. Several countries have resorted to overseas recruiting in order to address the shortfall of nurses (e.g. Humphries 2008).

The mix of nurses can be quantified in terms of skill mix, grade mix or qualification mix. Skill mix may refer to the mix of "licensed" and "unlicensed" staff in the case of the US nursing workforce (Kane 2007) or registered or unregistered staff in the case of the Irish, Australian and the UK workforce, or "the proportion of different nursing grades, and levels of qualification, expertise and experience" (Ayre 2007; Buchan 2002; Spilsbury 2001). Grade mix refers to the proportion of nursing grades in the nursing workforce. These are occupational grades that are assigned to posts rather than individuals, and the grading models vary within and across countries. Grade may be used as a proxy for skill (Carr-Hill 1995), but skill mix is more than grade mix - it relates to qualifications, experience and competencies. Qualification mix refers to the proportion of different nursing qualifications in the work force. Changes in the mix of nurses with different educational qualifications may also result in a change in skill mix in relation to the proportion of nurses with or without additional or more advanced skills and knowledge. Skill mix, grade mix or qualification mix may refer to the mix of nurses in a hospital, in a hospital unit or on a hospital ward.

Internationally, the education and training of nurses has rapidly evolved to attempt to address issues of shortage of supply, increased demand, and expansion of the role of nurses. Examples include the introduction of a shorter programme (often of two years duration instead of three), the introduction of degree programmes, and the introduction of post registration education programmes.

New models of nurse staffing have also been introduced in different countries which relate to how patients are assigned to nurses working on a hospital ward or unit. One example of this is primary nursing. In primary nursing, one nurse (the primary nurse) is responsible for total care of a number of patients 24 hours a day, seven days a week, aimed at providing "comprehensive, individualised and consistent care" (Kozier 2008, p133). The primary nurse assesses and prioritises each patient's needs, and plans and evaluates the patient's care. The primary nurse co-ordinates the patient's care and is their "first line manager ... with all its inherent accountabilities and responsibilities". However, other nursing staff may also be involved in the patient's care (Kozier 2008, p134).

Changes have also been made to nursing shifts or nurses' work patterns and there is a greater reliance on the use of overtime and agency staff to cover nursing shifts (Rogers 2004).

\section{How the intervention might work}

It is suggested that nurse staffing is closely related to the quality of the nursing practice environment, and subsequently to patient outcomes (Leiter 2006). Further it is suggested that nurse staffing and the practice environment together influence patient outcomes directly and indirectly through "nurse job outcomes" (Lake 2006). It has been argued that nurse staffing and nursing skill mix are "directly linked" to quality of care, with a lower proportion of registered nurses in the nursing workforce being associated with increased patient length of stay, incidence of hospital acquired infections, and prevalence of pressure ulcers (Currie 2005). The evidence base in the area of skill mix is limited. Some studies report improvements in cost effectiveness and quality improvements following the introduction of care assistants, but other studies report decreases in quality of care, higher workload for registered nurses, and higher turnover or absence rates. Increases in costs to cover time on call, sick leave and overtime have also been reported (Buchan 2005). The evidence is also limited in relation to changes in nursing shifts or nurses' work patterns. A recent systematic re- 
view reported equivocal results when the effects of shift length on quality of patient care was examined (Estabrooks 2009).

\section{Why it is important to do this review}

Although the effects of changes to nurse staffing have important implications for healthcare provision, the bulk of the public policy driving these changes is not evidence-based because of "an insufficient body of credible evidence linking changes in the hospital nurse work force to potentially adverse effects on patient outcomes" (Buerhaus 2000). Further, it is suggested that the "considerable research" capable of informing the debate about the relationship between the nursing work force and patient outcomes is often "selectively quoted to support arguments" (Lankshear 2005). Several reviews of nurse staffing and patient outcomes have been conducted previously but are limited in relation to the scope of the literature search. For example, Lankshear 2005's systematic review of nurse staffing and healthcare outcomes was limited to studies published between 1990 and 2004. The method used by Spilsbury 2001 to examine nursing outcomes, skill mix, and changing roles included a literature review and use of an expert panel to inform debate. Their review of the literature was limited to studies conducted in the UK between 1992 and 1998. Lang 2004 conducted a systematic review of the effects of nurse staffing on patient, employee, and hospital outcomes. Their study was limited to studies conducted in the United States and published between 1980 and 2003. It is not possible to assess the breadth and depth of McKenna 1995's study of skill mix substitutions and quality of care, as details of the search are not outlined within the published work available.

Other reviews have included studies that are outside of the focus of this review in relation to the methods or outcomes. For example, Numata 2006 conducted a literature review and meta-analysis of nurse staffing levels and hospital mortality in critical care settings. This review involved a comprehensive search for studies going back to 1966 (MEDLINE) and was last updated in October 2005. All nine studies included were observational and did not include interventions. Kane 2007's systematic review of nurse staffing and the quality of patient care was limited to observational studies conducted in the United States and Canada between 1990 and 2006. Observational studies did not meet the inclusion criteria for our review. The concept of quality and relationship with staffing levels and skill mix was the focus of Currie 2005's literature review, which involved a 'comprehensive search' of the literature. Currie's study discussed the literature but did not weigh evidence to support associations between nurse staffing and patient outcomes. Crossan 2005's 'descriptive review' of nursing skill mix is very broad in nature with little reference to patient outcomes or scrutiny of the quality of the identified research.

A small number of reviews have been conducted that focus on a single aspect of the review presented here. De Broe 2001's rapid review of the role of specialist nurses in multiple sclerosis in- volved a detailed and comprehensive search strategy across electronic databases. Their review also included a less extensive review of the role of the specialist nurse in diabetes, epilepsy and Parkinson's disease. Estabrooks 2009 conducted a systematic review of shift length on patient and health provider outcomes. Some of these very specific reviews have also been limited in relation to the scope of the search strategy. For example, Carter 2007's study of the impact of nurse practitioners working in the emergency department was limited to studies published in English listed in MEDLINE and CINAHL before November 2006. Lookinland 2005 's study of non-traditional practice models in nursing and patient outcomes was limited to studies listed in CINAHL, MEDLINE and PubMed between 1998 and April 2004.

This study aimed to address the limitations identified in this comprehensive list of related studies through an inclusive systematic review of the current research evidence in relation to the effect of hospital nurse staffing models on patient and staff-related outcomes.

\section{O B JE C T I VES}

The purpose of this review was to explore the effect of hospital nurse staffing models on patient and staff-related outcomes, specifically:

1. To identify which staffing model(s) are associated with better outcomes for patients in the hospital setting.

2. To identify which staffing model(s) are associated with better staff-related outcomes in the hospital setting.

To address these aims, the effects of hospital nurse staffing model interventions were compared with the effects of controls (previously existing hospital nurse staffing models) using the criteria found in evaluations of nurse staffing models.

\section{METHODS}

\section{Criteria for considering studies for this review}

\section{Types of studies}

We sought all relevant published and unpublished randomised controlled trials (RCTs), controlled clinical trials (CCTs), controlled before and after studies (CBAs), or interrupted time series studies (ITSs) that met the EPOC eligibility criteria. There were no restrictions on time period, jurisdiction, or language. Relevant studies which did not use one of the previously mentioned designs were excluded. We assessed the risk of bias of all included studies using the EPOC criteria (EPOC 2009). 


\section{Types of participants}

Participants were hospital nursing staff and hospital patients. Hospitals included acute and non-acute, small, medium and large, teaching and non-teaching, and public and private. Staff were registered nurses or their international equivalents (e.g. registered general nurse, staff nurse, professional nurse), licensed practical nurses or their international equivalents (e.g. licensed vocational nurse, enrolled nurse), and unlicensed assistive personnel or their international equivalents (e.g. nurses' aide, auxiliary nurse, nursing assistant). We excluded studies of nurse staffing outside of hospitals (e.g. community, nursing homes). Staffing models in residential/ nursing home/extended care settings are the focus of a separate Cochrane Review (Haesler 2007).

\section{Types of interventions}

We considered all studies of hospital nurse staffing model interventions. These included interventions of staffing models, staffing levels, skill mix, grade mix, or qualification mix. Staffing models are models used to identify and allocate nursing staff, shift patterns, use of overtime, or use of non-core staff. Staffing levels include nurse to patient ratios, hours of nursing care, nurse full time equivalents (FTEs), or nurse whole time equivalents (WTEs). Skill mix refers to the proportion of total hours of nursing care provided by registered nurses, number of registered nurse hours per day, proportion of registered nurses in the work force, or proportion of advanced nurse practitioners. Grade mix refers to the proportion of nursing grades in the work force. Qualification mix refers to the proportion of graduate nurses in the nursing work force, the proportion of nurses with a post-registration qualification (obtained following registration as a nurse), or the proportion of nurses with a post-graduate qualification. We excluded studies of the substitution of doctors by nurses. Such substitution is the focus of a separate Cochrane Review (Laurant 2004). Studies of ratios between nurses and other professionals were also beyond the scope of this review.

\section{Types of outcome measures}

The primary outcomes of interest to this review were any objective measures of patient or staff-related outcomes (using the methodological inclusion criteria for an EPOC review (EPOC 2002)). These included patient mortality, risk-adjusted patient mortality, in-hospital death, length of patient's stay, staff sick leave rates, and staff turnover rates.

Other objective outcome measures included "nursing-sensitive patient outcomes" which are defined as "variable patient or family caregiver states, behaviours, or perceptions at a low level of abstraction that are responsive to nursing interventions and used for determining a patient outcome" (Gordon 1998). Doran 2003 defines nursing-sensitive outcomes as "those that are relevant, based on nurses' scope and domain of practice, and for which there is empirical evidence linking nursing inputs and interventions to the outcomes." Several measures of nurse-sensitive or nursing-sensitive patient outcomes can be found in the literature (Kane 2007; Doran 2006). Examples of objective nursing-sensitive outcomes include infections, falls, pressure/decubitus ulcer, complications, or medication errors.

Studies focusing on outcomes that were not considered to be objective were excluded from this review (as is required for EPOC reviews EPOC 2002). Examples found in studies of nurse staffing included patient satisfaction, staff satisfaction, quality of life, disease impact, staff stress, and staff burnout.

\section{Search methods for identification of studies}

The following databases were searched through to May 2009 to identify primary studies: 1) Cochrane databases (DARE, CENTRAL) and the EPOC Specialised Register; 2) Bibliographic databases including CINAHL (Ebsco) Medline (OVID), EMBASE (OVID), Cochrane Library (Wiley), CAB Health (OVID) and the Joanna Briggs database; 3 ) the British Library and British and Irish Theses database, University of Michigan database of US Theses and Dissertations and other international theses databases; and 4) generic search engines (Google, Yahoo) for government or nursing organisation reports. In addition, the following were used to identify primary studies: handsearches of high-yield journals and conference proceedings not already handsearched on behalf of the Cochrane Collaboration; searches of reference lists of all papers and relevant reviews identified; contacting authors of relevant papers and other related reviews seeking information on any further published or unpublished work; and a search of the ISI Web of Science for papers which cite studies included in the review. We searched electronic databases using a strategy incorporating the methodological component of EPOC search terms with selected $\mathrm{MeSH}$ terms and free text terms relating to hospital nurse staffing. The search strategies used for each electronic database are included in Appendix One.

\section{Data collection and analysis}

Two authors (MB and one assigned author) independently assessed each potentially relevant study for inclusion using pre-established inclusion criteria. We excluded studies if they were not of the appropriate design (i.e. RCT, CCT, CBA with at least two control and two intervention groups, or ITS with at least three data points pre- and post-intervention), did not relate to hospital staff or hospital patients, did not relate to one of the interventions specified (i.e. staffing models, staffing levels, skill mix, grade mix or qualification mix), or included only secondary outcomes or outcomes that were not considered to be objective. We catalogued all excluded studies along with their reason for exclusion. We retrieved and stored electronically full text copies of all potentially relevant studies. Two authors independently extracted data 
using a modified version of the EPOC data collection checklist. We resolved any disagreement in the screening or data extraction process by discussion between authors. Two authors assessed the risk of bias of all eligible studies.

\section{Analysis}

Effects of interventions were measured based on changes in absolute numbers or mean values and data were used to calculate risk ratios, mean differences and confidence intervals for some outcomes. In order to provide a visual presentation of findings, where data were available for outcomes from two or more similar studies, these were entered into Revman to produce forest plots. However, our meta-analysis is limited because of the small number of eligible studies identified for each intervention.

In accordance with EPOC guidelines, where possible, results from CBA studies are presented in terms of: (1) absolute difference (mean or proportion in intervention group minus control); (2) relative percentage difference (absolute difference divided by postintervention score in the control group); (3) absolute change from baseline (pre to post changes in both groups); and (4) difference in absolute change from baseline. In studies without baseline data, only absolute difference and relative percentage difference were calculated.

\section{On-going studies}

We have reported on-going studies detailing the primary author, research question(s), methods and outcome measures. Analysis of these studies will be included in future updates of the review.

\section{RE S U L T S}

\section{Description of studies}

See: Characteristics of included studies; Characteristics of excluded studies; Characteristics of ongoing studies.

The search resulted in the identification of 6,202 potentially relevant studies. Further assessment of these studies resulted in the inclusion of 15 eligible studies. The process for study inclusion and exclusion is represented in Figure 1.

Figure I. Identification and screening of relevant studies

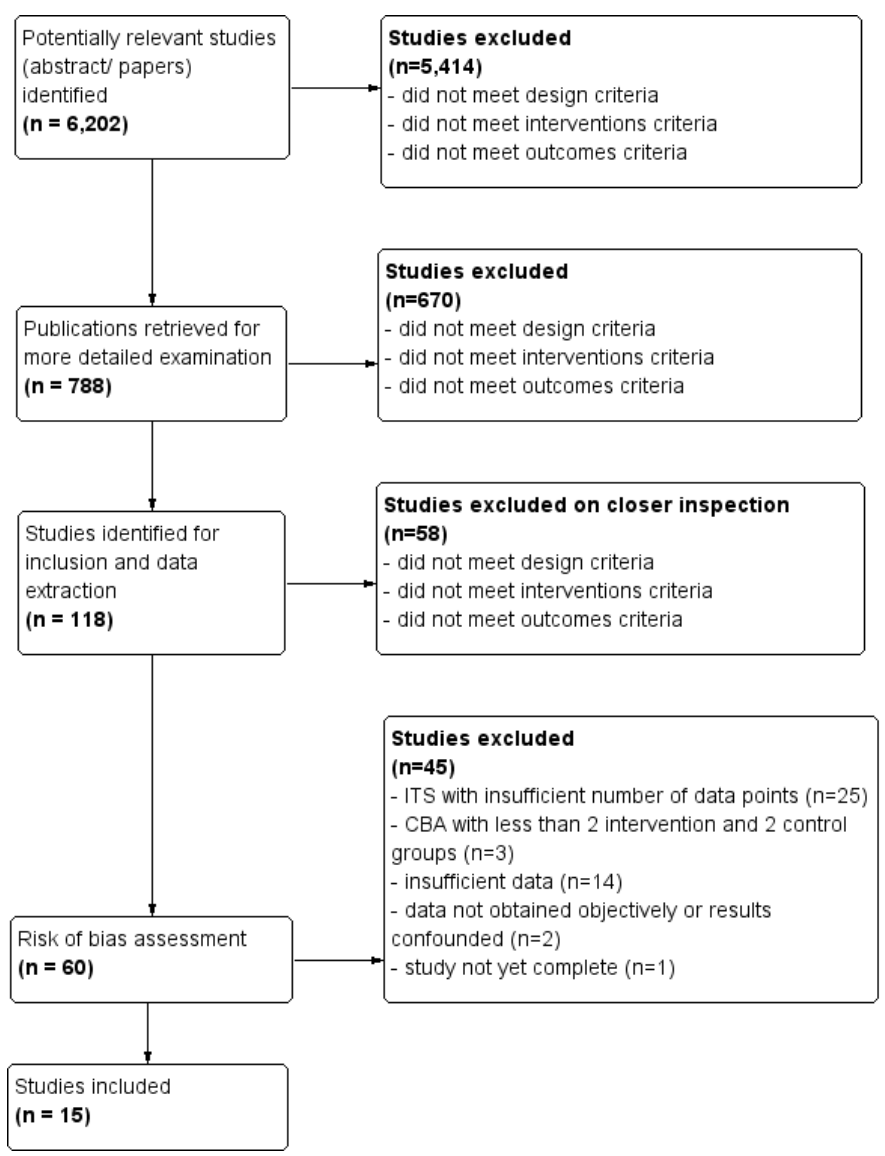

Hospital nurse staffing models and patient and staff-related outcomes (Review)

Copyright $\odot 201$ I The Cochrane Collaboration. Published by John Wiley \& Sons, Ltd. 


\section{Results of the search}

We conducted two searches for this review: an initial search in November 2007 and a second search in May 2009. The two searches yielded a total of 6,202 studies, 486 of which were identified as potentially relevant to our study. The search included electonic databases, generic search engines, hand searches, reference lists, information from authors about other studies and a search of the ISI web of science. Table 1 provides further information on the sources of included studies.

\section{Included studies}

Following closer examination of studies through the data extraction and risk of bias assessment process, 15 studies were identified for inclusion in this study. There were four studies of staffing models which included interventions relating to primary nursing, self-scheduling and team midwifery. There were 11 studies relating to nursing skill-mix. We identified two types of nurse staffing interventions in relation to staffing skill mix: 1) the addition of specialist nurse(s) to usual staffing (nine studies), and 2) increasing the proportion of support staff versus usual nurse staffing (two studies).

Of the 15 studies included, eight were randomised controlled trials (Biro 2000; Davies 2001; Dawes 2007; Duncan 2006; Forster 2005; Pozen 1977; Ritz 2000; Talley 1990), two were controlled clinical trials (Einstadter 1996; Feddersen 1994), and five were controlled before and after studies (Boumans 1999; Forbes 2006; Melchoir 1996; Neidlinger 1993; O’Connor 1992).

A range of different patient and staff-related outcomes was found across studies. Most studies of staffing models focused on staffrelated outcomes such as absenteeism, staff retention and staff turnover. However, one study also included patient outcomes (patient falls, medication errors and adverse incidents) and costs. Studies relating to nursing skill-mix focused on patient outcomes and costs. Patient outcomes included length of stay, patient mortality, readmission and attendance at the emergency department post-discharge, and several other clinical outcomes (seeTable 2). Biro 2000's study of the effect of team midwifery examined delivery outcomes including procedures in labour, mode of delivery and perinatal outcomes.

\section{Excluded studies}

Several other potentially relevant studies were identified for these and other interventions (staffing levels, grade mix, partnership models, qualification mix) but they were excluded because they did not meet other inclusion criteria (e.g. design, outcomes). Twenty-five studies were classified as interrupted time series studies (Armstrong 2004; Arts 2000; Burnes Bolton 2007; Cavan
2001; Donaldson 2005; Eck 1999; Gardner 1991; Grillo-Peck 1995; Hinshaw 1981; Jansen 1994; Lea 2003; Lee 2005; Lewis 1994; Brett 1990; O’Hare 2006; Pratt 1993; Rideout 2007; Sarkissan 1999; Sheill 1993; Smith 2006; Strayer 2008; Vaska 1993; Williams 2000; Yong 2002; Zidek 2003). However, none of these studies met the EPOC criterion for inclusion which is the collection of data at three or more data points pre- and postintervention. Most studies had just one or two data points before or after the intervention. The EPOC inclusion criteria for ITS studies are quite strict in order to minimise the threats to internal validity that may arise in ITS studies due to history, maturation, instrumentation bias and selection bias (EPOC 1998).

Eight relevant CBA studies were identified but three of these studies (Hanneman 1993; Lengacher 1994; Tourangeau 1999) were excluded because they did not have the minimum number of intervention and control groups (four groups) required in the EPOC minimum criteria for CBA studies (EPOC 2002).

A further 16 relevant studies were identified but not included because results were not reported adequately (Benson 2008; Campolo 1998; Chavigny 1984; Choi 1986; Ciske 1974; Counsell 1999; Danello 2008; Davis 1997; Eriksen 1992; Heinemann 1996; Kenney 2001; McPhail 1990; Ringerman 2000; Sullivan 2002) or because of problems with the results (in one, the results were confounded (Barkell 2002)); in another, data were not obtained objectively (Sinclair 2006).

\section{Risk of bias in included studies}

The risk of bias of all studies was assessed using criteria set out in the EPOC risk of bias tool. RCT and CCT studies were also assessed using the GRADE Working Group Grades of Evidence criteria (Guyatt 2008). The risk of bias of included studies is described in the following section by study type.

\section{A. Randomised controlled trials}

Of the eight RCTs, three were assessed to be of low risk of bias (Biro 2000; Dawes 2007; Duncan 2006). Three studies were assessed to be of moderate risk of bias (Davies 2001; Forster 2005; Talley 1990) and the remaining two were assessed to be of high risk of bias. Only four RCT studies provided sufficient information to demonstrate that the sequence had been adequately generated and that allocation was concealed (Biro 2000; Dawes 2007; Duncan 2006; Forster 2005). Blinding of the participants or clinicians was only done or feasible in three studies (Biro 2000; Dawes 2007; Forster 2005) and outcomes assessment was blinded in three of the eight studies (Dawes 2007; Duncan 2006; Forster 2005). With the exception of one study (Ritz 2000), outcome reporting appeared complete across RCTs. Seven studies conducted a baseline assessment of groups. In the remaining study, the results reported

Hospital nurse staffing models and patient and staff-related outcomes (Review) 
are of differences between sub-groups rather than between the intervention and the control group (Talley 1990). In seven studies the control group appeared to be similar but some differences were noted between groups in the remaining study (Forster 2005).

\section{B. Clinical controlled trials}

Both CCT studies were assessed to be of moderate risk of bias (Einstadter 1996; Feddersen 1994). In both cases blinding of participants/clinicians and blinding of outcome assessment was not done.

\section{Controlled before and after studies}

Five studies were CBAs (Boumans 1999; Forbes 2006; Melchoir 1996; Neidlinger 1993; O'Connor 1992) and all were assessed to be of moderate risk of bias. All five studies fulfilled the criteria for pre-specification of the features to be assessed, adequate recording of what happened in the study and prospective collection of data pre- and post-intervention. None of the studies blinded participants/clinicians or outcome assessment. Data were incomplete in two studies (Forbes 2006; Melchoir 1996). In only three studies was it possible to determine that the study was free of selective outcome reporting (Boumans 1999; Neidlinger 1993; O’Connor 1992). Only two studies provided sufficient detail to show that the control group was similar to the study group (Boumans 1999; O'Connor 1992). Two studies reported specific sources of bias (Boumans 1999; Melchoir 1996).

\section{Effects of interventions}

See: Summary of findings for the main comparison The effect of adding a specialist nursing post(s) to nurse staffing compared to usual nurse staffing on patient outcomes; Summary of findings 2 Effect of adding dietary assistants to nurse staffing compared to usual nurse staffing on patient outcomes; Summary of findings 3 The effect of team midwifery compared to usual midwifery staffing on maternity care outcomes

A. Addition of a specialist nursing post to nurse staffing versus usual nurse staffing

Patient outcomes were assessed in eight studies (Davies 2001; Dawes 2007; Einstadter 1996; Feddersen 1994; Forbes 2006;
Forster 2005; Pozen 1977; Talley 1990). Specialist nurse roles varied from study to study but all were focused around the needs of specific groups of patients, such as patients with diabetes, multiple sclerosis, myocardial infarction, mental health problems, or gynaecology patients. The specialist nurse was usually educated to master's degree level. The role of the specialist nurse usually involved co-ordinating care including arranging tests and procedures, assessing patients, planning their care and reviewing their progress, undertaking or prescribing specific interventions based on assessed needs, and educating patients, nurses, and other staff. Five studies were RCTs (Forster 2005; Davies 2001; Dawes 2007; Pozen 1977; Talley 1990), and the remainder were either CCTs or CBAs. One study examined the impact of this intervention on patient mortality and concluded that the intervention had no impact on in-hospital patient mortality (Forster 2005). Our analysis of Forster 2005's data identified a risk ratio (RR) of 0.96 (95\% CI 0.59 to $1.56 ; \mathrm{Z}=0.17, \mathrm{p}=0.86$ ), indicating no effect.

Six studies examined the impact on length of stay (Davies 2001; Dawes 2007; Einstadter 1996; Feddersen 1994; Forster 2005; Talley 1990). Two RCTs identified the potential for the introduction of a specialist nursing position to reduce patient length of stay (Davies 2001; Dawes 2007), whereas a third Forster 2005 found the intervention had no impact on length of stay. Dawes 2007 reported that the savings made due to reduction in patient length of stay offset the costs of employing the additional nurse specialist. Davies 2001 found no evidence of adverse effects from the reduced length of stay in terms of readmission rates, use of community resources or patient perceptions of quality of care. Talley 1990 examined the impact of a Psychiatric Liaison Nurse Specialist consultation for acute medical-surgical patients requiring constant observation and found the intervention had no impact on length of stay. Of the two other studies, Feddersen 1994 associated the intervention with a reduction in length of stay $(\mathrm{p}<0.001)$, whereas Einstadter 1996 found no effect on length of stay. A meta-analysis of the data provided by Dawes 2007 and Feddersen 1994 suggests an impact (reduction) on length of stay (RR $-1.35,95 \%$ CI -1.92 to $0.78 ; Z=4.61, p<0.00001$ ) (see Figure 2 ). (Note: median values were reported only or SD not reported in remaining four studies, therefore not included in the analysis).

Figure 2. Forest plot of comparison: I Addition of specialist nursing post to staffing versus standard staffing, outcome: I.5 Length of stay (days).

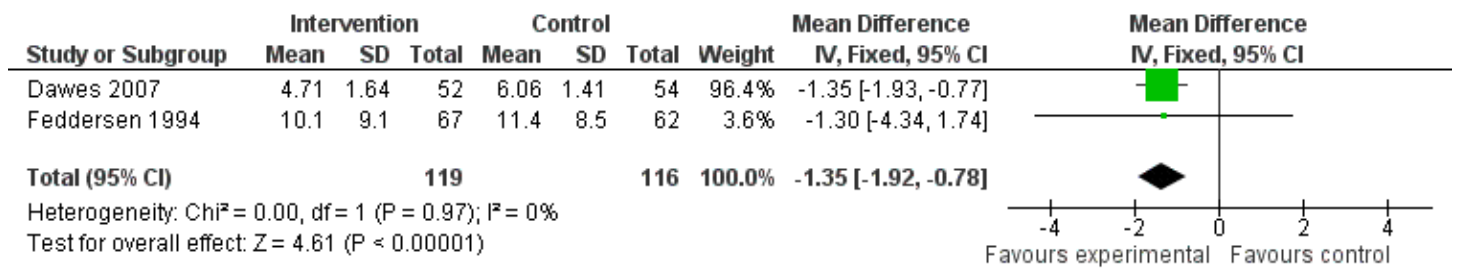

Hospital nurse staffing models and patient and staff-related outcomes (Review) 
Four studies examined the impact of the intervention on readmission rates (Davies 2001; Dawes 2007; Einstadter 1996; Forbes 2006). All four studies concluded that there was no impact on readmission rates. Our meta-analysis of the data from the three RCT/CCT studies supports this conclusion of no effect (RR 1.15, 95\% CI 0.88, 1.52; $Z=1.02, \mathrm{p}=0.31$ ) (see Figure 3).

Figure 3. Forest plot of comparison using RCTs and CCTs: I Addition of specialist nursing post to staffing versus standard staffing, outcome: I.3 Readmission.

\begin{tabular}{lrrrrr} 
& \multicolumn{3}{c}{ Intervention } & \multicolumn{3}{c}{ Control } \\
Study or Subgroup & Events & Total & Events & Total & Weight \\
\hline Davies 2001 & 37 & 152 & 38 & 148 & $50.4 \%$ \\
Dawes 2007 & 5 & 52 & 4 & 54 & $5.1 \%$ \\
Einstadter 1996 & 48 & 243 & 33 & 229 & $44.5 \%$ \\
& & & & 431 & $\mathbf{1 0 0 . 0} \%$ \\
Total (95\% Cl) & & 447 & & & \\
Total events & 90 & 55 & \\
Heterogeneity: Chi $=1.69, \mathrm{df}=2(\mathrm{P}=0.43) ; \mathrm{I}^{\mathbf{2}}=0 \%$ \\
Test for overall effect: $Z=1.02(\mathrm{P}=0.31)$
\end{tabular}

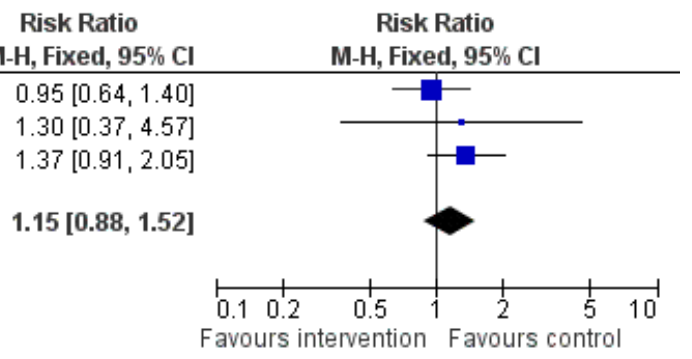

Einstadter 1996 also examined the impact of the intervention on attendance at the emergency department within 30 days of admission and found no effect. Forster 2005 examined the effect on post-discharge adverse events and found no significant effect but reported a trend towards an increased risk of emergency room visit, readmission or death post discharge (all three measures combined) for the CNS group.

In relation to adverse events or complications in hospital, Forbes 2006 examined the impact of a specialist nursing post on pressure ulcer rates and identified a statistically significant improvement in the incidence of pressure ulcers $(\mathrm{p}=0.001)$ (Table 3).

One study looked at the impact of a diabetes nurse specialist

on blood glucose control and found no significant differences in metabolic control (Feddersen 1994). Another study examined the impact of a CCU-based nurse rehabilitator on patients' employment status at six months post myocardial infarction and reported that the intervention was effective in increasing patients' return to work (Pozen 1977). Pozen 1977 reports that the difference between the intervention and control group for high risk patients was significant ( $81 \%$ intervention group, $61 \%$ control group, $\mathrm{p}<.05$ ). However, further analysis of the study data suggests there was no significant impact (RR 1.32, 95\% CI 0.87 to $2.00 ; \mathrm{Z}=1.32, \mathrm{p}=$ 0.19) (see Figure 4).

Hospital nurse staffing models and patient and staff-related outcomes (Review) 
Figure 4. Forest plot of comparison: I Addition of specialist nursing post to staffing versus standard staffing, outcome: 1.9 Employment status 6 months post-discharge (of patients previously employed).

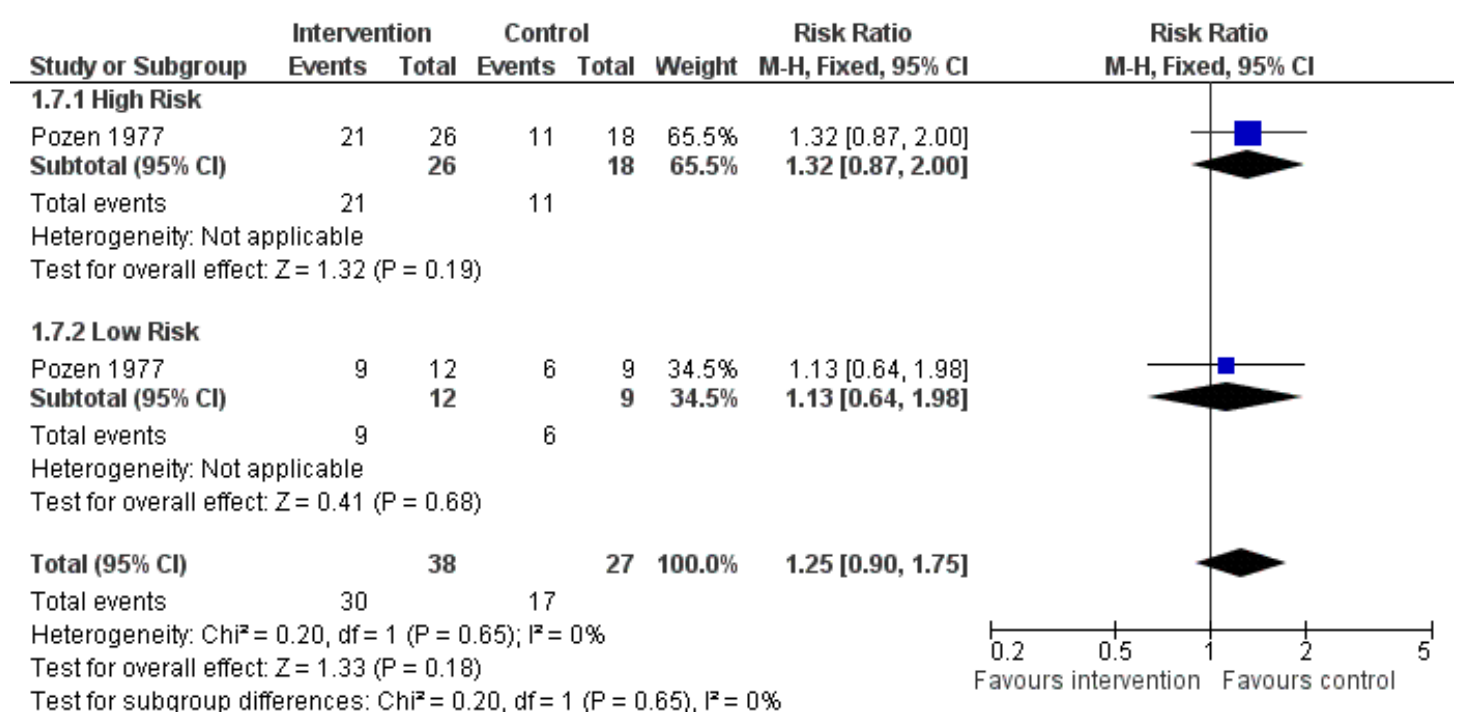

In relation to staff-related outcomes, two RCTs examined the costs associated with the introduction of specialist nursing posts versus usual nurse staffing (Dawes 2007; Ritz 2000). Ritz 2000 found no significant differences between the intervention and control groups. However, cost data was only complete for 141 of 211 participants. Dawes 2007 identified cost savings arising from the significant reduction in patient length of stay and found they offset the costs of employing the specialist nurse.

The results for this group of interventions for RCTs and CCTs are presented in the summary of findings table in Summary of findings for the main comparison.

B. Increasing the proportion of support staff versus usual nurse staffing

Patient outcomes were assessed in two studies in relation to this intervention. One study was an RCT (Duncan 2006), and one was a CBA (Neidlinger 1993). Looking at patient mortality, Duncan 2006 found the additional support of dietetic assistants led to a $6 \%$ reduction in trauma ward mortality $(\mathrm{p}=0.048)$. Using Duncan 2006's data, we calculated a RR of 0.41 (95\% CI 0.16 to $1.01 ; \mathrm{Z}$ $=1.94, \mathrm{p}=0.05$ ), which supports this finding. Duncan 2006 also identified significantly lower incidences of deaths in hospital (total hospital stay, including trauma ward) and at four months after discharge. We calculated a RR of 0.56 (95\% CI 0.29 to $1.09 ; \mathrm{Z}=$ $1.69, \mathrm{p}=0.09)$ for deaths in hospital and a RR of $0.57(95 \% \mathrm{CI}$ 0.34 to $0.95 ; Z=2.16, p=0.03$ ) for deaths at four months. Duncan 2006 also examined the impact of this intervention on length of stay and found no significant effect. A summary of findings table for Duncan's study is presented in Summary of findings 2.

In relation to staff-related outcomes, Neidlinger 1993 examined the effect of introducting nursing assistive personnel into the existing "professional pratice model" of staffing on costs and found unit personnel costs associated with patient care increased on the intervention units (reduced skill mix) 'for undetermined reasons'. The results from Neidlinger's study are presented in Table 4.

C. New rosters or shifts versus usual shifts

One study examined the effect of introducing a self-scheduling system on staff-related outcomes and reported a reduction in turnover (O’Connor 1992, Table 5).

D. Primary nursing versus usual model of nursing

Two studies (both CBAs) (see Table 6) examined the effect of introducing primary nursing on staff-related outcomes. Boumans 1999 found the intervention had no significant effect on absenteeism. Melchoir 1996 reported strong indications that the intervention reduced turnover rates.

\section{E. Team midwifery versus standard care}

One RCT was identified that examined the impact of introducing team midwifery (versus standard care) on maternity care outcomes (Biro 2000, Summary of findings 3). Team midwifery is defined by Biro 2000 as: "a new model of maternity care characterised by continuity of midwifery care from early pregnancy to the postnatal period". Continuity of midwifery care refers to care being provided by the same midwife who plans most of the care for the woman from the beginning of her care to the end of the postnatal period. The authors concluded that the intervention resulted in a reduction in medical procedures during labour and a shorter length of stay without compromising maternal or perinatal safety. Our analysis of the results for length of stay in hospital (RR -0.30 , $95 \% \mathrm{CI}-0.54,-0.06 ; \mathrm{Z}=2.41, \mathrm{p}=0.02)$ and length of stay in

Hospital nurse staffing models and patient and staff-related outcomes (Review) 
special care nursery $(\mathrm{SCN})(\mathrm{RR}-2.00,95 \% \mathrm{CI}-2.07,-1.93 ; \mathrm{Z}=$

59.46, $\mathrm{p}<0.00001)$ support Biro 2000's findings.

ADDITIONALSUMMARY OF F INDINGS [Explanation]

Effect of adding dietary assistants to nurse staffing compared to usual nurse staffing on patient outcomes

Patient or population: patients with patient outcomes

Settings: hospital

Intervention: adding dietary assistants to nurse staffing

Comparison: usual nurse staffing

\begin{tabular}{|c|c|c|c|c|c|c|}
\hline \multirow[t]{3}{*}{ Outcomes } & \multicolumn{2}{|c|}{ Illustrative comparative risks* $(95 \% \mathrm{CI})$} & \multirow{3}{*}{$\begin{array}{l}\text { Relative effect } \\
(95 \% \text { CI) }\end{array}$} & \multirow{3}{*}{$\begin{array}{l}\text { No of Participants } \\
\text { (studies) }\end{array}$} & \multirow{3}{*}{$\begin{array}{l}\text { Quality of the evidence } \\
\text { (GRADE) }\end{array}$} & \multirow[t]{3}{*}{ Comments } \\
\hline & \multicolumn{2}{|r|}{ Corresponding risk } & & & & \\
\hline & Usual nurse staffing & $\begin{array}{l}\text { Adding dietary assis- } \\
\text { tants to nurse staffing }\end{array}$ & & & & \\
\hline \multirow{4}{*}{$\begin{array}{l}\text { Mortality - Deaths in } \\
\text { trauma unit }\end{array}$} & \multicolumn{2}{|l|}{ Study population } & \multirow{4}{*}{$\begin{array}{l}\text { RR } 0.41 \\
(0.16 \text { to } 1.01)\end{array}$} & \multirow{4}{*}{$\begin{array}{l}302 \\
\text { (1 study) }\end{array}$} & \multirow{4}{*}{$\begin{array}{l}\oplus \oplus \oplus \bigcirc \\
\text { moderate }\end{array}$} & \\
\hline & 102 per 1000 & $\begin{array}{l}\mathbf{4 2} \text { per } 1000 \\
(16 \text { to } 103)\end{array}$ & & & & \\
\hline & \multicolumn{2}{|c|}{ Medium risk population } & & & & \\
\hline & 102 per 1000 & $\begin{array}{l}42 \text { per } 1000 \\
(16 \text { to } 103)\end{array}$ & & & & \\
\hline \multirow{3}{*}{$\begin{array}{l}\text { Mortality - Deaths in } \\
\text { hospital }\end{array}$} & \multicolumn{2}{|l|}{ Study population } & \multirow{3}{*}{$\begin{array}{l}\text { RR } \mathbf{0 . 5 6} \\
(0.29 \text { to } 1.09)\end{array}$} & \multirow{3}{*}{$\begin{array}{l}302 \\
\text { (1 study) }\end{array}$} & \multirow{3}{*}{$\begin{array}{l}\oplus \oplus \oplus \bigcirc \\
\text { moderate }\end{array}$} & \\
\hline & 146 per 1000 & $\begin{array}{l}82 \text { per } 1000 \\
(42 \text { to } 159)\end{array}$ & & & & \\
\hline & \multicolumn{2}{|c|}{ Medium risk population } & & & & \\
\hline
\end{tabular}




\section{7 per $1000 \quad 82$ per 1000}

(43 to 160$)$

\begin{tabular}{|c|c|c|c|c|c|}
\hline \multirow{4}{*}{$\begin{array}{l}\text { Mortality - Deaths at } 4 \\
\text { months }\end{array}$} & \multicolumn{2}{|c|}{ Study population } & \multirow{4}{*}{$\begin{array}{l}\text { RR } 0.57 \\
-(0.34 \text { to } 0.95)\end{array}$} & \multirow{4}{*}{$\begin{array}{l}302 \\
\text { (1 study) }\end{array}$} & \multirow{4}{*}{$\begin{array}{l}\oplus \oplus \oplus \bigcirc \\
\text { moderate }\end{array}$} \\
\hline & 229 per 1000 & $\begin{array}{l}131 \text { per } 1000 \\
\text { (78 to } 218)\end{array}$ & & & \\
\hline & \multicolumn{2}{|c|}{ Medium risk population } & & & \\
\hline & 229 per 1000 & $\begin{array}{l}131 \text { per } 1000 \\
(78 \text { to } 218)\end{array}$ & & & \\
\hline
\end{tabular}

*The basis for the assumed risk (e.g. the median control group risk across studies) is provided in footnotes. The corresponding risk (and its $95 \%$ confidence interval) is based on the assumed risk in the comparison group and the relative effect of the intervention (and its $95 \% \mathrm{Cl}$ ).

Cl: Confidence interval; RR: Risk ratio;

GRADE Working Group grades of evidence

High quality: Further research is very unlikely to change our confidence in the estimate of effect.

Moderate quality: Further research is likely to have an important impact on our confidence in the estimate of effect and may change the estimate.

Low quality: Further research is very likely to have an important impact on our confidence in the estimate of effect and is likely to change the estimate.

Very low quality: We are very uncertain about the estimate. 


\begin{tabular}{|c|c|c|c|c|c|c|}
\hline \multicolumn{7}{|c|}{ The effect of team midwifery compared to usual midwifery staffing on maternity care outcomes } \\
\hline \multicolumn{7}{|c|}{$\begin{array}{l}\text { Patient or population: patients with maternity care outcomes } \\
\text { Settings: hospital } \\
\text { Intervention: team midwifery } \\
\text { Comparison: usual midwifery staffing }\end{array}$} \\
\hline \multirow[t]{3}{*}{ Outcomes } & \multicolumn{2}{|c|}{ Illustrative comparative risks* $(95 \% \mathrm{CI})$} & \multirow{3}{*}{$\begin{array}{l}\text { Relative effect } \\
(95 \% \text { CI })\end{array}$} & \multirow{3}{*}{$\begin{array}{l}\text { No of Participants } \\
\text { (studies) }\end{array}$} & \multirow{3}{*}{$\begin{array}{l}\text { Quality of the evidence } \\
\text { (GRADE) }\end{array}$} & \multirow[t]{3}{*}{ Comments } \\
\hline & Assumed ris & Corresponding risk & & & & \\
\hline & Usual midwi & Team midwifery & & & & \\
\hline \multirow[t]{4}{*}{ Perinatal death } & Study popula & & \multirow{4}{*}{$\begin{array}{l}\text { RR } 1.22 \\
(0.33 \text { to } 4.5)\end{array}$} & \multirow{4}{*}{$\begin{array}{l}884 \\
\text { (1 study) }\end{array}$} & \multirow{4}{*}{$\begin{array}{l}\oplus \oplus \oplus \oplus \\
\text { high }\end{array}$} & \\
\hline & 9 per 1000 & $\begin{array}{l}11 \text { per } 1000 \\
(3 \text { to } 40)\end{array}$ & & & & \\
\hline & \multicolumn{2}{|c|}{ Medium risk population } & & & & \\
\hline & 9 per 1000 & $\begin{array}{l}11 \text { per } 1000 \\
\text { (3 to } 40)\end{array}$ & & & & \\
\hline $\begin{array}{l}\text { Length of stay in hospital } \\
\text { (days) }\end{array}$ & & $\begin{array}{l}\text { The mean Length of stay } \\
\text { in hospital (days) in the } \\
\text { intervention groups was } \\
\mathbf{0 . 3} \text { lower } \\
\text { ( } 0.54 \text { to } 0.06 \text { lower) }\end{array}$ & & $\begin{array}{l}884 \\
\text { (1 study) }\end{array}$ & $\begin{array}{l}\oplus \oplus \oplus \oplus \\
\text { high }\end{array}$ & \\
\hline $\begin{array}{l}\text { Length of stay in special } \\
\text { care nursery (days) }\end{array}$ & & $\begin{array}{l}\text { The mean Length of stay } \\
\text { in SCN (days) in the inter- } \\
\text { vention groups was } \\
2 \text { lower } \\
\text { ( } 2.07 \text { to } 1.93 \text { lower) }\end{array}$ & & $\begin{array}{l}884 \\
\text { (1 study) }\end{array}$ & $\begin{array}{l}\oplus \oplus \oplus \oplus \\
\text { high }\end{array}$ & \\
\hline
\end{tabular}


*The basis for the assumed risk (e.g. the median control group risk across studies) is provided in footnotes. The corresponding risk (and its $95 \%$ confidence interval) is based on the assumed risk in the comparison group and the relative effect of the intervention (and its $95 \% \mathrm{Cl}$ ).

Cl: Confidence interval; RR: Risk ratio;

GRADE Working Group grades of evidence

High quality: Further research is very unlikely to change our confidence in the estimate of effect.

Moderate quality: Further research is likely to have an important impact on our confidence in the estimate of effect and may change the estimate.

Low quality: Further research is very likely to have an important impact on our confidence in the estimate of effect and is likely to change the estimate.

Very low quality: We are very uncertain about the estimate. 


\section{DISCUSSION}

This review set out to identify which staffing models are associated with improved outcomes for patients in the hospital setting and which staffing models are associated with improved staff-related outcomes in the hospital setting. The scope of this review was broad and included a wide range of interventions relating to nurse staffing models. It also sought to identify relevant studies conducted across all jurisdictions and in all languages. As such, this was a very comprehensive review.

\section{Summary of main results}

We found no evidence that the addition of specialist nurses to nursing staff reduces patient death rates, attendance at the emergency department, or readmission rates, but it is likely to result in shorter patient hospital stays and reductions in pressure ulcers. Only two studies included costs in the outcomes measured and one of these studies was missing a significant amount of data.

Only two studies examined the effect of adding support staff to the nursing staff complement and therefore the evidence is weak in relation to this type of intervention. However, Duncan 2006's study demonstrated the potential of such interventions to make real improvements in patient outcomes where support staff are trained to meet the particular needs of patients; in this case, the dietary needs of patients on trauma wards.

Only a small number of studies relating to primary nursing or nurse rostering were identified and as a result the evidence is very limited. However, it does suggest that there may be some improvement in relation to nursing staff turnover.

One study of team midwifery (versus standard care) identified a reduction in medical procedures during labour, and a shorter length of stay without compromising maternal or perinatal safety.

\section{Overall completeness and applicability of evidence}

Our review failed to identify any studies of interventions relating to nurse staffing levels, education mix, or grade mix that met our inclusion criteria. This is despite the range of developments that have occurred across countries over recent decades in relation to nurse education and the introduction of mandatory staffing levels in some states in the US and Australia.

\section{Quality of the evidence}

Our review identified a large number of papers written around the topic. However, many papers were commentaries or literature reviews. Over 145 studies were identified which were relevant in terms of the nurse staffing interventions included in the research and the outcomes measured but which did not use an appropriate design to be included in this review. Most of these studies were observational studies and used secondary or administrative data. Despite the shortcomings of such designs, many of these studies are often cited as evidence that the skill mix, grade mix, or educational mix of nursing staff makes a difference to patient outcomes.

The quality of evidence in relation to the impact of hospital nurse staffing based on the final set of studies included in this review is mixed and the findings should be treated with caution. Although the use of strict inclusion criteria reduced the amount of evidence available for review, systematic reviews can be very useful in identifying areas where there is insufficient evidence and where further research is required (Egger 2001). Although this review did not include more detailed analyses (e.g. an overall meta-analysis, subgroup analysis), the findings from the included studies allow some tentative conclusions which can inform further research on this topic. Particularly, it highlights topics around which findings are limited and where priorities may lie (e.g. the impact of nurse education interventions on patient outcomes), or where knowledge is developing and can be further enhanced through research (e.g. the impact of specialist nurse roles on patient outcomes; the impact of specialist support staff on patient outcomes). It also highlights the types of outcome measures used to date in studies of nurse staffing and how different researchers have operationalised such measures in individual studies.

\section{Potential biases in the review process}

The particular limitations of this review relate to the small number of studies identified around each of the interventions which did not permit more detailed analysis. In addition, no relevant studies were identified of interventions relating to staffing levels, education mix, or grade mix. Moreover, the scope of the review did not include outcomes that were not considered to be objective measures of patient or staff-related outcomes. As such, the large volume of published studies that focus on outcomes such as nurse or patient satisfaction, quality of life, burnout, or staff stress was not included.

\section{Agreements and disagreements with other studies or reviews}

We have already identified the limitations of the systematic and literature reviews previously conducted of hospital nurse staffing. Only one of these reviews identified studies using RCTs in their review of Nurse Practitioners in the Emergency Department study (Carter 2007). Several studies used secondary or administrative data.

Although this review only included studies that used RCTs, CCTs, CBAs and ITSs, all of the existing reviews identified above also include observational and even qualitative studies. On that basis, several reviews support the association between higher staffing levels and better patient outcomes (Crossan 2005; Currie 2005; Kane 2007; Lankshear 2005) and better staff-related outcomes (Currie 2005), and between the higher proportion of RNs and better patient outcomes (Currie 2005). However, Lankshear 2005 identified one study that did not support an association between 
staffing levels and patient outcomes. Lang 2004 suggests the literature offers minimal support for specific minimum nurse: patient ratios in the acute hospital setting but suggests there are other factors involved in the quality of care that should be considered in addition to nurse staffing ratios. In relation to the evidence to support these suggestions, our review failed to identify any eligible studies of staffing levels.

The impact of specialist nursing roles is also explored in other reviews. Carter 2007 looked at the impact of nurse practitioners (NPs) in the emergency department. Once again, Carter 2007's review included qualitative and observational studies in its analysis in addition to the three RCTs identified. They concluded that NPs could reduce waiting times in the emergency department and had similar or better outcomes to medical residents in relation to the accuracy of $\mathrm{x}$-ray examinations, physical examinations, appropriateness of urgent referrals and patient satisfaction. De Broe 2001's rapid and systematic review failed to find support, other than that based on expert opinion and anecdotal evidence, for the benefits of specialist nurses for patients with multiple sclerosis, diabetes and epilepsy. Our review identified eight eligible studies of the impact of specialist nurse roles on patient outcomes and suggests such interventions can reduce length of stay for patients but found no evidence of an impact on patient mortality or readmission rates. There is some evidence also to suggest that there may be an impact on the incidence of pressure ulcers.

In relation to replacing the proportion of registered nurses with licensed practical nurses, licensed vocational nurses, or nursing assistants, some authors (Crossan 2005; Currie 2005) suggest there is no or little evidence to suggest that it compromises the quality of patient care. Lankshear 2005 found one study which associated higher levels of Licenced Practical Nurses/Licensed Vocational Nurses (LPN/LVNs) with higher rates of patient complications. Spilsbury 2001 suggests the evidence shows RNs do make a difference but the research fails to offer guidance in relation to the most effective skill mix to provide the "best" patient care. We only identified one eligible study relating to the impact of replacing RNs with less qualified staff support staff and could not draw conclusions. However, we did find one study which showed that the addition of trained support staff could enhance patient outcomes. In relation to nursing shifts, Estabrooks 2009 states there is insufficient evidence to suggest that shift length affects patient or provider outcomes. Although we did identify studies of nursing shifts, none were eligible for inclusion. We only identified one such eligible study which suggested self-scheduling may reduce nursing staff turnover.

A review of non-traditional staffing models (Lookinland 2005) did not draw conclusions overall. We found two studies of primary nursing and concluded that there may be an impact on nursing staff turnover.

Kane 2007, drawing again on observational studies, identifies a significant negative correlation between the proportion of Bachelor Degree (BSN) nurses in nursing staff and the incidence of pa- tient deaths. We found no eligible studies in relation to education mix.

However, several review authors (Crossan 2005; Currie 2005; Estabrooks 2009; McKenna 1995) highlight the limitations in the evidence base due to the small numbers of studies conducted, and an overall lack of rigour due to design issues such as sample size, methodology and measurement issues. In addition, Spilsbury 2001 identifies a tendency for researchers to measure grade mix rather than skill mix and a difficulty comparing studies around the same intervention. Our review supports this finding in relation to the quality of evidence. Further, the restriction of our review to studies only which can provide the highest level of evidence to support the impact of interventions on patient and staff-related outcomes (RCTs,CCTs, CBAs and ITSs) helps to demonstrate the lack of high quality evidence around this broad topic and the need for more robust research.

\section{A U THORS'CONCLUSIONS}

\section{Implications for practice}

The findings suggest the addition of specialist nurses to nursing staff is likely to result in shorter patient hospital stays and reductions in pressure ulcers. Limited research suggests this intervention to be cost-effective.

The evidence in relation to the impact that replacing Registered Nurses with unqualified nursing assistants has on patient outcomes is very limited. However, it is suggested that specialist support staff, such as dietary assistants, may have an important impact on certain patient outcomes.

The evidence relating to primary nursing and nurse rostering systems is very limited. However, it is suggested that self-scheduling and primary nursing may reduce staff turnover.

Team midwifery may reduce the number of medical procedures during labour, and may result in a shorter length of stay without compromising maternal or perinatal safety.

No studies of educational interventions, grade mix interventions, or staffing levels met the criteria for inclusion in this study and therefore we are unable to draw conclusions in relation to the impact of these interventions on patient or staff-related outcomes.

\section{Implications for research}

This review highlights the limited nature of research conducted on this topic. More specifically, it highlights the large number of studies conducted in the area that are not of an appropriate design to be considered an adequate source of evidence on the impact of nurse staffing models on patient and staff-related outcomes. 
The limitations of the studies included highlight the need for larger studies, preferably using an RCT, CCT or CBA design, and for ITS studies that use several data points pre- and post-intervention, and that draw on primary data. Funders of potential studies of hospital nurse staffing should ensure that further research around hospital nurse staffing includes such designs.

While this review highlights the inadequacies of research conducted across nurse staffing interventions generally, it particularly highlights the need for research in relation to educational, grade mix and staffing level interventions.

Finally, the range of studies being conducted in different countries in isolation from each other suggests there may be particular merit in international collaboration in conducting research in this area.

\section{ACKNOW LEDGEMENTS}

We would like to thank Alain Mayhew (EPOC Review Group Managing Editor) and Russ Gruen (EPOC Contact Editor) for their advice and support in the conduct of the review. We would like to thank Lorna Dodd and Susan Boyle (Librarians, Health Sciences Library, University College Dublin) and Doug Salzwedel and Michelle Fiander (EPOC Trials Search Co-ordinators) for their advice and support on the development of the search strategy. We would like to thank Isabel Hidalgo (Executive Assistant, UCD School of Nursing, Midwifery and Health Systems) for her support with the retrieval and cataloguing of studies and other project support. We would like to acknowledge the peer review contribution from Salma Debs-Ivall, Robin Devey, Craig Ramsay, and Simon Lewin. We would like to thank Tomas Pantoja for editorial support.

\section{R E F E R E N C E S}

\section{References to studies included in this review}

\section{Biro 2000 \{published data only\}}

Biro MA, Waldenstrom U, Pannifex JH. Team midwifery care in a tertiary level obstetric service: a randomized controlled trial. Birth 2000;27(3):168-73. [MEDLINE: 11251497]

Boumans 1999 \{published data only\} Boumans NP, Landeweerd JA. Nurses' well-being in a primary nursing care setting in The Netherlands. Scand J Caring Sci 1999;13(2):116-22. [MEDLINE: 10633742]

Davies 2001 \{published data only\} Davies M, Dixon S, Currie CJ, Davis RE, Peters JR. Evaluation of a hospital diabetes specialist nursing service: a randomized controlled trial. Diabet Med 2001;18(4): 301-7. [MEDLINE: 11437861]

Dawes 2007 \{published data only\} Dawes HA, Docherty T, Traynor I, Gilmore DH, Jardine AG, Knill-Jones R. Specialist nurse supported discharge in gynaecology: a randomised comparison and economic evaluation. Eur J Obstet Gynecol Reprod Biol 2007 (Epub 2006 Mar 10);130(2):262-70. [MEDLINE: 16530916]

Duncan 2006 \{published data only\} Duncan DG, Beck SJ, Hood K, Johansen A. Using dietetic assistants to improve the outcome of hip fracture: a randomised controlled trial of nutritional support in an acute trauma ward. Age Ageing 2006 (Epub 2005 Dec 14); 35(2):148-53. [MEDLINE: 16354710]

Einstadter 1996 \{published data only\} Einstadter D, Cebul RD, Franta PR. Effect of a nurse case manager on postdischarge follow-up. J Gen Intern Med 1996;11(11):684-8. [MEDLINE: 9120655]
Feddersen 1994 \{published data only\}

Feddersen E. An inpatient Diabetes Educator's impact on length of hospital stay. The Diabetes Educator 1994;20(2): 125-8. [MEDLINE: 7851225]

Forbes 2006 \{published data only\} Forbes A, While A, Mathes L, Griffiths P. Evaluation of a MS specialist nurse programme. Int J Nurs Stud 2006;43 (8):985-1000. [MEDLINE: 16412443]

\section{Forster 2005 \{published data only\}}

Forster A, Clark H, Menard A, Dupuis N, Chernish R, Chandok N, et al.Effect of a nurse team co-ordinator on outcomes for hospitalized medicine patients. The American Journal of Medicine 2005;118:1148-53. [MEDLINE: 16194647]

Melchoir 1996 \{published data only\} Melchoir MEH, Philipsen H, Abu-Saad HH, Halfens RJG, van de Berg AA, Gassman P. The effectiveness of primary nursing on burnout among psychiatric nurses in long-stay settings. J Adv Nurs 1996;24:694-702. [MEDLINE: 8894886]

Neidlinger 1993 \{published data only\} Neidlinger SH, Bostrum J, Stricker A, Hild J, Qing Zhang $\mathrm{J}$. Incorporating nursing assistive personnel into a nursing professional practice model. JONA 1993;23(3):29-37. [MEDLINE: 8473926]

O’Connor 1992 \{published data only\} O'Connor, MA. A behavioral intervention's influence on nurse turnover rate. PhD Thesis, Department of Human Development and Family Life, University of Kansas. Kansas: Department of Human Health and Family Life, University of Kansas, 1992.

Pozen 1977 \{published data only\} Pozen MW, Stechmiller JA, Harris W, Smith S, Fried DD, Voigt CG. A nurse rehabilitator's impact on patients with 
myocardial infarction. Med Care 1977;15(10):830-7. [MEDLINE: 909325]

Ritz 2000 \{published data only\}

Ritz LJ, Nissen MJ, Swenson KK, Farrell JB, Sperduto PW, Sladek ML, et al.Effects of advanced nursing care on quality of life and cost outcomes of women diagnosed with breast cancer. Oncol Nurs Forum 2000;27(6):923-32. [MEDLINE: 10920832]

Talley 1990 \{published data only\}

Talley S, Davis DS, Goicoechea N, Brown L, Barber LL. Effect of psychiatric liaison nurse specialist consultation on the care of medical-surgical patients with sitters. Arch Psychiatr Nurs 1990;4(2):114-23. [MEDLINE: 2357109]

\section{References to studies excluded from this review}

Armstrong 2004 \{published data only\}

Armstrong R. Mandated Staffing Ratios: Effect on Nurse Work Satisfaction, Anticipated Turnover, and Nurse Retention in an Acute Care Hospital. PhD Thesis, College of Nursing and Health Science, George Mason University 2004.

Arts 2000 \{published data only\}

Arts SEL, Francke AL, Hutten JBF. Liaison nursing for stroke patients: results of a Dutch evaluation study. Journal of Advanced Nursing 2000;32(2):292-300. [MEDLINE: 10964175]

Barkell 2002 \{published data only\}

Barkell NP, Killinger KA, Schultz SD. The relationship between nurse staffing models and patient outcomes: a descriptive study. Outcomes Management 2002 Jan-Mar;6 (1):27-33. [MEDLINE: 12500413]

Benson 2008 \{published data only\}

Benson L, Mitchell C, Link M, Carlson G, Fisher J. Using an advanced practice nursing model for a rapid response team. Jt Comm J Qual Patient Saf 2008;34(12):743-7.

Brett 1990 \{published data only\} Brett JL, CrabtreeTonges M. Restructured patient care delivery: evaluation of the ProACT Model. Nurs Econ 1990;8(1):36-44. [MEDLINE: 2300221]

Burnes Bolton 2007 \{published data only\} Burnes Bolton L, Aydin C, Donaldson N, Storer Brown D, Sandhu M, Fridman M, Udin Aronow H. Mandated nurse staffing ratios in California: a comparison of staffing and nursing-sensitive outcomes pre and post regulation. Policy, Politics and Nursing Practice 2007;8(4):238-50. [MEDLINE: 18337430]

Campolo 1998 \{published data only\} Campolo M, Pugh J, Thompson L, Wallace M. Pioneering the 12-hour shift in Australia--implementation and limitations. Australian Critical Care 1998;11(4):112-5. [MEDLINE: 10188407]

Cavan 2001 \{published data only\}

Cavan DA, Hamilton P, Everett J, Kerr D. Reducing hospital inpatient length of stay for patients with diabetes. $J$ Mol Biol 2001;234(1):165-78. [MEDLINE: 11251683]

\section{Chavigny 1984 \{published data only\}}

Chavigny K, Lewis A. Team or primary nursing care? . Nursing Outlook 1984;32(6):322-7. [MEDLINE: 6567848]

Choi 1986 \{published data only\} Choi T, Jameson H, Brekke ML, Podratz RO, Mundahl H. Effects on nurse retention. An experiment with scheduling. Medical Care 1986;24(11):1029-43. [MEDLINE: 3773577]

Ciske 1974 \{published data only\} Ciske KL. Primary nursing evaluation. American Journal of Nursing 1974;74:1436-8. [MEDLINE: 4495281]

\section{Counsell 1999 \{published data only\}}

Counsell C, Gilbert M. Implementation of a nurse practitioner role in an acute care setting. Critical Care Nursing Clinics of North America 1999;11(2):277-82. [MEDLINE: 10838989]

Danello 2008 \{published data only\} Danello S. Open shift management. Nursing Management 2008;39(12):30-2. [MEDLINE: 19155862]

Davis 1997 \{published data only\}

Davis A. Work redesign in the intensive care unit setting. Critical Care Nursing Quarterly 1997;20(2):28-33. [MEDLINE: 9313424]

Donaldson 2005 \{published data only\} Donaldson N, Burnes Bolton L, Aydin C, Brown D, Elashoff JD, Sandhu M. Impact of California’s Licensed Nurse-Patient Ratios on Unit-Level Nurse Staffing and Patient Outcomes. Policy, Politics and Nursing Practice 2005; 6(3):198-210. [MEDLINE: 16443975]

Eck 1999 \{published data only\} Eck S. Effect of a Change in Nursing Skill Mix on Patient and Organisational Outcomes in One Teaching Hospital. PhD Thesis, School of Nursing, Yale University 1999.

Eriksen 1992 \{published data only\} Eriksen LR, Quandt B, Teinert D, Look DS, Loosle R, Mackey G, Strout B. A registered nurse-licensed vocational nurse partnership model for critical care nursing. Journal of Nursing Administration 1992 Dec;22(12):28-38. [MEDLINE: 1469485]

Gardner 1991 \{published data only\} Gardner K. A summary of findings of a five-year comparison study of primary and team nursing. Nursing Research 1991; 40(2):113-7. [MEDLINE: 2003070]

Grillo-Peck 1995 \{published data only\} Grillo-Peck AM, Risner PB. The effect of a partnership model on quality and length of stay. Nurs Econ 1995;13(6): 367-72, 374. [MEDLINE: 8538811]

Hanneman 1993 \{published data only\} Hanneman SK, Bines AS, Sajtar WS. The indirect patient care effect of a unit-based clinical nurse specialist on preventable pulmonary complications. Am J Crit Care 1993;2(4):331-8. [MEDLINE: 8358480] 
Heinemann 1996 \{published data only\}

Heinemann D, Lengacher CA, VanCott ML, Mabe PR, Swymer S. Partners in patient care: measuring the effects on patient satisfaction and other quality indicators. Nursing Economics 1996;14(5):278-85. [MEDLINE: 8998022]

Hinshaw 1981 \{published data only\}

Hinshaw A, Scofield R, Atwood JR. Staff, patient and cost outcomes of all-Registered Nurse staffing. J Nurs Adm 1981;Nov-Dec:30-6. [MEDLINE: 6915081]

Jansen 1994 \{published data only\} Jansen D. The impact of a clinical nurse's role on CVC infections and bacteremia: a two-year comparative, retrospective study. Aust Nurs J 1994;1(7):22-5. [MEDLINE: 7697164]

Kenney 2001 \{published data only\}

Kenney PA. Maintaining quality care during a nursing shortage using licensed practical nurses in acute care. Journal of Nursing Care Quality 2001;15(4):60-8. [MEDLINE: 11452642]

Lea 2003 \{published data only\}

Lea A, Bloodworth C. Modernising the 12-hour shift. Nurs Stand 2003;17(19):33-6. [MEDLINE: 12613422]

Lee 2005 \{published data only\}

Lee TY, Yeh ML, Chen HH, Lien GH. The skill mix practice model for nursing: measuring outcome. J Adv Nurs 2005;51(4):406-13. [MEDLINE: 16086809]

Lengacher 1994 \{published data only\} Lengacher CA, Kent K, Mabe PR, Heinemann D, VanCott $\mathrm{ML}$, Bowling CD. Effects of the partners in care practice model on nursing outcomes. Nurs Econ 1994;12(6):300-8. [MEDLINE: 7885486]

Lewis 1994 \{published data only\}

Lewis JA, Della PR. Alternative nurse rostering: an evaluation. Aust Health Rev 1994;17(2):29-39. [MEDLINE: 10138377]

McPhail 1990 \{published data only\}

McPhail A, Pikula H, Roberts J, Browne G, Harper D. Primary nursing: a randomized crossover trial. Western Journal of Nursing Research 1990 April;12(2):188-97. [MEDLINE: 2181780]

O'Hare 2006 \{published data only\} O'Hare BA, Nakakeeto M, Southall DP. A pilot study to determine if nurses trained in basic neonatal resuscitation would impact the outcome of neonates delivered in Kampala, Uganda. J Trop Pediatr 2006;52(5):376-9. [MEDLINE: 16782724]

Pratt 1993 \{published data only\}

Pratt R, Burr G, Leelarthaepin B, Blizard P, Walsh S. The effects of All-RN and RN-EN staffing on the quality and cost of patient care. Aust J Adv Nurs 1993 Mar-May;10(3): 27-39. [MEDLINE: 8240762]

Rideout 2007 \{published data only\}

Rideout K. Evaluation of a PNP care coordinator model for hospitalized children, adolescents, and young adults with cystic fibrosis. Pediatr Nurs 2007;33(1):29-35. [MEDLINE: 17410998]
Ringerman 2000 \{published data only\}

Ringerman ES, Ventura S. An outcomes approach to skill mix change in critical care. Nursing Management 2000 October;31(10):42-4, 46. [MEDLINE: 15127557]

Sarkissan 1999 \{published data only\} Sarkissian S, Wennberg R. Effects of the Acute Care Nurse Practitioner role on epilepsy monitoring outcomes. Outcomes Management for Nursing Practice 1999;3(4): 161-6. [MEDLINE: 10876541]

Sheill 1993 \{published data only\} Sheill A, Kenny B, Farnworth MG. The role of the clinical nurse co-ordinator in the provision of cost-effective orthopaedic services for elderly people. J Adv Nurs 1993; 18:1424-8. [MEDLINE: 8258601]

Sinclair 2006 \{published data only\} Sinclair L, Hunter R, Hagen S, Nelson D, Hunt J. How effective are mental health nurses in A\&E departments?. Emerg. Med. J 2006;23:687-92. [MEDLINE: 16921080]

Smith 2006 \{published data only\} Smith SL, Manfredi T, Hagos O, Drummond-Huth B, Moore PD. Application of the clinical nurse leader role in an acute care delivery model. J Nurs Adm 2006;36(1): 29-33. [MEDLINE: 16404198]

Strayer 2008 \{published data only\} Strayer N, Daignault-Cerullo EM. Closed staffing: a staff nurse strategy. Crit Care Nurse 2008;28(6):51-7. [MEDLINE: 19047695]

Sullivan 2002 \{published data only\} Sullivan C. Nursing shortages: let's be flexible. Collegian: Journal of the Royal College of Nursing, Australia 2002;9(4): 24-8. [MEDLINE: 12539924]

Tourangeau 1999 \{published data only\}

Tourangeau AE, Scott PJ, McAllister M, Giles L. Evaluation of a partnership model of care delivery involving Registered Nurses and Unlicensed Assistive Personnel. CJML 1999;12 (2):4-20. [MEDLINE: 11094929]

Vaska 1993 \{published data only\}

Vaska PL. The clinical nurse specialist in cardiovascular surgery: a new twist. AACN Clin Issues Crit Care Nurs 1993;4(4):637-44. [MEDLINE: 8123372]

Williams 2000 \{published data only\}

Williams G, Slater K. Absenteeism and the impact of a 38hour week, rostered day off option. Aust Health Rev 2000; 23(4):89-96. [MEDLINE: 11256275]

Yong 2002 \{published data only\}

Yong A, Power E, Gill G. Improving glycaemic control of insulin-treated diabetic patients--a structured audit of specialist nurse intervention. J Clin Nurs 2002;11(6): 773-6. [MEDLINE: 12427182]

Zidek 2003 \{published data only\} Zidek CK. Assessment of nursing care quality and the judgement of the professional nurse as reflected in nursedetermined patient acuity classification and staffing decisions. PhD Thesis, Graduate School, Indiana University of Pennsylvania 2003. 


\section{References to ongoing studies}

Valentine 2008 \{published data only (unpublished sought but not used)\}

Valentine NM, Nash J, Hughes D, Douglas K. Achieving effective staffing through a shared decision-making approach to open shift management. JONA July/ August 2008;38(7/ 8):331-5.

\section{Additional references}

\section{AIHW 2006}

AIHW. Australian hospital statistics 2004-05. Australian Institute of Health and Welfare, Health Services Series no. 26. Canberra: Australian Institute of Health and Welfare, 2006. [: AIHW cat. no. HSE 41]

Ayre 2007

Ayre T, Gerdtz M, Parker J, Nelson S. Nursing skill mix and outcomes: a Singapore perspective. International Nursing Review 2007;54:56-62.

\section{Buchan 2002}

Buchan J, Dal Poz M. Skill mix in the health care workforce: . Bulletin of the World Health Organization 2002;80:575-9.

\section{Buchan 2005}

Buchan J, Calman L. Summary: The Global Shortage of Registered Nurses. International Council of Nurses, Geneva. Geneva: International Council of Nurses, 2005.

\section{Buchan 2009}

Buchan, J. The nursing workforce and global economic recession. Collegian (Royal College of Nursing, Australia) 2009;16(1):1-2.

\section{Buerhaus 2000}

Buerhaus P, Needleman J. Policy implications of research on nurse staffing and quality of patient care. Policy, Politics, \& Nursing Practice 2000;1(1):5-15.

\section{Carr-Hill 1995}

Carr-Hill R, Dixon P, Griffiths M, Higgins M, McCaughan $\mathrm{D}$, Rice N, Wright $\mathrm{K}$. The impact of nursing grade on the quality and outcome of nursing care. Health Economics 1995;4(1):57-72.

\section{Carter 2007}

Carter A, Chochinov A. A systematic review of the impact of nurse practitioners on cost, quality of care, satisfaction and wait times in the emergency department. Canadian Journal of Emergency Medicine 2007;9(4):286-95.

\section{Crossan 2005}

Crossan F, Ferguson D. Exploring nursing skill mix: a review. Journal of Nursing Management 2005;13:356-62.

\section{Currie 2005}

Currie V, Harvey G, West E, McKenna H, Keeney S. Relationship between quality of care, staffing levels, skill mix and nurse autonomy: literature review. Journal of Advanced Nursing 2005;51(1):73-82.

\section{De Broe 2001}

De Broe S, Christopher F, Waugh N. The role of specialist nurses in multiple sclerosis:a rapid and systematic review. Health Technology Assessment 2001; Vol. 5, issue 17.
Doran 2003

Doran, DM. Preface. In: Doran, DM editor(s). Nursing sensitive outcomes: State of the science. Sudbury, MA: Jones and Bartlett, 2003.

Doran 2006

Doran DM, Harrison MB, Laschinger HS, Hirdes JP, Rukholm E, Sidani S, McGillis Hall L, Tourangeau AE. Nursing-sensitive outcomes data collection in acute care and long-term-care settings. Nursing Research March/April 2006;55(2):S75-S81.

\section{Egger 2001}

Egger M, Davey Smith G, Altman DG. Systematic Reviews in Health Care: Meta-analysis in context. London: BMJ Books, 2001.

\section{EPOC 1998}

EPOC (Effective Practice and Organisation of Care Review Group). Interrupted Time Series (ITS) Designs in an EPOC Review. EPOC Methods Papers Revised April 21 1998; Vol. http://epoc.cochrane.org/sites/epoc.cochrane.org/files/ uploads/inttime.pdf, last accessed 21 June 2010.

\section{EPOC 2002}

EPOC. Data Collection Checklist. http:// epoc.cochrane.org/epoc-resources-review-authors 2002, last accessed 21/12/2010.

EPOC 2009

EPOC (Effective Practice and Organisation of Care Review Group). Risk of bias. EPOC resources for review authors. http://epoc.cochrane.org/epoc-resources-review-authors 13-02-2009.

Estabrooks 2009

Estabrooks CA, Cummings GG, Olivo SA, Squires JE, Giblin C, Simpson N. Effects of shift length on quality of patient care and health provider outcomes: systematic review. Qual Saf Health Care 2009 Jun;18(3):181-8.

\section{Gordon 1998}

Gordon M. Nursing Nomeclature and Classification System development. Online Journal of Issues in Nursing 1998.

\section{Guyatt 2008}

Guyatt GH, Oxman AD, Vist GE, Kunz R, Falck-Ytter Y, Schunermann HJ. GRADE: what is "quality of evidence" and why is it important to clinicians?. British Medical Journal 3 May 2008;336:995-8.

\section{Haesler 2007}

Haesler EJ, Nay R, O’Donnell MH, McAuliffe LP. Effectiveness of staffing models in residential/subacute/ extended aged care settings. Cochrane Database of Systematic Reviews 2007, Issue 2. [DOI: 10.1002/ 14651858.CD006563]

\section{Humphries 2008}

Humphries N, Brugha R, McGee H. Overseas nurse recruitment: Ireland as an illustration of the dynamic nature of nurse migration. Health Policy 2008;87(2):264-72.

\section{ICN 2006}

ICN. The Global Nursing Shortage:Priority Areas for Intervention (A Report From ICN/FNIF). International 
Council of Nurses, Geneva. Geneva: International Council of Nurses, 2006.

\section{Kane 2007}

Kane R, Shamliyan T, Mueller C, Duval S, Wilt T. Nursing Staffing and Quality of Patient. AHRQ Publication No. 07-E005. Agency for Healthcare Research and Quality, Rockville, MD, 2007.

\section{Kozier 2008}

Kozier B, Erb G, Berman AJ, Burke K. Fundamentals of Nursing: Concepts, Process and Practice. Essex: Pearson, 2008.

\section{Lake 2006}

Lake E, Friese C. Variations in nursing practice environments: relation to staffing and hospital characteristics. Nursing Research 2006;55(1):1-9.

Lang 2004

Lang T, Hodge M, Olson V, Romano P, Kravitz R. Nursepatient ratios: a systematic review on the effects of nurse staffing on patient, nurse employee, and hospital outcomes. JONA 2004;34(7/8):326-37.

\section{Lankshear 2005}

Lankshear A, Sheldon T, Maynard A. Nurse staffing and healthcare outcomes: A Systematic review of the international research evidence. Advances in Nursing Science 2005;28(2):163-74.

\section{Laurant 2004}

Laurant M, Reeves D, Hermens R, Braspenning J, Grol R, Sibbald B. Substitution of doctors by nurses in primary care. Cochrane Database of Systematic Reviews 2004, Issue 4. [DOI: 10.1002/14651858.CD001271.pub2; : ]

\section{Leiter 2006}

Leiter M, Spence Laschinger H. Relationships of work and practice environment to professional burnout. Nursing Research 2006;55(3):137-46.

\section{Lookinland 2005}

Lookinland S, Tiedeman M, Crosson A. Nontraditional models of care delivery: have they solved the problems?. JONA 2005;35(2):74-80.

\section{McKenna 1995}

McKenna H. Nursing skill mix substitutions and quality of care: an exploration of assumptions from the research literature. Journal of Advanced Nursing 1995;21:452-9.

\section{Numata 2006}

Numata Y, Schulzer M, van der Wal R, Globerman J, Semeniuk P, Balka E, et al.Nurse staffing levels and hospital mortality in critical care settings: literature review and metaanalysis. Journal of Advanced Nursing 2006;55(4):435-48.

\section{Potempa 2009}

Potempa KM, Redman RW, Landstrom G. Human resources in nursing education: a worldwide crisis. Collegian (Royal College of Nursing, Australia) 2009;16(1):19-23.

\section{Preston 2009}

Preston B. The Australian nurse and midwifery workforce: issues, developments and the future. Collegian (Royal College of Nursing, Australia) 2009;16(1):25-34.

\section{Rogers 2004}

Rogers A, Hwang W-T, Scott L, Aiken L, Dinges D. The working hours of hospital staff nurses and patient safety. Health Affairs 2004;23(4):202-14.

\section{Spilsbury 2001}

Spilsbury K, Meyer J. Defining the nursing contribution to patient outcome: lessons from a review of the literature examining nursing outcomes, skill mix and changing roles. Journal of Clinical Nursing 2001;10:3-14.

* Indicates the major publication for the study 


\section{CHARACTERISTICS OF STUDIES}

\section{Characteristics of included studies [ordered by study ID]}

Biro 2000

\begin{tabular}{ll}
\hline Methods & RCT \\
\hline Participants & $\begin{array}{l}1,000 \text { eligible women who booked for care at the Monasch Medical Centre (Clayton } \\
\text { Campus), Melbourne, Australia, were recruited between March } 1996 \text { and January } 1998 . \\
502 \text { women allocated to team midwifery and } 498 \text { allocated to standard care } \\
888 \text { women participated (449 intervention (team), } 439 \text { control (standard)), } 112 \text { missing } \\
\text { participants } \\
14 \text { team and } 18 \text { standard care were lost to follow up, } 30 \text { team and } 36 \text { standard had a } \\
\text { miscarriage or termination, } 9 \text { team and } 5 \text { standard were inadvertently re-recruited when } \\
\text { they returned for a successive pregnancy after a miscarriage and were eliminated. 5\% of } \\
\text { women assigned to team care elected other care models }\end{array}$ \\
\hline
\end{tabular}

Interventions

Care provided for low-risk women by a team midwife at each visit except for 3 scheduled visits with obstetric staff at 12 to 16,28 and 36 weeks' gestation. Women not yet delivered at 41 weeks also had an additional visit with obstetric staff. High risk women had an individualised care plan developed in consultation with a senior consultant. Women attending consultant visits also saw a team midwife. In most cases, intrapartum and postnatal care was also provided by a team midwife

\begin{tabular}{ll} 
Outcomes & Procedures in labour \\
Mode of delivery \\
Perineal status \\
Admission to special care nursery \\
Pre-term \\
Birthweight \\
Apgar \\
Perinatal death \\
Length of stay \\
\hline
\end{tabular}

Notes

Risk of bias

Bias Authors' judgement Support for judgement

Random sequence generation (selection Low risk Quote: “Allocations were computer generated” (p169) bias)

Allocation concealment (selection bias) Low risk

Quote: Allocations were "processed onto paper strips with the text "standard care" or "team care". The paper strips were inserted into opaque envelopes, which were then placed in a lockable box kept by medical records staff, who were not associated with the project". "Midwives involved in the assessment clinic were asked to present the team midwifery project briefly to each woman. If a woman was interested and met the inclusion cri-

Hospital nurse staffing models and patient and staff-related outcomes (Review) 
teria, a member of the research team was contacted to speak with her. Once the woman had consented to recruitment, the research team member telephoned the medical records staff and asked them to select an envelope with the randomized treatment allocation" (p169)

Incomplete outcome data (attrition bias) Low risk All outcomes

Some outcome results missing but in all cases total number for which data was available is provided. Analysis was on an intention to treat basis

\begin{tabular}{lll}
\hline Selective reporting (reporting bias) & Low risk & All outcomes reported \\
\hline Other bias & Low risk & No evidence of any other sources of bias. \\
\hline $\begin{array}{l}\text { Baseline assessment? } \\
\begin{array}{l}\text { Baseline characteristics similar for interven- } \\
\text { tion group and control? }\end{array}\end{array}$ & Low risk & Participants completed a questionnaire prior to randomisation \\
\hline
\end{tabular}

Blinding of outcome assessment?

Unclear risk
Baseline data collected before randomisation and clinical outcome data recorded from medical records but it is not clear if allocation was concealed from those recording outcomes from medical records

No evidence of contamination.

Adequately protected against contamina- Low risk tion?

Boumans 1999

Methods

Participants

Interventions
CBA

Nurses working on 5 units in a 850-bed hospital in The Netherlands. 5 units were: 2 surgical units (units A and C), 2 internal medicine units (units B and D) and 1 orthopaedic unit (unit E). Units A and B made up the experimental group (group 1); units $\mathrm{C}, \mathrm{D}$ and $\mathrm{E}$ the control group (group 2) (see Fig. 1). The units were selected on the basis of comparable size, staff structure, bed capacity and patient population. Before the implementation of Primary Nursing, all 5 units used a Functional Nursing system The sample comprised 145 nurses at $\mathrm{t} 1,131$ nurses at $\mathrm{t} 2$ and 119 nurses at $\mathrm{t} 3$. A total of 59 nurses ( 57 females and 2 males) participated at all 3 measuring moments; 23 in group 1 and 36 in group 2 . These 59 nurses were included in the analyses

Dutch version of primary nursing introduced to 2 units ( 1 surgical and 1 medical) in a Dutch hospital. This comprised the following:

- $\quad$ each unit was divided into 2 teams

- $\quad$ in each team $2 \mathrm{RNs}$ were responsible for a specific

- $\quad$ group of about 6 patients

- $\quad$ this patient allocation lasted 8 hours a day (1 work shift)

- 5 days a week 
Boumans 1999 (Continued)

RNs used the nursing process as the basis for practice.

\begin{tabular}{ll}
\hline Outcomes & $\begin{array}{l}\text { Absence } \\
\text { Job satisfaction } \\
\text { Experience of job significance } \\
\text { Health complaints }\end{array}$ \\
\hline Notes & Absence is the only outcome relevant to this review \\
\hline
\end{tabular}

\section{Risk of bias}

Bias

Incomplete outcome data (attrition bias) Low risk All outcomes

\begin{tabular}{|c|c|c|}
\hline Selective reporting (reporting bias) & Low risk & Results were reported for all outcomes \\
\hline Other bias & High risk & $\begin{array}{l}\text { The following "Methodological flaws" were identified by au- } \\
\text { thors: } \\
\text { Quote: “... several scores in group } 2 \text { changed even before the } \\
\text { actual intervention in this group (i.e. between } 11 \text { and t } 2 \text { ) and/ } \\
\text { or changed in the same direction as those in group } 1 \text {. There are } \\
\text { several possible explanations for this result. First, the problem of } \\
\text { contamination must be considered. Group } 1 \text { may have served } \\
\text { as a model for group } 2 \text { between t } 1 \text { and t } 2 \text {. As a result, it is quite } \\
\text { possible that the nursing units of group } 2 \text { had already started } \\
\text { to introduce some elements of Primary Nursing in the period } \\
\text { between tland t } 2 \text {. A second explanation might be that changes } \\
\text { were not so much caused by the intervention itself, but rather } \\
\text { by external variables such as changes in general hospital policy. } \\
\text { A final explanation might be found in the already mentioned } \\
\text { 'Hawthorne effect' which entails 'the effect on the dependent } \\
\text { variable caused by subjects' awareness that they are 'special' par- } \\
\text { ticipants under study' ( } 20 \text { ). Furthermore, it is possible that the } \\
\text { non-response led to biased results such that the 'responders' dif- } \\
\text { fered significantly from the 'non-responders' on certain charac- } \\
\text { teristics (for example, motivation for the study)" (p120) } \\
\text { Comment: Also, absence data were obtained by self-reporting } \\
\text { rather than recorded absence. There is a risk relating to self- } \\
\text { reporting as an objective source of data }\end{array}$ \\
\hline
\end{tabular}

Baseline assessment?

Low risk

Baseline characteristics similar for interven- Low risk tion group and control?

\section{Authors' judgement Support for judgement}

Outcome data were reported for all three time periods

Quote: "There were no differences between groups 1 and 2 in sex, age, employment rate, and number of years in service as a nurse, in either the hospital or the unit" (p119)

3 similar units using the traditional "functional nursing system" were selected on the basis of comparable size, staff structure, bed capacity and patient population. As reported above, there 
Boumans 1999 (Continued)

were no differences between intervention and control groups in baseline characteristics

\begin{tabular}{|c|c|c|}
\hline Blinding of outcome assessment? & High risk & $\begin{array}{l}\text { Data were collected via self-completion questionnaire at all } 3 \\
\text { data collection points }\end{array}$ \\
\hline $\begin{array}{l}\text { Adequately protected against contamina- } \\
\text { tion? }\end{array}$ & Unclear risk & $\begin{array}{l}\text { Authors report that contamination was possible - see "Free of } \\
\text { other bias?" above. }\end{array}$ \\
\hline
\end{tabular}

Davies 2001

\begin{tabular}{ll}
\hline Methods & RCT \\
\hline Participants & 300 patients admitted to the medical and surgical wards at UHW, Cardiff with type 1 \\
& $\begin{array}{l}14 \text { diabetes }(\mathrm{n}=148 \text { intervention group) }(\mathrm{n}=152 \text { control group) } \\
\text { tient knowledge, diabetes quality of life, post-discharge events, subsequent attendances, } \\
\text { contacts with primary and social care and time away from normal activities) sent } 1 \text { month } \\
\text { post discharge }\end{array}$ \\
\hline
\end{tabular}

Interventions

Care and advice from a Diabetes Specialist Nurse (DSN) in addition to standard care. DSN care was individual structured patient education appropriate to need, practical management advice including verbal and written case-note feedback to ward-based medical and nursing staff. DSN care began on randomisation until discharge

\begin{tabular}{ll}
\hline Outcomes & Length of stay \\
& Readmission \\
& Time to readmission \\
& Quality of life \\
& Patient knowledge \\
& Patient satisfaction \\
\hline Notes & Only length of stay and readmission outcomes relevant to this review \\
\hline
\end{tabular}

\section{Risk of bias}

\section{Bias}

Random sequence generation (selection Unclear risk bias)

\begin{tabular}{l|l|l} 
Allocation concealment (selection bias) & Unclear risk & $\begin{array}{l}\text { Not reported, therefore it is not clear if patients/clinicians/asses- } \\
\text { sors were aware of allocation }\end{array}$ \\
\hline $\begin{array}{l}\text { Incomplete outcome data (attrition bias) } \\
\text { All outcomes }\end{array}$ & Low risk & $\begin{array}{l}\text { Comment: Poor response to post-discharge questionnaire ex- } \\
\text { plained: } \\
\text { Quote: “...129 were unable to complete the questionnaires be- }\end{array}$
\end{tabular}


Davies 2001 (Continued)

\begin{tabular}{|c|c|c|}
\hline & & $\begin{array}{l}\text { cause they were either visually impaired, non-English speaking, } \\
\text { confused, or had reduced consciousness. A further } 24 \text { failed to } \\
\text { return the } 1 \text {-week post-discharge questionnaires, and } 14 \text { patients } \\
\text { died (control group eight, intervention group six). The overall } \\
\text { questionnaire response rate was therefore } 47 \% \text { ( } 66 \text { control vs. } \\
67 \text { intervention)" (p303) }\end{array}$ \\
\hline Selective reporting (reporting bias) & High risk & Glucose control outcomes not included \\
\hline Other bias & Unclear risk & There may be some bias in relation to allocation \\
\hline Baseline assessment? & Low risk & $\begin{array}{l}\text { Age, gender, dependency on admission, diabetes status, and spe- } \\
\text { cialty of admission measured in both groups }\end{array}$ \\
\hline $\begin{array}{l}\text { Baseline characteristics similar for interven- } \\
\text { tion group and control? }\end{array}$ & Low risk & $\begin{array}{l}\text { Quote: "Patient characteristics in the two study groups were gen- } \\
\text { erally similar, although there is evidence of a greater proportion } \\
\text { of patients with Type } 1 \text { diabetes in the intervention group (Table } \\
\text { 1)" (p303) }\end{array}$ \\
\hline Blinding of outcome assessment? & Unclear risk & Not reported if outcome assessors were aware of group allocation \\
\hline $\begin{array}{l}\text { Adequately protected against contamina- } \\
\text { tion? }\end{array}$ & Low risk & No evidence of contamination \\
\hline
\end{tabular}

Dawes 2007

\begin{tabular}{ll}
\hline Methods & RCT \\
\hline Participants & $\begin{array}{l}111 \text { women scheduled for major abdominal or pelvic surgery for benign gynaecological } \\
\text { disease recruited } \\
5 \text { women withdrew - reasons provided } \\
106 \text { women randomly allocated - } 52 \text { intervention group and } 54 \text { control group } \\
96 \% \text { response rate to questionnaire (50 intervention and } 52 \text { control); } 102 \text { participated }\end{array}$ \\
\hline Interventions & $\begin{array}{l}\text { In addition to usual care, participants met with specialist nurse who supplemented advice, } \\
\text { developed discharge plan, planned discharge on day } 3 \text { (subject to satisfactory assessment } \\
\text { and provided fit for discharge) }\end{array}$ \\
\hline Outcomes & $\begin{array}{l}\text { Health status } \\
\text { Length of stay } \\
\text { Readmission } \\
\text { Information on discharge } \\
\text { Satisfaction } \\
\text { Costs }\end{array}$ \\
\hline Notes & \begin{tabular}{l} 
Only length of stay, readmission and cost outcomes relevant to this review \\
\hline
\end{tabular} \\
\hline
\end{tabular}

\section{Risk of bias}

Hospital nurse staffing models and patient and staff-related outcomes (Review) 
Dawes 2007 (Continued)

\begin{tabular}{|c|c|c|}
\hline Bias & Authors' judgement & Support for judgement \\
\hline $\begin{array}{l}\text { Random sequence generation (selection } \\
\text { bias) }\end{array}$ & Low risk & $\begin{array}{l}\text { Quote:"The study design was a randomised controlled trial with } \\
\text { randomisation to intervention or routine care... Randomisation } \\
\text { numbers were generated using Excel software before the start of } \\
\text { the trial" (p264) }\end{array}$ \\
\hline Allocation concealment (selection bias) & Low risk & $\begin{array}{l}\text { Quote: "Allocation was by sealed envelopes, which were kept by } \\
\text { the ward clerk and opened in numerical sequence on the day of } \\
\text { admission by the research nurse" (p264) }\end{array}$ \\
\hline $\begin{array}{l}\text { Incomplete outcome data (attrition bias) } \\
\text { All outcomes }\end{array}$ & Low risk & Results reported fully \\
\hline Selective reporting (reporting bias) & Low risk & Results reported for all outcomes \\
\hline Other bias & Low risk & $\begin{array}{l}\text { Comment: Authors note small sample size as a limitation to } \\
\text { the study but this appears to have been the result of a concern } \\
\text { to prevent bias due to women expressing a preference for the } \\
\text { intervention model as the study progressed: }\end{array}$ \\
\hline Baseline assessment? & Low risk & $\begin{array}{l}\text { The SF-36 health survey questionnaire was used to measure } \\
\text { women's evaluations of their health status before surgery. De- } \\
\text { mographic data also collected using a questionnaire }\end{array}$ \\
\hline $\begin{array}{l}\text { Baseline characteristics similar for interven- } \\
\text { tion group and control? }\end{array}$ & Low risk & $\begin{array}{l}\text { Quote: "The baseline characteristics of women randomly allo- } \\
\text { cated to specialist nurse care (mean age 46.8) when compared to } \\
\text { women randomised to routine care (mean age 46.4) were very } \\
\text { similar (Table 1). The groups were balanced for all variables. } \\
\text { There was no significant difference in general demographic char- } \\
\text { acteristics of the women" (p265) }\end{array}$ \\
\hline Blinding of outcome assessment? & Low risk & $\begin{array}{l}\text { An independent research nurse, who was blinded to treatment } \\
\text { allocation, administered the questionnaires at discharge from } \\
\text { hospital and at } 6 \text { weeks follow-up. Women in either arm of the } \\
\text { study had no identifying marks on their case notes }\end{array}$ \\
\hline $\begin{array}{l}\text { Adequately protected against contamina- } \\
\text { tion? }\end{array}$ & Low risk & $\begin{array}{l}\text { Quote: "Recruitment for the study reached } 54 \text { in the control } \\
\text { group and } 52 \text { in the intervention and the study was stopped } \\
\text { because of potential contamination of the control group and staff } \\
\text { who appeared to have accepted the earlier hospital discharge" } \\
\text { (p268) } \\
\text { Comment: This action is likely to have prevented a potential } \\
\text { source of bias }\end{array}$ \\
\hline
\end{tabular}

Hospital nurse staffing models and patient and staff-related outcomes (Review) 


\begin{tabular}{|c|c|}
\hline Methods & RCT \\
\hline Participants & $\begin{array}{l}318 \text { women aged over } 65 \text { admitted to a single trauma ward with hip fracture from normal } \\
\text { place of residence ( } 165 \text { control, } 153 \text { intervention) }\end{array}$ \\
\hline Interventions & $\begin{array}{l}\text { Addition of } 2 \text { part-time Dietetic Assistants (DAs), with } 14 \text { days orientation and training } \\
\text { to provide presence for } 6 \text { hours per day, } 7 \text { days per week } \\
\text { DAs were asked to try to ensure that patients allocated to them received appropriate help } \\
\text { in meeting their nutritional needs. They did this in many ways, including: } \\
\text { - checking personal and cultural food preference; } \\
\text { - co-ordinating appropriate meal orders with catering staff; } \\
\text { - ordering nutritional supplements when necessary; } \\
\text { - provision of appropriate feeding aids; } \\
\text { - assisting with food choice, portion size and positioning at mealtimes; } \\
\text { - sitting with, encouraging and feeding the frailest patients at mealtimes and } \\
\text { - collecting information to aid nutritional assessment by the dietician. }\end{array}$ \\
\hline Outcomes & $\begin{array}{l}\text { Mortality } \\
\text { Length of stay } \\
\text { Patient satisfaction } \\
\text { Complication rate } \\
\text { Nutritional status } \\
\text { Energy intake }\end{array}$ \\
\hline Notes & Only mortality and length of stay relevant to this review \\
\hline
\end{tabular}

\section{Risk of bias}

Bias

Random sequence generation (selection Unclear risk bias)

\section{Authors' judgement Support for judgement}

Comment: Stated that subjects were randomised

Quote: "Subjects were randomised either to receive the conventional pattern of nurse- and dietitian-led care, normally provided on the trauma unit (which included the routine provision of oral nutritional supplements to all patients) or to receive the additional personal attention of the DAs" (p149).

Comment: However, method of sequence generation not clear

Allocation concealment (selection bias) Low risk

Quote: "Randomisation was by sequentially numbered, opaque, sealed envelope method in blocks of 10 , prepared by a member of staff not directly involved in the trial. The DAs or the dietitian would approach those suitable for inclusion, and if consent or assent was obtained would open the next numbered envelope" (p150)

Incomplete outcome data (attrition bias) Low risk All outcomes
Comment: Results reported fully and supplementary data also provided

Some attrition:

Quote: "Four participants were moved out of the base trauma 
Duncan 2006 (Continued)

ward, prior to theatre, to a high-dependency unit, and since this precluded their receiving DA support were ineligible for inclusion in the study. A further seven patients were excluded as they died preoperatively, and five because they were treated conservatively" (p151). Adequately accounted for

\begin{tabular}{lll}
\hline Selective reporting (reporting bias) & Low risk & Results reported for all outcomes \\
\hline Other bias & Low risk & No evidence of bias \\
\hline Baseline assessment? & Low risk & $\begin{array}{l}\text { Admission - SAHFE protocol, Waterlow score and Abbreviated } \\
\text { Mental Test, medical record data on complications and satisfac- } \\
\text { tion }\end{array}$ \\
\hline
\end{tabular}

Baseline characteristics similar for interven- Low risk tion group and control?
Comment: Control group was comprised of patients receiving conventional (nursing/ nurse-led) care, and had similar relevant characteristics

Quote: "Patients in the two arms of the trial were comparable in respect of age, and the presence of medical, nutritional and psychiatric factors known to be predictive of poor outcome. $56.9 \%$ of participants had an Abrreviated Mental Test (AMT) score $<8$, suggestive of cognitive impairment $(54.2 \%$ of the DA support arm and $59.2 \%$ of the conventional care arm)" (p151)

Blinding of outcome assessment? Low risk
Quote: “Assessments were based on the protocol of the Standardised Audit of Hip Fractures in Europe (SAHFE) and performed on admission, at discharge from the acute trauma ward and at 4-month follow-up. This allowed a member of the trial team, blind to patient allocation and independent of the dietitian and DAs, to profile subjects' progress through rehabilitation ... We approached the 4 month follow-up assessment using a postal questionnaire. If no response was received, the participant or their carer was telephoned. Date of death was confirmed with medical records or the audit department" (p149)

Einstadter 1996

\begin{tabular}{ll}
\hline Methods & CCT (Prospective Cohort Trial) \\
\hline Participants & $\begin{array}{l}472 \text { medical patients admitted to resident physicians of a particular firm at a tertiary } \\
\text { referral centre in Ohio, over a } 6 \text { month period } \\
243 \text { were admitted to nurse case manager team and } 229 \text { to the control team }\end{array}$ \\
\hline Interventions & $\begin{array}{l}\text { A master's prepared nurse practitioner and nurse case manager (also assigned part-time } \\
\text { to work in the medical clinic) was assigned to work with one team in the selected medical } \\
\text { firm }\end{array}$ \\
\hline
\end{tabular}


Einstadter 1996 (Continued)

\begin{tabular}{|c|c|c|}
\hline Outcomes & \multicolumn{2}{|c|}{$\begin{array}{l}\text { Appointment within } 3 \text { days } \\
\text { One documented visit within } 30 \text { days } \\
\text { Readmission within } 30 \text { days } \\
\text { Attendance at the emergency department (ED) within } 30 \text { days }\end{array}$} \\
\hline Notes & \multicolumn{2}{|c|}{$\begin{array}{l}\text { Only readmission within } 30 \text { days and attendance at } \mathrm{ED} \text { within } 30 \text { days relevant to this } \\
\text { study }\end{array}$} \\
\hline \multicolumn{3}{|l|}{ Risk of bias } \\
\hline Bias & Authors' judgement & Support for judgement \\
\hline $\begin{array}{l}\text { Incomplete outcome data (attrition bias) } \\
\text { All outcomes }\end{array}$ & Low risk & Results reported fully \\
\hline Selective reporting (reporting bias) & Low risk & Results provided for all outcomes \\
\hline Other bias & Unclear risk & $\begin{array}{l}\text { Used secondary data obtained from the computerised } \\
\text { hospital system but reports that data were collected } \\
\text { for all patients admitted to the medical service during } \\
\text { the study period and data files were obtained for all } \\
\text { subsequent outpatient medical activity up to } 30 \text { days } \\
\text { post discharge }\end{array}$ \\
\hline Baseline assessment? & Low risk & $\begin{array}{l}\text { Demographics, Diagnosis Related Group (DRG) } \\
\text { data }\end{array}$ \\
\hline $\begin{array}{l}\text { Baseline characteristics similar for interven- } \\
\text { tion group and control? }\end{array}$ & Low risk & $\begin{array}{l}\text { Comment: The other team in the firm acted as the } \\
\text { control. They received usual care } \\
\text { Quote: "There were no statistically significant differ- } \\
\text { ences between the two groups in age, gender, race, } \\
\text { median length of stay, median DRG weight, insur- } \\
\text { ance status, or admission source" (p686) }\end{array}$ \\
\hline Blinding of outcome assessment? & High risk & $\begin{array}{l}\text { Data collected for each patient admitted during study } \\
\text { period from computerised hospital systems }\end{array}$ \\
\hline $\begin{array}{l}\text { Adequately protected against contamina- } \\
\text { tion? }\end{array}$ & Low risk & No evidence of contamination \\
\hline
\end{tabular}

Feddersen 1994

\begin{tabular}{ll}
\hline Methods & CCT \\
\hline Participants & $\begin{array}{l}129 \text { patients with diabetes admitted to one of } 4 \text { units }(2 \text { experimental, } 2 \text { control }) \text { at } \\
\text { Strong Memorial Hospital, Rochester, New York }\end{array}$
\end{tabular}

Hospital nurse staffing models and patient and staff-related outcomes (Review) 
Feddersen 1994 (Continued)

\begin{tabular}{l|l}
\hline Interventions & $\begin{array}{l}\text { Employment of a Certified Diabetes Educator for 20 hours per week on the experimental } \\
\text { units to provide in-service training for nursing staff and to co-ordinate diabetes education } \\
\text { for all insulin-requiring patients with diabetes }\end{array}$ \\
\hline Outcomes & $\begin{array}{l}\text { Length of stay } \\
\text { Glycosylated haemoglobin } \\
\text { Patient knowledge } \\
\text { Nurse knowledge }\end{array}$ \\
\hline Notes & Only length of stay and gylcosylated haemoglobin relevant to this review \\
\hline
\end{tabular}

Risk of bias

\begin{tabular}{|c|c|c|}
\hline Bias & Authors' judgement & Support for judgement \\
\hline $\begin{array}{l}\text { Incomplete outcome data (attrition bias) } \\
\text { All outcomes }\end{array}$ & Unclear risk & $\begin{array}{l}\text { Results are reported for length of stay for } 129 \text { patients but only } \\
\text { reported for glycosylated haemoglobin for } 88 \text { patients. No ex- } \\
\text { planation given for this }\end{array}$ \\
\hline Selective reporting (reporting bias) & Unclear risk & Results not reported for complications associated with diabetes \\
\hline Other bias & Low risk & Appears free of bias other than concerns raised above \\
\hline Baseline assessment? & Low risk & $\begin{array}{l}\text { Demographics, duration of diabetes and gylcosylated haemo- } \\
\text { globin levels }\end{array}$ \\
\hline $\begin{array}{l}\text { Baseline characteristics similar for interven- } \\
\text { tion group and control? }\end{array}$ & Low risk & $\begin{array}{l}\text { Similar units, separated geographically to minimise contract be- } \\
\text { tween units } \\
\text { Reported that there were no significant differences between in- } \\
\text { tervention and control groups in relation to race, sex, duration } \\
\text { of diabetes, or initial gylcosylated haemoglobin levels }\end{array}$ \\
\hline Blinding of outcome assessment? & High risk & $\begin{array}{l}\text { Lab tests to measure Glycosylated Haemoglobin, length of stay } \\
\text { recorded in patient records }\end{array}$ \\
\hline $\begin{array}{l}\text { Adequately protected against contamina- } \\
\text { tion? }\end{array}$ & Low risk & No evidence of contamination \\
\hline
\end{tabular}

Forbes 2006

\begin{tabular}{l|l}
\hline Methods & CBA \\
\hline Participants & $\begin{array}{l}753 \text { patients with MS attending } 6 \text { neurological services in } 4 \text { English regions. } 616 \text { patients } \\
(82 \%) \text { completed follow-up }\end{array}$ \\
\hline Interventions & $\begin{array}{l}\text { Skill mix: addition of MS Specialist Nurse to usual care } \\
\text { Appointment of a MS specialist nurse to services. Intervention not specifically described }\end{array}$ \\
\hline $\begin{array}{l}\text { Hospital nurse staffing models and patient and staff-related outcomes (Review) } \\
\text { Copyright } \odot 20 \text { II The Cochrane Collaboration. Published by John Wiley \& Sons, Ltd. }\end{array}$
\end{tabular}


Forbes 2006 (Continued)

but refers to 4 dimensions to role described by Forbes (2003) in background section, as follows: psychological assessment and intervention, social assessment and intervention, physical assessment and intervention, co-ordination and care management, specialist MS assessment and intervention, education and support, and research and audit

\begin{tabular}{ll} 
Outcomes & $\begin{array}{l}\text { Hospital admissions within } 12 \text { months } \\
\text { Pressure sores } \\
\text { Experience and severity of MS-related problems } \\
\text { Health-related quality of life }\end{array}$ \\
\hline Notes & Only hospital admissions and pressure sores relevant to this review
\end{tabular}

Risk of bias

Bias

Incomplete outcome data (attrition bias) All outcomes

Selective reporting (reporting bias)

Other bias

High risk
Unclear risk

Authors' judgement Support for judgement

Not all data provided on readmission within 1 month

All outcomes reported

Comment: Some concerns about differences in process measures were noted

Quote: "Baseline comparisons of the process measures between the intervention and control groups revealed significant differences in some variables. A higher proportion of people in the intervention group: received information $(78 \%(n=193)$ compared to $65 \%(\mathrm{n}=171))$; had a named professional coordinating their care ( $48 \%(\mathrm{n}=96)$ compared to $27 \%(\mathrm{n}=57))$; had details of an MS contact person (55\% ( $\mathrm{n}=124)$ compared to $44 \%$ ( $\mathrm{n}$ = 102)); felt able to get help in an MS emergency $(66 \%$ ( $\mathrm{n}=$ $118)$ compared to $52 \%(\mathrm{n}=90))$; and felt more involved in their care (only $18 \%(\mathrm{n}=42)$ of the intervention group felt 'not at all' involved in their care compared to $31 \%(\mathrm{n}=71)$ in the control group) ( $\mathrm{p}<0.001$, in all cases). This difference was largely contributed by site I4 where the specialist nurse was established in the area prior to their appointment within the programme. No differences were noted in any of the outcome variables except for hospital admission ( $17 \%$ admitted in the intervention group and $27 \%$ in the control, $\left.X^{2}=8.2, \mathrm{df}=1, \mathrm{p}=0: 004\right)$. These differences did not prejudice the comparison as the analysis was focused on the group time effects which are independent of starting point, although the potential for improvement in the intervention group may have been prejudiced by the relatively higher starting point (ceiling effect)" (p991)

Baseline assessment?

Low risk

Data were collected prospectively before the appointment of the MS nurses and then at 12 and 24 months. Data were collected via a postal questionnaire 
Forbes 2006 (Continued)

\begin{tabular}{|l|l}
\hline $\begin{array}{l}\text { Baseline characteristics similar for interven- } \\
\text { tion group and control? }\end{array}$ & $\begin{array}{l}\text { Comment: Significant differences were identified between the } \\
\text { intervention and control groups in relation to age, disease du- } \\
\text { ration and relapse rates. Some account was made for this in the } \\
\text { analyses } \\
\text { Quote: "The intervention group was younger and had less dis- } \\
\text { ease duration compared to the control group. Therefore these } \\
\text { variables were also considered as covariates in the multivariate } \\
\text { modelling. However, as age and time of onset and diagnosis were } \\
\text { highly correlated (Pearson r40.8, po0.001), only age was used } \\
\text { to reduce the risk of multicollinearity. Post hoc site level analysis } \\
\text { (Tukey HSD) showed that this difference was attributable to } \\
\text { one site (I4)" (p991) } \\
\text { Comment: Control units described by authors and appear sim- } \\
\text { ilar to intervention units - 2 control units, 1 with a low level } \\
\text { of development and 1 with a moderate level. Authors note that } \\
\text { there was a major change of personnel at one of the control units } \\
\text { during the study. Unclear what impact this may have had on } \\
\text { outcomes }\end{array}$ \\
\hline
\end{tabular}

Blinding of outcome assessment?

High risk

Data collected using a self-report questionnaire

Adequately protected against contamina- Unclear risk tion?

Forster 2005

\begin{tabular}{|c|c|}
\hline Methods & RCT \\
\hline Participants & $\begin{array}{l}\text { Patients admitted to } 1 \text { of } 4 \text { general medicine teams at the Ottawa Hospital between } \\
\text { January } 21 \text { and April } 282002 \\
620 \text { randomised, } 361 \text { discharged to community, } 328 \text { completed study, } 290 \text { completed } \\
\text { satisfaction survey } \\
\text { Missing participants: } 33 \text { to completion, } 71 \text { to satisfaction survey }\end{array}$ \\
\hline Interventions & $\begin{array}{l}\text { Skill mix: addition of Clinical Nurse Specialist (CNS) to usual care } \\
\text { In addition to usual care, patients received care from a CNS added to } 1 \text { of } 4 \text { general } \\
\text { medicine teams. CNS's activities prioritised to: retrieving information collected by family } \\
\text { physicians and consultants before admission; arranging in-hospital imaging, procedures } \\
\text { and consultations; facilitating patient education; and telephoning patients early after } \\
\text { discharge from hospital (average } 3 \text { days) to answer questions and address early problems }\end{array}$ \\
\hline Outcomes & $\begin{array}{l}\text { In-hospital mortality } \\
\text { Transfer home or transfer } \\
\text { Time to discharge or patient transfer } \\
\text { Emergency room visit, readmission, or death } \\
\text { Time to emergency room visit, readmission, or death } \\
\text { Adverse events post-discharge } \\
\text { Patient satisfaction }\end{array}$ \\
\hline
\end{tabular}

Hospital nurse staffing models and patient and staff-related outcomes (Review) 
Forster 2005 (Continued)

Notes

Only in-hospital mortality, emergency room visit, readmission, or death, and adverse events post-discharge relevant to this review

Risk of bias

Bias

Random sequence generation (selection Low risk bias)

Allocation concealment (selection bias) Low risk
Randomisation was stratified by team in blocks of 4 with varying random order; unit of randomisation was the patient so that physicians had patients from both study arms in their team

Once baseline screening was conducted, nurse registered patients with study co-ordinator who then randomised patients to study groups using sequentially numbered opaque envelopes

All outcomes data appears complete

Incomplete outcome data (attrition bias) Low risk All outcomes

\begin{tabular}{|c|c|c|}
\hline Selective reporting (reporting bias) & Low risk & All outcomes reported \\
\hline Other bias & Low risk & No evidence of bias \\
\hline Baseline assessment? & Low risk & $\begin{array}{l}\text { Baseline and functional data collected on all participants prior } \\
\text { to randomisation } \\
\text { The clinical nurse specialist conducted baseline interviews or } \\
\text { chart reviews for all patients admitted during the study period } \\
\text { before assignment to study groups. Patients were unaware to } \\
\text { which group they were randomised. Before randomisation, pa- } \\
\text { tients (or their caregivers) were interviewed to determine the pa- } \\
\text { tient's disability score. The medical record was reviewed by study } \\
\text { physicians who were not involved in the patient's care and who } \\
\text { were unaware of the treatment group. Chart review recorded } \\
\text { chronic medical illnesses (the burden of which was measured } \\
\text { with the Charlson Comorbidity Index), number of acute in- } \\
\text { hospital diagnoses, and number of consultations }\end{array}$ \\
\hline
\end{tabular}

Baseline characteristics similar for interven- Unclear risk tion group and control?
Comment: Description is inadequate, just that patients received "usual care",

Comment: Analysis of group characteristics identified some differences:

Quote: “Overall, the control group appeared slightly sicker ... It was more likely to have a higher Charlson Comorbidity Index and disability score. The control group also had a greater number of acute diagnoses and was more likely to have congestive heart failure. In contrast, clinical nurse specialist patients had a greater number of consultations during their visit. With the exception of disability score, these differences were similar to the patients discharged to the community" (p1151) 
Forster 2005 (Continued)

\begin{tabular}{|c|c|c|}
\hline Blinding of outcome assessment? & Low risk & $\begin{array}{l}\text { Quote: "At least } 2 \text { physicians (who were blinded to the patient } \\
\text { group) reviewed all post discharge symptoms to determine if the } \\
\text { patient had experienced an adverse event" ( } \mathrm{p} 1150 \text { ) } \\
\text { Comment: Data on post-discharge outcomes and satisfaction } \\
\text { were collected via telephone interview. The telephone inter- } \\
\text { viewer was blinded to which group the patient had been assigned }\end{array}$ \\
\hline $\begin{array}{l}\text { Adequately protected against contamina- } \\
\text { tion? }\end{array}$ & Low risk & No evidence of contamination \\
\hline
\end{tabular}

Melchoir 1996

\begin{tabular}{|c|c|}
\hline Methods & $\mathrm{CBA}$ \\
\hline Participants & $\begin{array}{l}492 \text { nurses (psychiatric nurses, practical nurses, nurses' aides) providing direct care on } 1 \\
\text { of } 35 \text { long-stay psychiatric wards at } 5 \text { hospitals in the Netherlands randomly selected to } \\
\text { participate } \\
\text { High attrition reported over } 3 \text { times due to staff turnover } \\
366(74.3 \%) \text { participated at time } 1,161(32.7 \%) \text { at time } 3\end{array}$ \\
\hline Interventions & $\begin{array}{l}\text { Staffing models: primary nursing } \\
\text { The intervention was based on the general principles of primary nursing. Both psychiatric } \\
\text { and practical nurses were assigned to patients as primary nurses based on the complexity } \\
\text { of care needed } \\
\text { Nurse managers or quality care co-ordinators provided the primary nurse with the feed- } \\
\text { back and support needed. They also gave advice on skills needed and promoted commu- } \\
\text { nication between the primary nurses and other health care providers. A special support } \\
\text { meeting between primary nurses and other health care specialists was planned. Primary } \\
\text { nurses followed a training programme that emphasized communication skills. The in- } \\
\text { terventions were fully described in an intervention book. The process of implementing } \\
\text { the intervention was supported by a group and was evaluated monthly }\end{array}$ \\
\hline Outcomes & $\begin{array}{l}\text { Staff turnover } \\
\text { Burnout }\end{array}$ \\
\hline Notes & Staff turnover only relevant outcome \\
\hline
\end{tabular}

\section{Risk of bias}

Bias

Incomplete outcome data (attrition bias) High risk All outcomes

\begin{tabular}{lll}
\hline Selective reporting (reporting bias) & Low risk & All outcomes reported \\
\hline Other bias & High risk & $\begin{array}{l}2 \text { major problems described by authors - high drop out due to } \\
\text { turnover and contamination of control units }\end{array}$
\end{tabular}




\section{Melchoir 1996 (Continued)}

\begin{tabular}{|c|c|c|}
\hline Baseline assessment? & Low risk & $\begin{array}{l}\text { Demographics, burnout questionnaire - pre-test measurement } x \\
2\end{array}$ \\
\hline $\begin{array}{l}\text { Baseline characteristics similar for interven- } \\
\text { tion group and control? }\end{array}$ & Unclear risk & $\begin{array}{l}\text { Comment: } 21 \text { comparable (long-stay psychiatric) wards where } \\
\text { intervention was not introduced } \\
\text { Quote: "major differences in the pretest scores between the in- } \\
\text { tervention group and the control group" (p697) }\end{array}$ \\
\hline Blinding of outcome assessment? & High risk & \\
\hline $\begin{array}{l}\text { Adequately protected against contamina- } \\
\text { tion? }\end{array}$ & Unclear risk & $\begin{array}{l}\text { Comment: Possibility of contamination described by authors. } \\
\text { Quote: "During the study it became apparent that some parts of } \\
\text { the intervention were introduced to some control wards through } \\
\text { information leakage and through nursing students who switched } \\
\text { wards. This led to the assumption that the control group could } \\
\text { be seen as an intervention group except for the fact that it did } \\
\text { not receive support from the support group" (p698) }\end{array}$ \\
\hline
\end{tabular}

\section{Neidlinger 1993}

\begin{tabular}{ll}
\hline Methods & CBA \\
\hline Participants & $\begin{array}{l}6769 \text { patients admitted to } 1 \text { of } 4 \text { units at a 560-bed hospital in San Francisco between } \\
\text { January and June } 1990 \text { (pre-intervention) and January and June 1991 (post-intervention) }\end{array}$ \\
\hline Interventions & $\begin{array}{l}\text { Staffing model \& skill mix: incorporating Nursing Assistive Personnel (NAP) into nurs- } \\
\text { ing professional practice model } \\
\text { Senior nurses and managers met to agree on the role of the NAP and to agree on the } \\
\text { educational needs of staff and other resources required for the intervention. 3 NAPs were } \\
\text { recruited to each unit and received a 2-day didactic preparation and a 2-week orientation } \\
\text { programme. Each NAP assigned to work with } 2 \text { to } 3 \text { registered nurses, assisting in the } \\
\text { care of } 12 \text { to } 18 \text { patients }\end{array}$ \\
\hline Outcomes & $\begin{array}{l}\text { Costs } \\
\text { Care quality } \\
\text { Patient satisfaction } \\
\text { Staff satisfaction }\end{array}$ \\
\hline Notes & \begin{tabular}{l} 
Only costs relevant to this review \\
\hline
\end{tabular}
\end{tabular}

\section{Risk of bias}

\section{Bias}

Incomplete outcome data (attrition bias) All outcomes

\section{Authors' judgement Support for judgement}

Low risk

Results reported fully 
Neidlinger 1993 (Continued)

\begin{tabular}{l|ll}
\hline Selective reporting (reporting bias) & Low risk & Results provided for all outcomes \\
\hline Other bias & Low risk & No evidence of bias \\
\hline Baseline assessment? & Unclear risk & No discussion of group characteristics \\
\hline $\begin{array}{l}\text { Baseline characteristics similar for interven- } \\
\text { tion group and control? }\end{array}$ & Unclear risk & $\begin{array}{l}\text { Stated that units were selected because of perceived similarities } \\
\text { in patient acuity and length of shift to experimental units but } \\
\text { not described }\end{array}$ \\
\hline $\begin{array}{l}\text { Blinding of outcome assessment? } \\
\begin{array}{l}\text { Adequately protected against contamina- } \\
\text { tion? }\end{array}\end{array}$ & Low risk & Data taken from hospital records and through chart audit \\
\hline
\end{tabular}

\section{O’Connor 1992}

\begin{tabular}{l|l}
\hline Methods & CBA \\
\hline Participants & 647 nurses working on one of 21 units over study period \\
\hline Interventions & $\begin{array}{l}\text { Self-staffing - in order to meet patient care demands, units would use only their own } \\
\text { nursing staff. The central staffing office did not supply additional help even if there were } \\
\text { increased patient care demands, staff from other units could not be moved around to } \\
\text { help. Therefore the unit took more responsibility for scheduling and staff had input into } \\
\text { policies and procedures concerning staffing on the units }\end{array}$ \\
\hline Outcomes & Turnover rate \\
\hline Notes & \\
\hline
\end{tabular}

\section{Risk of bias}

\begin{tabular}{|c|c|c|}
\hline Bias & Authors' judgement & Support for judgement \\
\hline $\begin{array}{l}\text { Incomplete outcome data (attrition bias) } \\
\text { All outcomes }\end{array}$ & Low risk & Results reported fully \\
\hline Selective reporting (reporting bias) & Low risk & Results provided for all outcomes \\
\hline Other bias & Low risk & No evidence of bias \\
\hline Baseline assessment? & Unclear risk & Baseline characteristics of groups not measured \\
\hline $\begin{array}{l}\text { Baseline characteristics similar for interven- } \\
\text { tion group and control? }\end{array}$ & Unclear risk & $\begin{array}{l}2 \text { control sites: } 1 \text { where intervention was not introduced and } 1 \\
\text { where intervention was implemented before the study began }\end{array}$ \\
\hline Blinding of outcome assessment? & High risk & \\
\hline
\end{tabular}


O’Connor 1992 (Continued)

\author{
Adequately protected against contamina- Low risk \\ No evidence of contamination \\ tion?
}

Pozen 1977

\begin{tabular}{ll} 
Methods & RCT \\
\hline Participants & $\begin{array}{l}313 \text { patients admitted to the CCU of Baltimore City Hospitals during a } 16 \text { month } \\
\text { period who had MI (documented by history, serial enzymes and typical ECG changes) } \\
\text { and were willing to participate in the study and follow-up }\end{array}$ \\
\hline Interventions & $\begin{array}{l}\text { In addition to routine care, patients had access to a CCU-based nurse rehabilitator. } \\
\text { Objectives were to 1) optimise patients' long-term work and rehabilitation through an } \\
\text { aggressive programme of psychological support and education, 2) to improve patients } \\
\text { knowledge and compliance to medical therapy by teaching them about MI, risk factors, } \\
\text { basic physiology, rationale for therapy, and the appropriate convalescent programme, } \\
\text { and 3) reduce anxiety by assisting the patient in understanding and coping with MI }\end{array}$ \\
\hline Outcomes & $\begin{array}{l}\text { Anxiety } \\
\text { Functional status } \\
\text { Complications } \\
\text { Knowledge } \\
\text { Smoking and weight regimes } \\
\text { Employment status at } 6 \text { months (previously employed) }\end{array}$ \\
\hline Notes & \begin{tabular}{l} 
Employment status only outcome relevant to this study \\
\hline
\end{tabular} \\
\hline
\end{tabular}

Risk of bias

Bias Authors' judgement Support for judgement

Random sequence generation (selection Unclear risk States that once classified as low or high risk 24 hours post adbias) mission; patients were randomised to study or control group. High risk patients were randomly assigned in equal proportions. Low risk patients assigned using a 2:1 ratio to study and control groups respectively, rationale or further details not reported. Also stated that rotational admission policy resulted in a similar distribution of patients among all house officers

\begin{tabular}{lll}
\hline Allocation concealment (selection bias) & Unclear risk & Not reported \\
\hline $\begin{array}{l}\text { Incomplete outcome data (attrition bias) } \\
\text { All outcomes }\end{array}$ & Low risk & Results reported fully \\
\hline Selective reporting (reporting bias) & Low risk & All outcomes reported \\
\hline Other bias & Low risk & No evidence of bias
\end{tabular}

Hospital nurse staffing models and patient and staff-related outcomes (Review) 
Pozen 1977 (Continued)

\begin{tabular}{lll}
\hline Baseline assessment? & Low risk & $\begin{array}{l}\text { Patient questionnaire to assess demographic and clinical charac- } \\
\text { teristics, and risk }\end{array}$ \\
\hline $\begin{array}{l}\text { Baseline characteristics similar for interven- } \\
\text { tion group and control? }\end{array}$ & Low risk & $\begin{array}{l}\text { Comment: Traditional MD/RN care. } \\
\text { Quote: "Distributions of patients' age, race, sex, income, em- } \\
\text { ployment, education and clinical characteristics were similar in } \\
\text { the study and control groups for both the high risk and low risk } \\
\text { categories" (p831) }\end{array}$ \\
\hline $\begin{array}{l}\text { Blinding of outcome assessment? } \\
\begin{array}{l}\text { Adequately protected against contamina- } \\
\text { tion? }\end{array}\end{array}$ & Low risk & Data collected using a self-completion questionnaire. \\
\hline
\end{tabular}

Ritz 2000

\begin{tabular}{l|l}
\hline Methods & RCT \\
\hline Participants & $\begin{array}{l}211 \text { women } 21 \text { years and older diagnosed with breast cancer between } 1995 \& 1997, \text { able } \\
\text { to read and write English and give informed consent. Also required physician referral, } \\
\text { care within the system and consent within } 2 \text { weeks of diagnosis }\end{array}$ \\
\hline Interventions & $\begin{array}{l}\text { Standard medical care plus Advanced Practice Nurse (APN) care } \\
\text { APN contact within } 2 \text { weeks of diagnosis, written and verbal information about breast } \\
\text { cancer, what to expect in consultations with physicians, decision-making support, an- } \\
\text { swering questions and presence for support. Subsequent contacts at scheduled clinic } \\
\text { visits, by telephone, home visits or patient initiated visits. Contacts based on need as } \\
\text { determined by patient, family and APNs. } 1 \text { of } 2 \text { APNs was on call 8am to 8pm Monday } \\
\text { to Friday and } 8 \text { am to } 12 \text { noon on weekends }\end{array}$ \\
\hline Outcomes & $\begin{array}{l}\text { Quality of life } \\
\text { Costs }\end{array}$ \\
\hline Notes & Only costs data relevant to this study \\
\hline
\end{tabular}

\section{Risk of bias}

Bias Authors' judgement Support for judgement

\begin{tabular}{l|l}
\hline Random sequence generation (selection Unclear risk $\quad$ It is stated that women were assigned randomly to 1 of 2 groups
\end{tabular} bias) but method is not described

\begin{tabular}{|c|c|c|}
\hline Allocation concealment (selection bias) & Unclear risk & Not discussed \\
\hline $\begin{array}{l}\text { Incomplete outcome data (attrition bias) } \\
\text { All outcomes }\end{array}$ & Unclear risk & $\begin{array}{l}\text { Comment: Cost data complete only for } 141 / 211 \text { participants. } \\
\text { States those not included in the cost analysis were missing: } \\
\text { Quote: "substantial amounts of data on costs [lost] either be- } \\
\text { cause they were referred for only oncology care or because they }\end{array}$ \\
\hline
\end{tabular}

Hospital nurse staffing models and patient and staff-related outcomes (Review)

Copyright $\odot 201$ I The Cochrane Collaboration. Published by John Wiley \& Sons, Ltd. 
Ritz 2000 (Continued)

moved, changed insurance, or transferred care to non system facilities" (p925)

\begin{tabular}{|c|c|c|}
\hline Selective reporting (reporting bias) & Low risk & All outcomes reported \\
\hline Other bias & Low risk & No evidence of bias \\
\hline Baseline assessment? & Low risk & Demographics, histology and treatment \\
\hline $\begin{array}{l}\text { Baseline characteristics similar for interven- } \\
\text { tion group and control? }\end{array}$ & Low risk & $\begin{array}{l}\text { Comment: Standard medical care } \\
\text { Quote: "The randomization process produced intervention and } \\
\text { control groups that were similar demographically and in charac- } \\
\text { teristics of disease at diagnosis and treatment .. with two excep- } \\
\text { tions: women in the intervention group were significantly more } \\
\text { likely to have a lower histology ( } \mathrm{p}=0.04 \text { ) and to receive adjuvant } \\
\text { hormone therapy ( } \mathrm{p}=0.03 \text { ) than women in the control group" } \\
\text { (p925) }\end{array}$ \\
\hline Blinding of outcome assessment? & High risk & $\begin{array}{l}\text { Data obtained from hospital records or through self-completion } \\
\text { questionnaire }\end{array}$ \\
\hline $\begin{array}{l}\text { Adequately protected against contamina- } \\
\text { tion? }\end{array}$ & Low risk & No evidence of contamination. \\
\hline
\end{tabular}

Talley 1990

\begin{tabular}{ll}
\hline Methods & RCT \\
\hline Participants & $\begin{array}{l}107 \text { patients ( } 85 \text { non-suicidal and } 22 \text { suicidal) admitted to an adult medical, surgical, } \\
\text { obstetrical or gynaecological unit in a large northeastern university hospital in the US } \\
\text { and assigned a sitter for at least } 1 \text { shift on } 2 \text { consecutive days between } 4 \text { th January and } \\
31 \text { st March } 1988\end{array}$ \\
\hline Interventions & $\begin{array}{l}\text { Consultation with a Psychiatric Liaison Nurse Specialist (PLNS) } \\
\text { Seen by PLNS for the duration of the sitter order. Consultation initiated as soon as } \\
\text { possible after the second sitter day by one of the hospitals } 2 \text { PNLSs. Consultation was } \\
\text { based on modified version of PLNS consultation (Lewis and Lewis 1982). Consultation } \\
\text { was individualised to the particular patient situation and typically began with the reason } \\
\text { for the sitter request, a review of the chart, and exploration of the staff nurse's view of the } \\
\text { patient problem. Patient then assessed and interventions based on identified problems } \\
\text { with approaches targeted to nursing staff, patients and sitters. Patients received ongoing, } \\
\text { direct PLNS interventions based on their potential for co-operation and the nature of } \\
\text { the problem necessitation sitters }\end{array}$ \\
\hline
\end{tabular}

Outcomes

Length of stay

Number of sitter shifts

Number of charted observations of mood, behaviour and mental status

Number of patient incident reports during the time with sitters

Hospital nurse staffing models and patient and staff-related outcomes (Review)

Copyright () 201 I The Cochrane Collaboration. Published by John Wiley \& Sons, Ltd. 
Talley 1990 (Continued)

Number of incidents of sitter refusal or walk-offs

Notes Only length of stay relevant to this review

Risk of bias

Bias

Authors' judgement Support for judgement

Random sequence generation (selection Unclear risk bias)

All patients with sitters who met study inclusion criteria were assigned to suicidal or non-suicidal group. Patients in each group then assigned randomly to either treatment or control group.

Method to generate sequence not described

\begin{tabular}{lll} 
Allocation concealment (selection bias) & Unclear risk & Not reported \\
\hline $\begin{array}{l}\text { Incomplete outcome data (attrition bias) } \\
\text { All outcomes }\end{array}$ & Low risk & All outcomes reported fully \\
\hline Selective reporting (reporting bias) & Unclear risk & Not clear which group 3 reported episodes relate to \\
\hline Other bias & Low risk & No evidence of bias \\
\hline Baseline assessment? & Unclear risk & $\begin{array}{l}\text { Demographics, diagnosis and history } \\
\text { Comparisons made between suicidal and non-suicidal groups } \\
\text { rather than intervention and control and no reference to signif- } \\
\text { icance of differences }\end{array}$ \\
\hline
\end{tabular}

Baseline characteristics similar for interven- Low risk Similar patients who received no intervention tion group and control?

Blinding of outcome assessment? High risk

Information collected using template or taken from hospital incident reports and sitter service records

Adequately protected against contamina- Low risk No evidence of contamination tion?

Characteristics of excluded studies [ordered by study ID]

\begin{tabular}{ll}
\hline Study & Reason for exclusion \\
\hline Armstrong 2004 & Insufficient data points pre- and post-intervention \\
\hline Arts 2000 & Insufficient data points pre- and post-intervention \\
\hline Barkell 2002 & Results confounded
\end{tabular}

Hospital nurse staffing models and patient and staff-related outcomes (Review) 
(Continued)

\begin{tabular}{|c|c|}
\hline Benson 2008 & Insufficient data reported \\
\hline Brett 1990 & Insufficient data points pre- and post-intervention \\
\hline Burnes Bolton 2007 & Insufficient data points pre- and post-intervention \\
\hline Campolo 1998 & Insufficient data reported \\
\hline Cavan 2001 & Insufficient data points pre- and post-intervention \\
\hline Chavigny 1984 & Insufficient data reported \\
\hline Choi 1986 & Insufficient data reported \\
\hline Ciske 1974 & Insufficient data reported \\
\hline Counsell 1999 & Insufficient data reported \\
\hline Danello 2008 & Insufficient data reported \\
\hline Davis 1997 & Insufficient data reported \\
\hline Donaldson 2005 & Insufficient data points pre- and post-intervention \\
\hline Eck 1999 & Insufficient data points pre- and post-intervention \\
\hline Eriksen 1992 & Insufficient data reported \\
\hline Gardner 1991 & Insufficient data points pre- and post-intervention \\
\hline Grillo-Peck 1995 & Insufficient data points pre- and post-intervention \\
\hline Hanneman 1993 & $\begin{array}{l}\text { Did not meet the EPOC minimum requirement for CBA studies of } 2 \text { intervention groups and } 2 \text { control } \\
\text { groups }\end{array}$ \\
\hline Heinemann 1996 & Insufficient data reported \\
\hline Hinshaw 1981 & Insufficient data points pre- and post-intervention \\
\hline Jansen 1994 & Insufficient data points pre- and post-intervention \\
\hline Kenney 2001 & Insufficient data reported \\
\hline Lea 2003 & Insufficient data points pre- and post-intervention \\
\hline Lee 2005 & Insufficient data points pre- and post-intervention \\
\hline
\end{tabular}

Hospital nurse staffing models and patient and staff-related outcomes (Review) 


\section{(Continued)}

\begin{tabular}{|c|c|}
\hline Lengacher 1994 & $\begin{array}{l}\text { Did not meet the EPOC minimum requirement for CBA studies of } 2 \text { intervention groups and } 2 \text { control } \\
\text { groups }\end{array}$ \\
\hline Lewis 1994 & Insufficient data points pre- and post-intervention \\
\hline McPhail 1990 & Insufficient data reported \\
\hline O’Hare 2006 & Insufficient data points pre- and post-intervention \\
\hline Pratt 1993 & Insufficient data points pre- and post-intervention \\
\hline Rideout 2007 & Insufficient data points pre- and post-intervention \\
\hline Ringerman 2000 & Insufficient data reported \\
\hline Sarkissan 1999 & Insufficient data points pre- and post-intervention \\
\hline Sheill 1993 & Insufficient data points pre- and post-intervention \\
\hline Sinclair 2006 & Data not obtained objectively \\
\hline Smith 2006 & Insufficient data points pre- and post-intervention \\
\hline Strayer 2008 & Insufficient data points pre- and post-intervention \\
\hline Sullivan 2002 & Insufficient data reported \\
\hline Tourangeau 1999 & $\begin{array}{l}\text { Did not meet the EPOC minimum requirement for CBA studies of } 2 \text { intervention groups and } 2 \text { control } \\
\text { groups }\end{array}$ \\
\hline Vaska 1993 & Insufficient data points pre- and post-intervention \\
\hline Williams 2000 & Insufficient data points pre- and post-intervention \\
\hline Yong 2002 & Insufficient data points pre- and post-intervention \\
\hline Zidek 2003 & Insufficient data points pre- and post-intervention \\
\hline
\end{tabular}


Characteristics of ongoing studies [ordered by study ID]

Valentine 2008

Trial name or title Achieving effective staffing through a shared decision-making approach to open shift management

\begin{tabular}{ll}
\hline Methods & ITS \\
\hline Participants & Hospital nurses at three magnet-designated acute care hospitals in Pennsylvania \\
\hline Interventions & Staffing models - open-shift management \\
\hline Outcomes & $\begin{array}{l}\text { Costs } \\
\text { Vurse turnover }\end{array}$ \\
\hline Starting date & Not stated \\
\hline Contact information & $\begin{array}{l}\text { Dr. Valentine, Main Line Health, Ist Floor Gerhard Building, 130 Bryn Mawr, PA 19010, valentinen@mlhs. } \\
\text { org }\end{array}$ \\
\hline Notes & Descriptive report, reports plans to roll program out further \\
\hline
\end{tabular}


DATA AND ANALYSES

Comparison 1. Addition of specialist nursing post to staffing versus standard staffing

\begin{tabular}{|c|c|c|c|c|}
\hline Outcome or subgroup title & $\begin{array}{l}\text { No. of } \\
\text { studies }\end{array}$ & $\begin{array}{c}\text { No. of } \\
\text { participants }\end{array}$ & Statistical method & Effect size \\
\hline 1 In-hospital mortality & 1 & 612 & Risk Ratio (M-H, Fixed, 95\% CI) & $0.96[0.59,1.56]$ \\
\hline 2 Length of stay & 2 & 235 & Mean Difference (IV, Fixed, 95\% CI) & $-1.35[-1.92,-0.78]$ \\
\hline 3 Readmission & 3 & 878 & Risk Ratio (M-H, Fixed, 95\% CI) & $1.15[0.88,1.52]$ \\
\hline $\begin{array}{l}4 \text { Attendance at ED within } 30 \\
\text { days }\end{array}$ & 1 & 472 & Risk Ratio (M-H, Fixed, 95\% CI) & $1.14[0.79,1.62]$ \\
\hline $\begin{array}{l}5 \text { Post-discharge admission, ED } \\
\text { visit or death }\end{array}$ & 1 & 328 & Risk Ratio (M-H, Fixed, 95\% CI) & $1.33[0.93,1.91]$ \\
\hline 6 Post-discharge adverse events & 1 & 328 & Risk Ratio (M-H, Fixed, 95\% CI) & $1.03[0.70,1.53]$ \\
\hline $\begin{array}{l}7 \text { Employment status } 6 \text { months } \\
\text { post-discharge (of patients } \\
\text { previously employed) }\end{array}$ & 1 & 65 & Risk Ratio (M-H, Fixed, 95\% CI) & $1.25[0.90,1.75]$ \\
\hline 7.1 High Risk & 1 & 44 & Risk Ratio (M-H, Fixed, 95\% CI) & $1.32[0.87,2.00]$ \\
\hline 7.2 Low Risk & 1 & 21 & Risk Ratio (M-H, Fixed, 95\% CI) & $1.13[0.64,1.98]$ \\
\hline 8 Glycosylated haemoglobin & 1 & 88 & Mean Difference (IV, Fixed, 95\% CI) & $-0.5[-1.90,0.90]$ \\
\hline
\end{tabular}

Comparison 2. Increasing the proportion of support staff versus usual staffing

\begin{tabular}{lccll} 
Outcome or subgroup title & $\begin{array}{c}\text { No. of } \\
\text { studies }\end{array}$ & $\begin{array}{c}\text { No. of } \\
\text { participants }\end{array}$ & Statistical method & Effect size \\
\hline 1 Deaths in trauma unit & 1 & 302 & Risk Ratio (M-H, Fixed, 95\% CI) & $0.41[0.16,1.01]$ \\
2 Deaths in hospital & 1 & 302 & Risk Ratio (M-H, Fixed, 95\% CI) & $0.56[0.29,1.09]$ \\
3 Deaths at 4 months & 1 & 302 & Risk Ratio (M-H, Fixed, 95\% CI) & $0.57[0.34,0.95]$ \\
\hline
\end{tabular}

Comparison 3. Team midwifery versus standard care

\begin{tabular}{lcclc} 
Outcome or subgroup title & $\begin{array}{c}\text { No. of } \\
\text { studies }\end{array}$ & $\begin{array}{c}\text { No. of } \\
\text { participants }\end{array}$ & Statistical method & Effect size \\
\hline 1 Perinatal death & 1 & 884 & Risk Ratio (M-H, Fixed, 95\% CI) & $1.22[0.33,4.50]$ \\
2 Length of stay in hospital (days) & 1 & 884 & Mean Difference (IV, Fixed, 95\% CI) & $-0.30[-0.54,-0.06]$ \\
3 Length of stay in SCN (days) & 1 & 884 & Mean Difference (IV, Fixed, 95\% CI) & $-2.00[-2.07,-1.93]$ \\
\hline
\end{tabular}

Hospital nurse staffing models and patient and staff-related outcomes (Review) 
Analysis I.I. Comparison I Addition of specialist nursing post to staffing versus standard staffing, Outcome I In-hospital mortality.

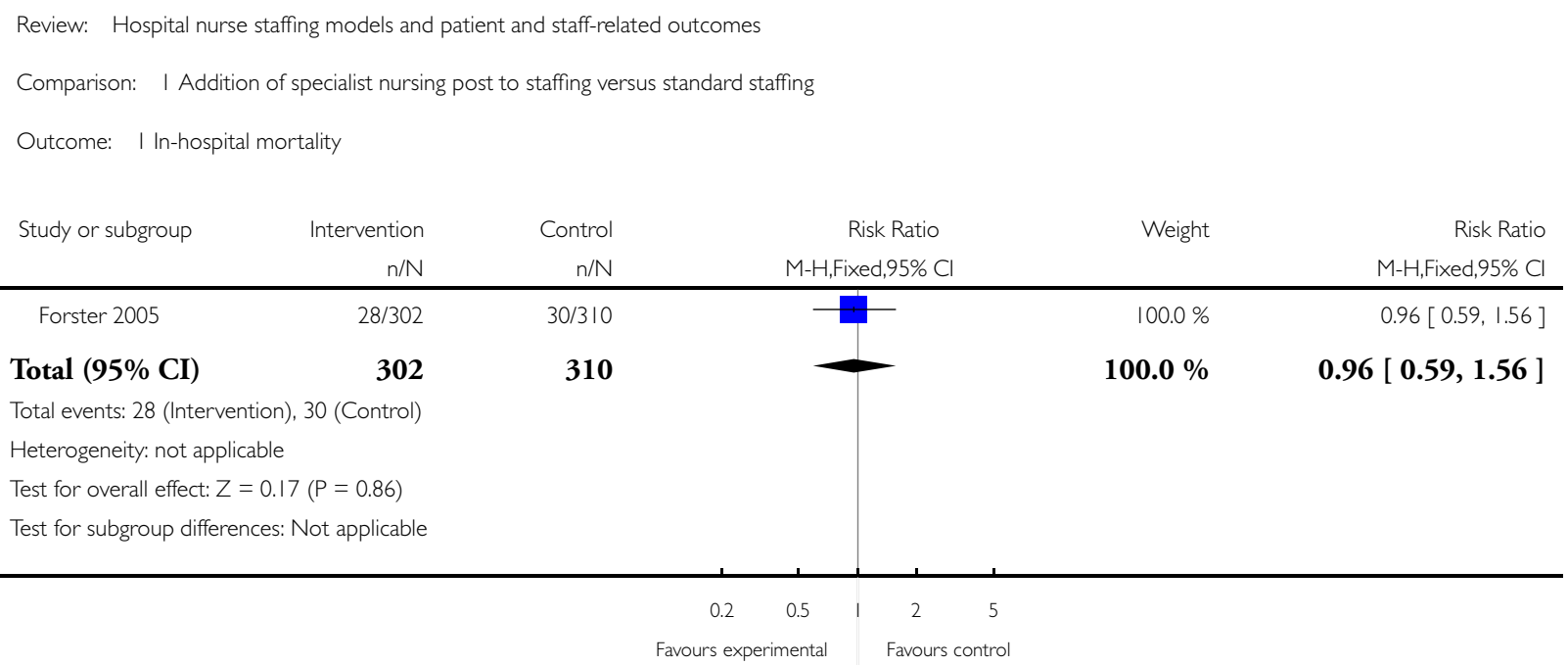

\section{Analysis I.2. Comparison I Addition of specialist nursing post to staffing versus standard staffing, Outcome} 2 Length of stay.

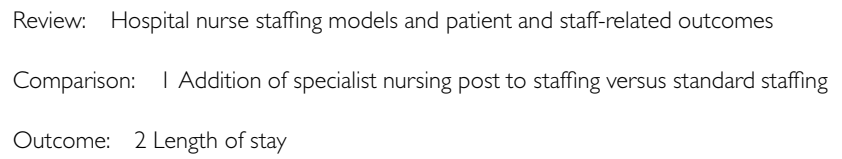

\begin{tabular}{|c|c|c|c|c|c|c|c|}
\hline \multirow[t]{2}{*}{ Study or subgroup } & \multirow{2}{*}{$\begin{array}{r}\text { Intervention } \\
\mathrm{N}\end{array}$} & \multicolumn{3}{|c|}{ Control } & \multirow{2}{*}{$\begin{array}{c}\text { Mean } \\
\text { Difference } \\
\text { IV,Fixed,95\% Cl }\end{array}$} & \multirow[t]{2}{*}{ Weight } & \multirow{2}{*}{$\begin{array}{r}\text { Mean } \\
\text { Difference } \\
\text { IV,Fixed,95\% Cl }\end{array}$} \\
\hline & & Mean(SD) & $N$ & Mean(SD) & & & \\
\hline Dawes 2007 & 52 & $4.71(1.64)$ & 54 & $6.06(1.41)$ & & $96.4 \%$ & $-1.35[-1.93,-0.77]$ \\
\hline Feddersen 1994 & 67 & $10.1(9.1)$ & 62 & I I.4 (8.5) & & $3.6 \%$ & $-1.30[-4.34,1.74]$ \\
\hline Total (95\% CI) & 119 & & 116 & & & $100.0 \%$ & $-1.35[-1.92,-0.78]$ \\
\hline
\end{tabular}

Heterogeneity: Chi $^{2}=0.00, \mathrm{df}=\mathrm{I}(\mathrm{P}=0.97) ; \mathrm{I}^{2}=0.0 \%$

Test for overall effect: $Z=4.61(P<0.0000 \mathrm{I})$

Test for subgroup differences: Not applicable 
Analysis I.3. Comparison I Addition of specialist nursing post to staffing versus standard staffing, Outcome 3 Readmission.

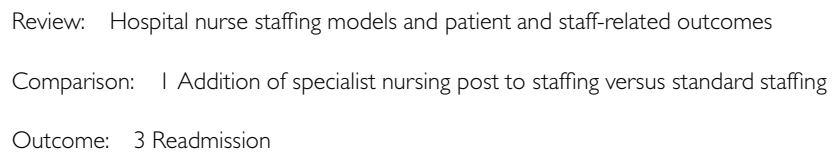

\begin{tabular}{|c|c|c|c|c|c|}
\hline \multirow[t]{2}{*}{ Study or subgroup } & Intervention & Control & Risk Ratio & Weight & Risk Ratio \\
\hline & $\mathrm{n} / \mathrm{N}$ & $\mathrm{n} / \mathrm{N}$ & M-H,Fixed,95\% Cl & & M-H,Fixed,95\% Cl \\
\hline Davies 200I & $37 / 152$ & $38 / 148$ & - & $50.4 \%$ & $0.95[0.64,1.40]$ \\
\hline Dawes 2007 & $5 / 52$ & $4 / 54$ & & $5.1 \%$ & $1.30[0.37,4.57]$ \\
\hline Einstadter 1996 & $48 / 243$ & $33 / 229$ & & $44.5 \%$ & $1.37[0.91,2.05]$ \\
\hline
\end{tabular}

Total (95\% CI) $\quad 447 \quad 431$

Total events: 90 (Intervention), 75 (Control)

Heterogeneity: $\mathrm{Chi}^{2}=1.69, \mathrm{df}=2(\mathrm{P}=0.43) ; \mathrm{I}^{2}=0.0 \%$

Test for overall effect: $Z=1.02(P=0.31)$

Test for subgroup differences: Not applicable

$100.0 \%$

$1.15[0.88,1.52]$ 
Analysis I.5. Comparison I Addition of specialist nursing post to staffing versus standard staffing, Outcome 5 Post-discharge admission, ED visit or death.

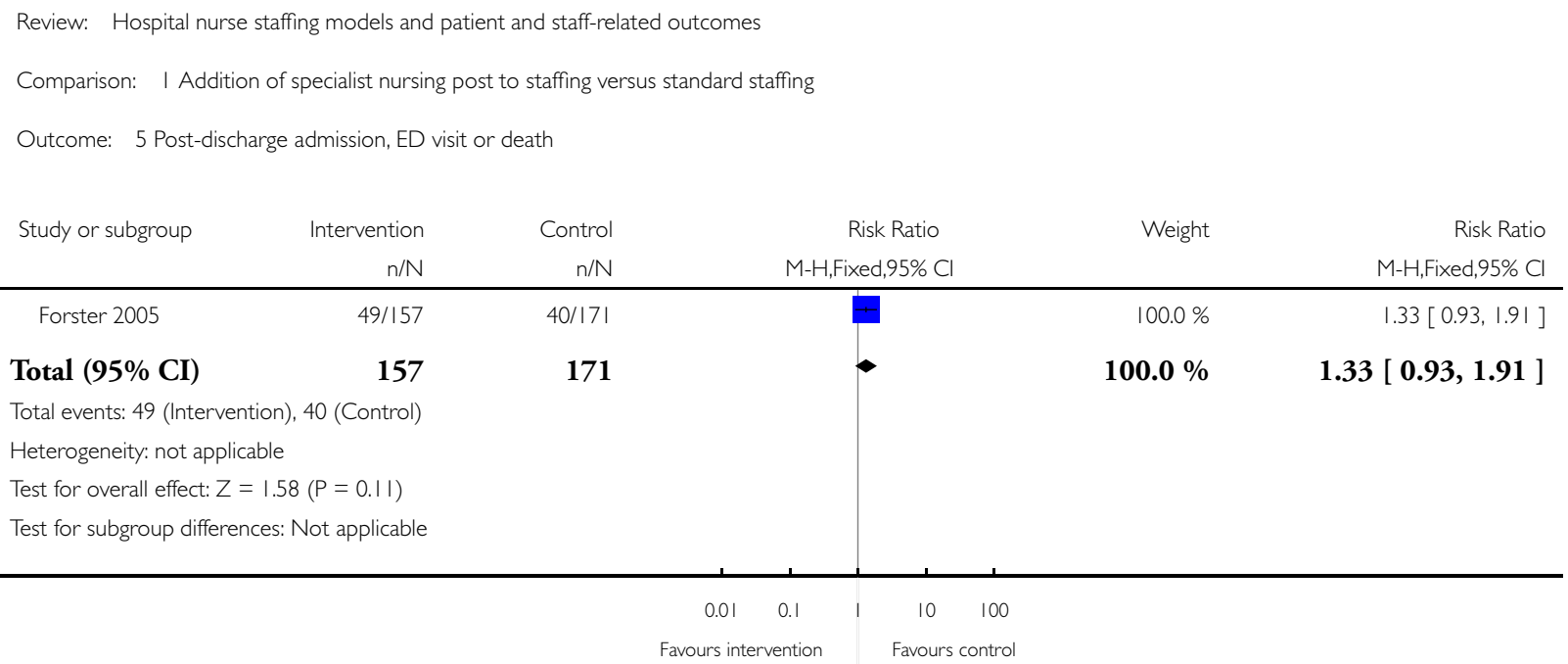


Analysis I.6. Comparison I Addition of specialist nursing post to staffing versus standard staffing, Outcome 6 Post-discharge adverse events.

\begin{tabular}{|c|c|c|c|c|c|}
\hline \multicolumn{6}{|l|}{ Review: } \\
\hline \multicolumn{6}{|c|}{ Comparison: I Addition of specialist nursing post to staffing versus standard staffing } \\
\hline Outcome: 6 Post- $c$ & adverse events & & & & \\
\hline \multirow[t]{2}{*}{ Study or subgroup } & Intervention & Control & Risk Ratio & \multirow[t]{2}{*}{ Weight } & Risk Ratio \\
\hline & $n / N$ & $n / N$ & M-H,Fixed,95\% Cl & & M-H,Fixed,95\% Cl \\
\hline Forster 2005 & $37 / 157$ & $39 / 171$ & & $100.0 \%$ & $1.03[0.70,1.53]$ \\
\hline Total $(95 \%$ CI $)$ & 157 & 171 & $\longrightarrow$ & $100.0 \%$ & $1.03[0.70,1.53]$ \\
\hline \multicolumn{6}{|c|}{ Total events: 37 (Intervention), 39 (Control) } \\
\hline \multicolumn{6}{|c|}{ Heterogeneity: not applicable } \\
\hline \multicolumn{6}{|c|}{ Test for overall effect: $Z=0.16(P=0.87)$} \\
\hline \multicolumn{6}{|c|}{ Test for subgroup differences: Not applicable } \\
\hline
\end{tabular}


Analysis I.7. Comparison I Addition of specialist nursing post to staffing versus standard staffing, Outcome 7 Employment status 6 months post-discharge (of patients previously employed).

Review: Hospital nurse staffing models and patient and staff-related outcomes

Comparison: I Addition of specialist nursing post to staffing versus standard staffing

Outcome: 7 Employment status 6 months post-discharge (of patients previously employed)

\begin{tabular}{|c|c|c|c|c|c|}
\hline \multirow[t]{2}{*}{ Study or subgroup } & Intervention & Control & Risk Ratio & \multirow[t]{2}{*}{ Weight } & \multirow{2}{*}{$\begin{array}{r}\text { Risk Ratio } \\
\text { M-H,Fixed,95\% Cl }\end{array}$} \\
\hline & $\mathrm{n} / \mathrm{N}$ & $\mathrm{n} / \mathrm{N}$ & M-H,Fixed,95\% Cl & & \\
\hline \multicolumn{6}{|l|}{ I High Risk } \\
\hline Pozen 1977 & $21 / 26$ & $11 / 18$ & & $65.5 \%$ & $1.32[0.87,2.00]$ \\
\hline Subtotal (95\% CI) & 26 & 18 & & $65.5 \%$ & $1.32[0.87,2.00]$ \\
\hline \multicolumn{6}{|c|}{ Total events: 2 I (Intervention), II (Control) } \\
\hline \multicolumn{6}{|c|}{ Heterogeneity: not applicable } \\
\hline \multicolumn{6}{|c|}{ Test for overall effect: $Z=1.32(P=0.19)$} \\
\hline \multicolumn{6}{|c|}{2 Low Risk } \\
\hline Pozen 1977 & $9 / 12$ & $6 / 9$ & & $34.5 \%$ & $1.13[0.64,1.98]$ \\
\hline Subtotal (95\% CI) & 12 & 9 & & $34.5 \%$ & $1.13[0.64,1.98]$ \\
\hline \multicolumn{6}{|c|}{ Total events: 9 (Intervention), 6 (Control) } \\
\hline \multicolumn{6}{|c|}{ Heterogeneity: not applicable } \\
\hline \multicolumn{6}{|c|}{ Test for overall effect: $Z=0.41(P=0.68)$} \\
\hline Total (95\% CI) & 38 & 27 & & $100.0 \%$ & $1.25[0.90,1.75]$ \\
\hline \multicolumn{6}{|c|}{ Total events: 30 (Intervention), 17 (Control) } \\
\hline \multicolumn{6}{|c|}{ Heterogeneity: Chi $^{2}=0.20, d f=I(P=0.65) ;\left.\right|^{2}=0.0 \%$} \\
\hline \multicolumn{6}{|c|}{ Test for overall effect: $Z=1.33(P=0.18)$} \\
\hline \multicolumn{6}{|c|}{ Test for subgroup differences: $\mathrm{Chi}^{2}=0.20, \mathrm{df}=\mathrm{I}(\mathrm{P}=0.65), \mathrm{I}^{2}=0.0 \%$} \\
\hline & & 0.2 & 0.5 & 5 & \\
\hline & & Favours in & Favour & ntrol & \\
\hline
\end{tabular}


Analysis I.8. Comparison I Addition of specialist nursing post to staffing versus standard staffing, Outcome 8 Glycosylated haemoglobin.

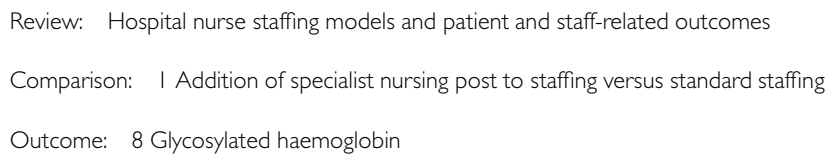

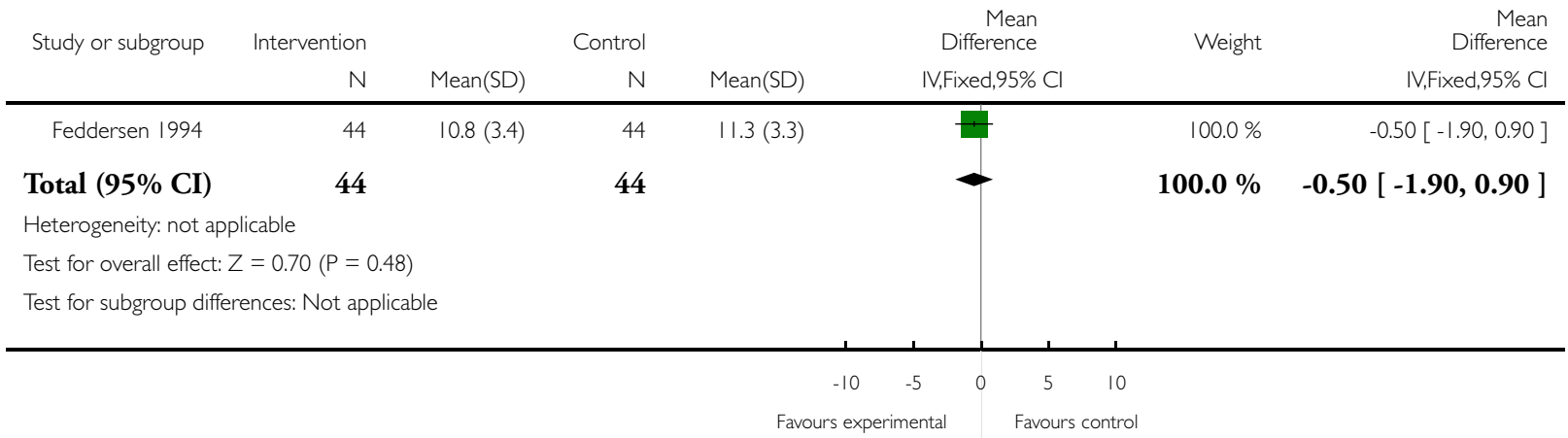

\section{Analysis 2.I. Comparison 2 Increasing the proportion of support staff versus usual staffing, Outcome I} Deaths in trauma unit.

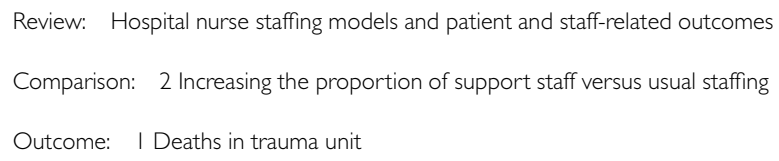

\begin{tabular}{|c|c|c|c|c|c|}
\hline \multirow[t]{2}{*}{ Study or subgroup } & Intervention & Control & Risk Ratio & \multirow[t]{2}{*}{ Weight } & Risk Ratio \\
\hline & $\mathrm{n} / \mathrm{N}$ & $\mathrm{n} / \mathrm{N}$ & M-H,Fixed,95\% Cl & & M-H,Fixed,95\% Cl \\
\hline Duncan 2006 & $6 / 145$ & $16 / 157$ & 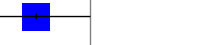 & $100.0 \%$ & $0.41[0.16,1.01]$ \\
\hline Total (95\% CI) & 145 & 157 & & $100.0 \%$ & $0.41[0.16,1.01]$ \\
\hline \multicolumn{6}{|c|}{ Total events: 6 (Intervention), 16 (Control) } \\
\hline \multicolumn{6}{|c|}{ Heterogeneity: not applicable } \\
\hline \multicolumn{6}{|c|}{ Test for overall effect: $Z=1.94(P=0.052)$} \\
\hline Test for subgroup diff & Vot applicable & & & & \\
\hline
\end{tabular}

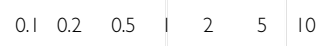

Favours intervention Favours control 
Analysis 2.2. Comparison 2 Increasing the proportion of support staff versus usual staffing, Outcome 2 Deaths in hospital.

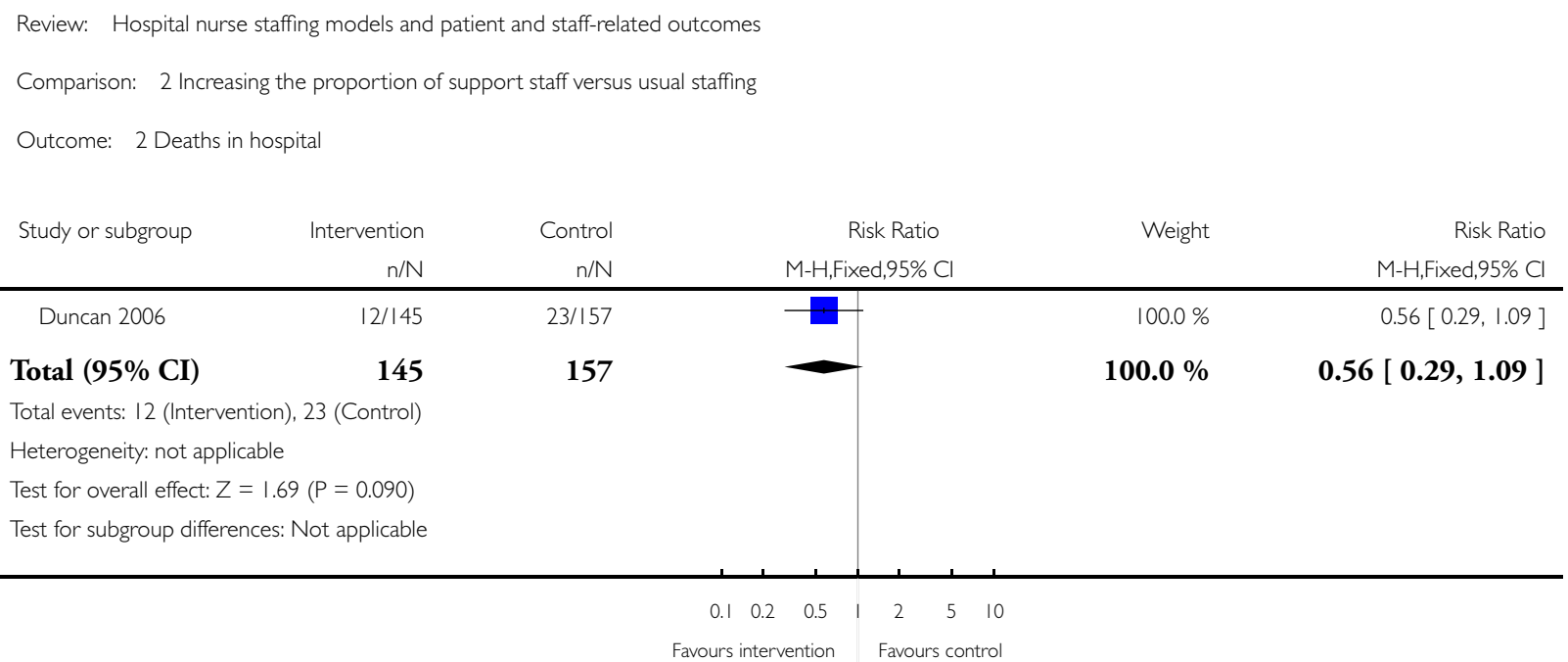

\section{Analysis 2.3. Comparison 2 Increasing the proportion of support staff versus usual staffing, Outcome 3}

Deaths at 4 months.

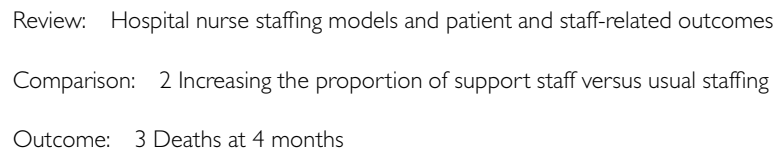

\begin{tabular}{|c|c|c|c|c|c|}
\hline \multirow[t]{2}{*}{ Study or subgroup } & Intervention & Control & Risk Ratio & \multirow[t]{2}{*}{ Weight } & Risk Ratio \\
\hline & $\mathrm{n} / \mathrm{N}$ & $\mathrm{n} / \mathrm{N}$ & M-H,Fixed,95\% Cl & & M-H,Fixed,95\% Cl \\
\hline Duncan 2006 & $19 / 145$ & $36 / 157$ & I & $100.0 \%$ & $0.57[0.34,0.95]$ \\
\hline Total (95\% CI) & 145 & 157 & & $100.0 \%$ & $0.57[0.34,0.95]$ \\
\hline \multicolumn{6}{|c|}{ Total events: 19 (Intervention), 36 (Control) } \\
\hline \multicolumn{6}{|c|}{ Heterogeneity: not applicable } \\
\hline \multicolumn{6}{|c|}{ Test for overall effect: $Z=2.16(P=0.031)$} \\
\hline Test for subgroup diff & Vot applicable & & & & \\
\hline
\end{tabular}

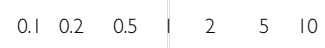

Favours intervention Favours control 


\section{Analysis 3.I. Comparison 3 Team midwifery versus standard care, Outcome I Perinatal death.}

\begin{tabular}{|c|c|c|c|c|c|}
\hline \multicolumn{6}{|c|}{ Comparison: 3 Team midwifery versus standard care } \\
\hline Outcome: I Perina & & & & & \\
\hline \multirow[t]{2}{*}{ Study or subgroup } & Intervention & Control & Risk Ratio & Weight & Risk Ratio \\
\hline & $n / N$ & $\mathrm{n} / \mathrm{N}$ & M-H,Fixed,95\% Cl & & M-H,Fixed,95\% Cl \\
\hline Biro 2000 & $5 / 448$ & $4 / 436$ & & $100.0 \%$ & $1.22[0.33,4.50]$ \\
\hline Total $(95 \% \mathrm{CI})$ & 448 & 436 & & $100.0 \%$ & $1.22[0.33,4.50]$ \\
\hline \multicolumn{6}{|c|}{ Total events: 5 (Intervention), 4 (Control) } \\
\hline \multicolumn{6}{|c|}{ Heterogeneity: not applicable } \\
\hline \multicolumn{6}{|c|}{ Test for overall effect: $Z=0.29(P=0.77)$} \\
\hline \multicolumn{6}{|c|}{ Test for subgroup differences: Not applicable } \\
\hline
\end{tabular}

\section{Analysis 3.2. Comparison 3 Team midwifery versus standard care, Outcome 2 Length of stay in hospital}

(days).

Review: Hospital nurse staffing models and patient and staff-related outcomes

Comparison: 3 Team midwifery versus standard care

Outcome: 2 Length of stay in hospital (days)

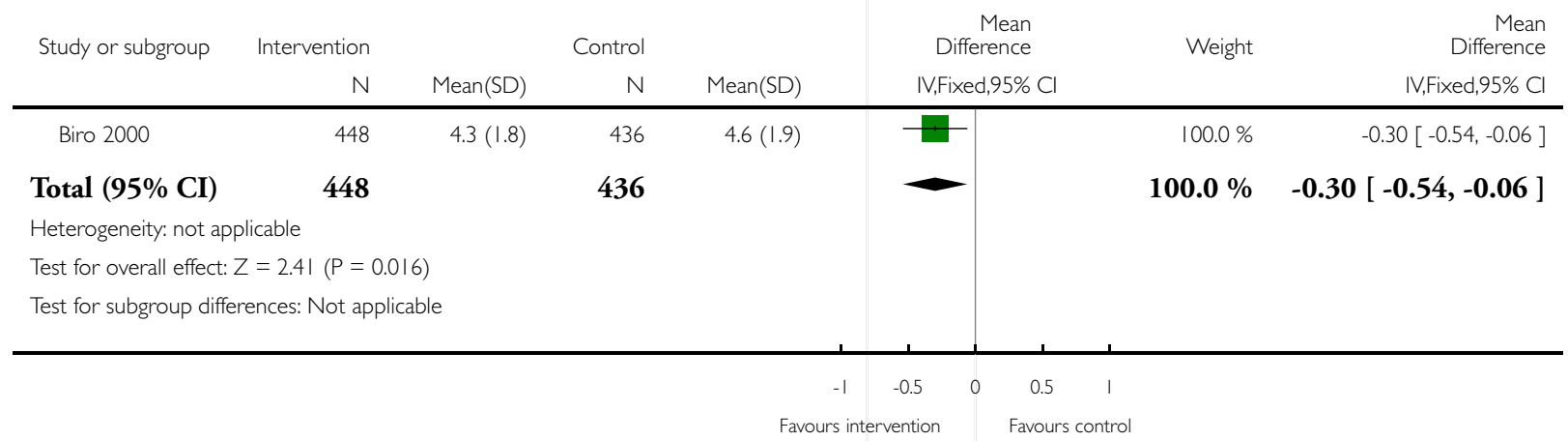


Analysis 3.3. Comparison 3 Team midwifery versus standard care, Outcome 3 Length of stay in SCN (days).

Review: Hospital nurse staffing models and patient and staff-related outcomes

Comparison: 3 Team midwifery versus standard care

Outcome: 3 Length of stay in SCN (days)

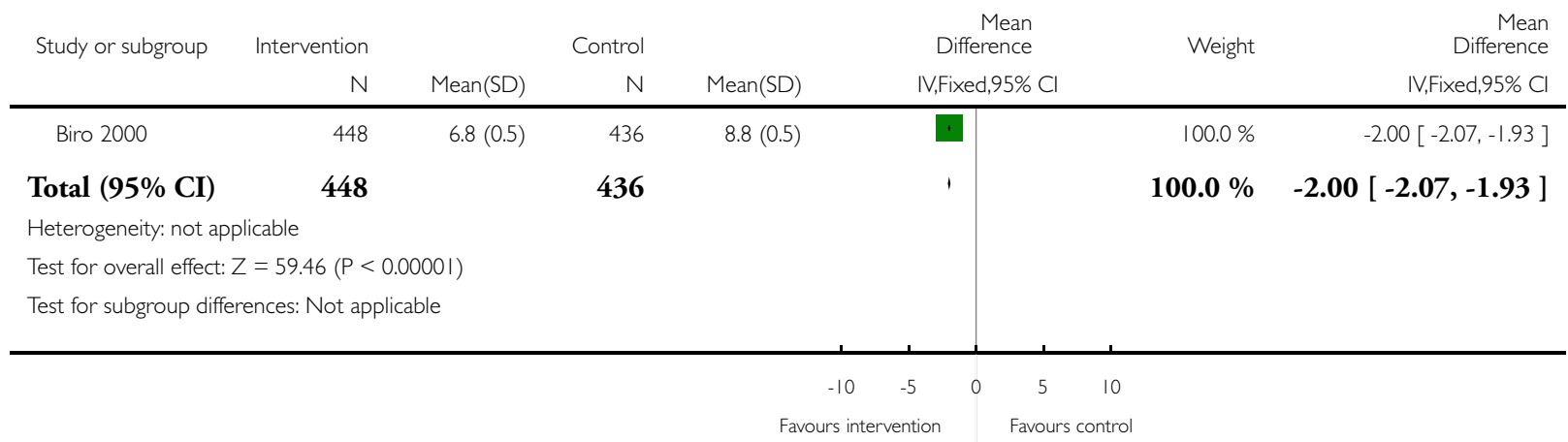

ADDITIONAL TABLES

Table 1. Sources of studies

\begin{tabular}{|c|c|c|c|c|c|}
\hline Source & & $\begin{array}{l}\text { Initial results/ } \\
\text { hits }\end{array}$ & $\begin{array}{l}\text { Potentially } \\
\text { relevant } \\
\text { studies }\end{array}$ & $\begin{array}{l}\text { Studies identified } \\
\text { for inclusion }\end{array}$ & $\begin{array}{l}\text { Studies included } \\
\text { following further } \\
\text { examination }\end{array}$ \\
\hline \multirow{9}{*}{$\begin{array}{l}\text { Database search to } \\
\text { November } 2007 \\
\text { using search strategy }\end{array}$} & CINAHL & 1,525 & & & \\
\hline & MEDLINE & 1,489 & & & \\
\hline & EMBASE & 819 & & & \\
\hline & CENTRAL & 186 & & & \\
\hline & DARE & 34 & 486 & 95 & \\
\hline & CAB Health & 9 & & & \\
\hline & Joanna Briggs & 0 & & & \\
\hline & Virginia Henderson & 0 & & & \\
\hline & EPOC register & 6 & & & \\
\hline
\end{tabular}


Table 1. Sources of studies (Continued)

\begin{tabular}{|c|c|c|c|c|c|}
\hline \multicolumn{2}{|c|}{$\begin{array}{l}\text { Supplementary search of all databases using } \\
\text { search strategy (July 2007-April 2009) }\end{array}$} & 1,461 & 91 & 7 & 15 \\
\hline \multicolumn{2}{|l|}{ Reference list search } & 312 & 193 & 16 & \\
\hline \multirow{6}{*}{$\begin{array}{l}\text { Grey literature us- } \\
\text { ing } \\
\text { search engines }\end{array}$} & OpenSIGLE & 48 & & & \\
\hline & Medscape & 116 & & & \\
\hline & $\begin{array}{l}\text { CRD (DARE \& } \\
\text { NHS EED) }\end{array}$ & 31 & & & \\
\hline & Biomed Central & 43 & 18 & 0 & \\
\hline & CRISP & 1 & & & \\
\hline & Google Scholar & 122 & & & \\
\hline TOTAL & & 6,202 & 788 & 118 & 15 \\
\hline
\end{tabular}

Table 2. Outcomes reported across studies

\begin{tabular}{l|ll|l|l|l|l|l|l}
\hline Study & Mortality & $\begin{array}{l}\text { Length } \\
\text { stay }\end{array}$ & of & $\begin{array}{l}\text { Readmission } \\
\text { rates }\end{array}$ & $\begin{array}{l}\text { Pressure ul- } \\
\text { cers }\end{array}$ & $\begin{array}{l}\text { Other clini- Costs } \\
\text { cal }\end{array}$ & Staff absence & Staff turnover \\
\hline
\end{tabular}

Adding a specialist nurse position(s) to staffing

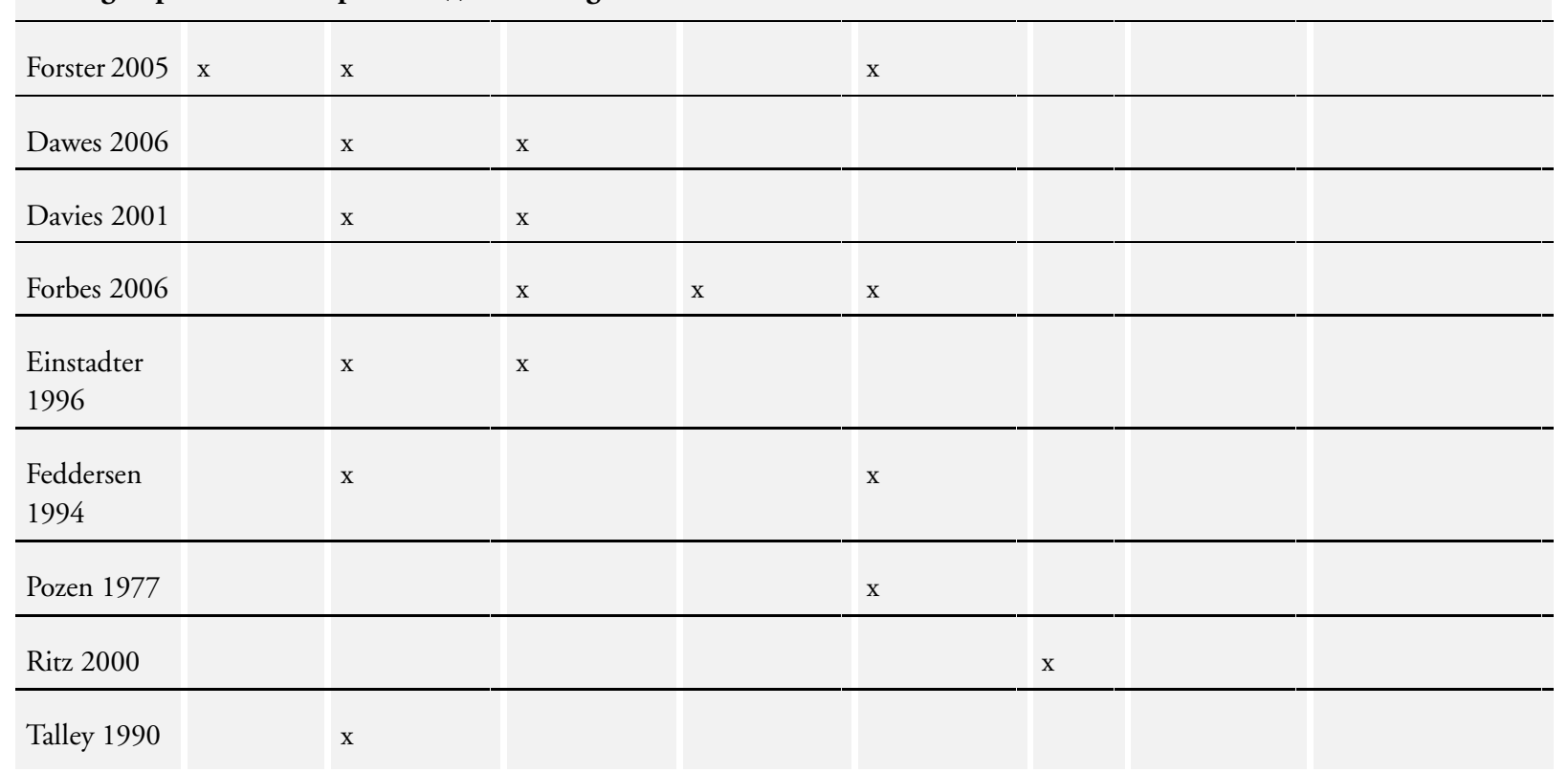


Table 2. Outcomes reported across studies (Continued)

Diluting the skill mix with UAPs or other support staff

\begin{tabular}{|c|c|c|c|c|c|}
\hline $\begin{array}{l}\text { Duncan } \\
2005\end{array}$ & $\mathrm{x}$ & $\mathrm{x}$ & & & \\
\hline $\begin{array}{l}\text { Neidlinger } \\
1993\end{array}$ & & & $\mathrm{x}$ & & \\
\hline \multicolumn{6}{|c|}{ Primary nursing versus usual staffing } \\
\hline $\begin{array}{l}\text { Boumans } \\
1999\end{array}$ & & & & $\mathrm{x}$ & \\
\hline $\begin{array}{l}\text { Melchoir } \\
1996\end{array}$ & & & & & $\mathrm{x}$ \\
\hline \multicolumn{6}{|c|}{ Self-scheduling versus usual scheduling } \\
\hline $\begin{array}{l}\text { O'Connor } \\
1992\end{array}$ & & & & & $\mathrm{x}$ \\
\hline
\end{tabular}

Notes: This table does not include the outcomes measured in Biro's (2000) study of team midwifery

Table 3. Results from Forbes 2006

\begin{tabular}{|c|c|c|c|c|}
\hline \multirow{3}{*}{$\begin{array}{l}\text { Forbes } 2006 \\
\text { Pressure sores (\%) }\end{array}$} & \multicolumn{4}{|c|}{ MS Specialist Nurse } \\
\hline & \multicolumn{2}{|c|}{ Post-Time 1} & \multicolumn{2}{|c|}{ Post-Time 2} \\
\hline & Study & Control & Study & Control \\
\hline Pre & 23 & 17 & 23 & 17 \\
\hline Post & 6 & 12 & 6 & 14 \\
\hline Change & -17 & -5 & -17 & -3 \\
\hline Pretest mean & 23 vs 17 & & 23 vs 17 & \\
\hline Posttest mean & 6 vs 12 & & 6 vs 14 & \\
\hline Absolute change (post): & -6 & & -8 & \\
\hline $\begin{array}{l}\text { Relative percentage } \\
\text { change (post): }\end{array}$ & -50.00 & & -57.14 & \\
\hline
\end{tabular}


Table 3. Results from Forbes 2006 (Continued)

\begin{tabular}{l|l|l}
$\begin{array}{l}\text { Absolute change from }-17 \text { vs }-5 \\
\text { baseline: }\end{array}$ & -17 vs -3 \\
\hline $\begin{array}{l}\text { Difference in absolute }-12 \\
\text { change from base }\end{array}$ & -14 \\
\hline
\end{tabular}

Table 4. Outcomes for addition of nursing assistive personnel to usual nurse staffing

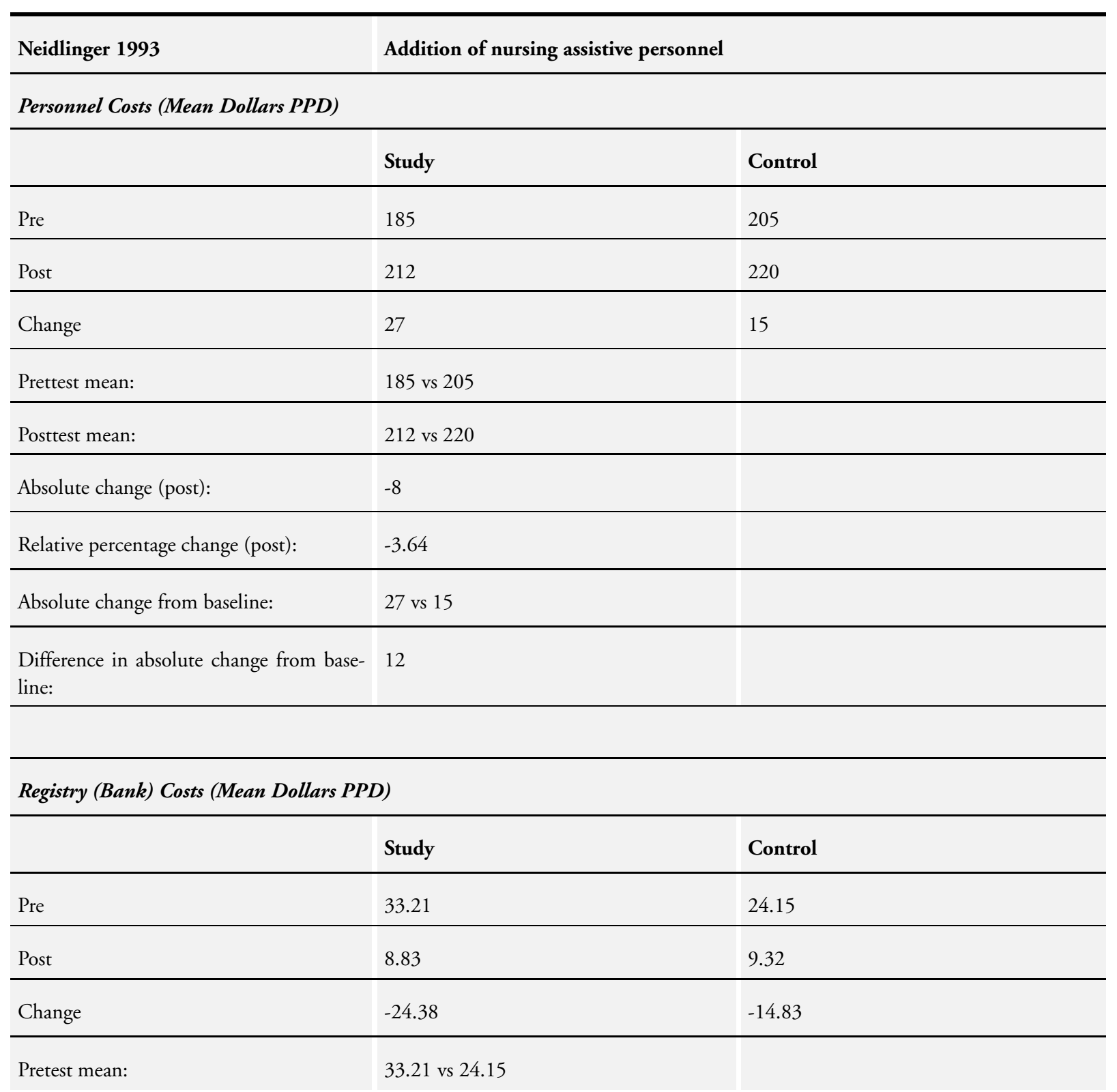


Table 4. Outcomes for addition of nursing assistive personnel to usual nurse staffing (Continued)

\begin{tabular}{l|l}
\hline Posttest mean: & 8.83 vs 9.32 \\
\hline Absolute change (post): & -0.49 \\
\hline Relative percentage change (post): & -5.26 \\
\hline Absolute change from baseline: & -24.38 vs -14.83 \\
\hline $\begin{array}{l}\text { Difference in absolute change from base- } \\
\text { line: }\end{array}$ & -9.55 \\
\hline
\end{tabular}

Table 5. Outcomes for self-staffing versus usual staffing models

\begin{tabular}{|c|c|c|c|c|}
\hline O'Connor 1992 & \multicolumn{4}{|c|}{ Self-staffing } \\
\hline & \multicolumn{4}{|c|}{ Group A vs Control (D) } \\
\hline \multirow[t]{2}{*}{ Turnover (\%) } & \multicolumn{2}{|l|}{ Post 1} & \multicolumn{2}{|l|}{ Post 2} \\
\hline & Study & Control & Study & Control \\
\hline Pre & 10 & 28 & 10 & 28 \\
\hline Post & 11 & 7 & 10 & 29 \\
\hline Change & 1 & -21 & 0 & 1 \\
\hline Pretest mean: & 10 vs 28 & & 10 vs 28 & \\
\hline Posttest mean: & 11 vs 7 & & 10 vs 29 & \\
\hline Absolute change (post): & 4 & & -19 & \\
\hline $\begin{array}{l}\text { Relative percentage } \\
\text { change (post): }\end{array}$ & 57.14 & & -65.52 & \\
\hline $\begin{array}{l}\text { Absolute change from } \\
\text { baseline: }\end{array}$ & 1 vs -21 & & 0 vs 1 & \\
\hline $\begin{array}{l}\text { Difference in absolute } \\
\text { change from baseline: }\end{array}$ & 22 & & -1 & \\
\hline
\end{tabular}

\section{Group B vs Control (D)}

Turnover (\%)

\section{Post 1}

Hospital nurse staffing models and patient and staff-related outcomes (Review)

Copyright () 201 I The Cochrane Collaboration. Published by John Wiley \& Sons, Ltd. 
Table 5. Outcomes for self-staffing versus usual staffing models (Continued)

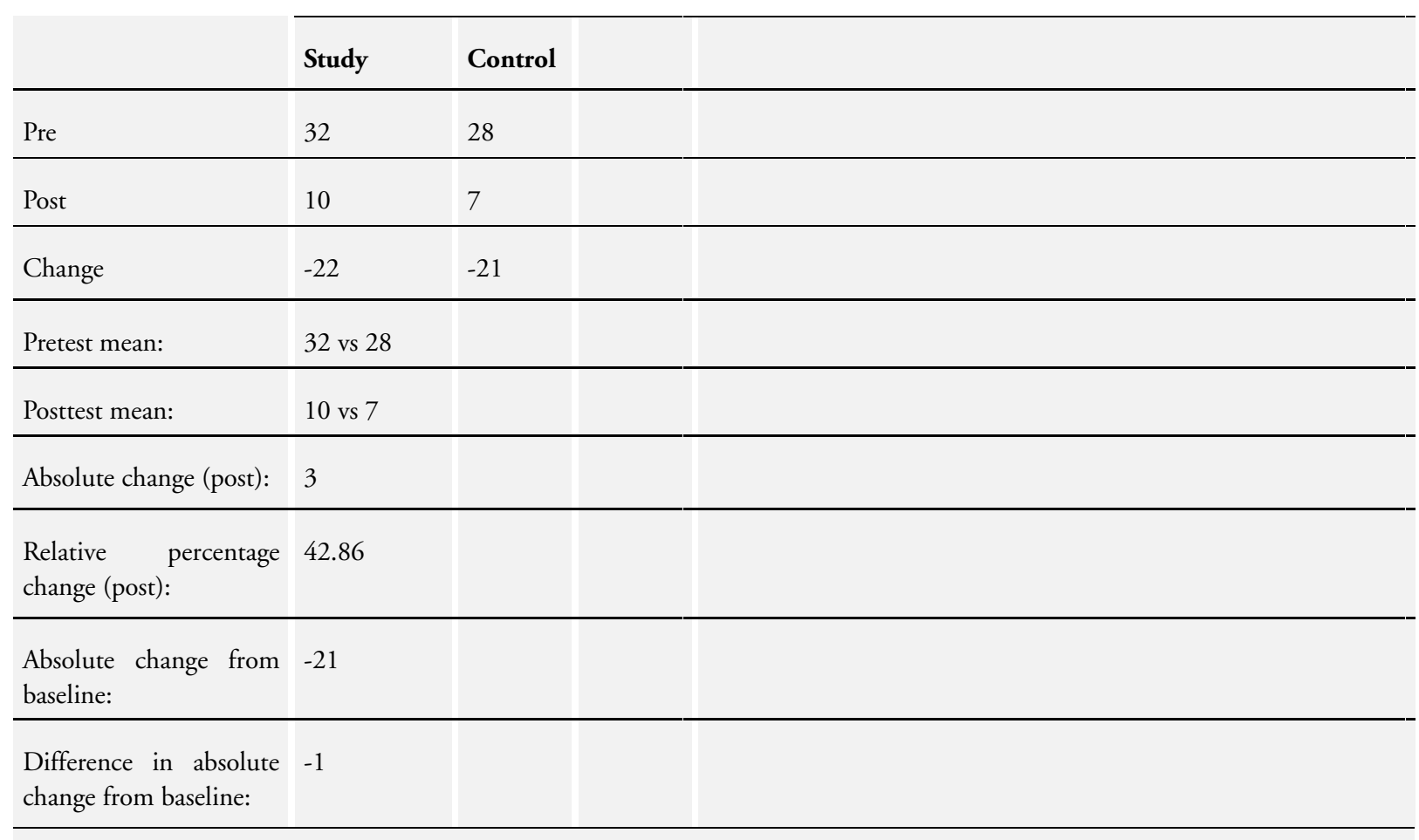

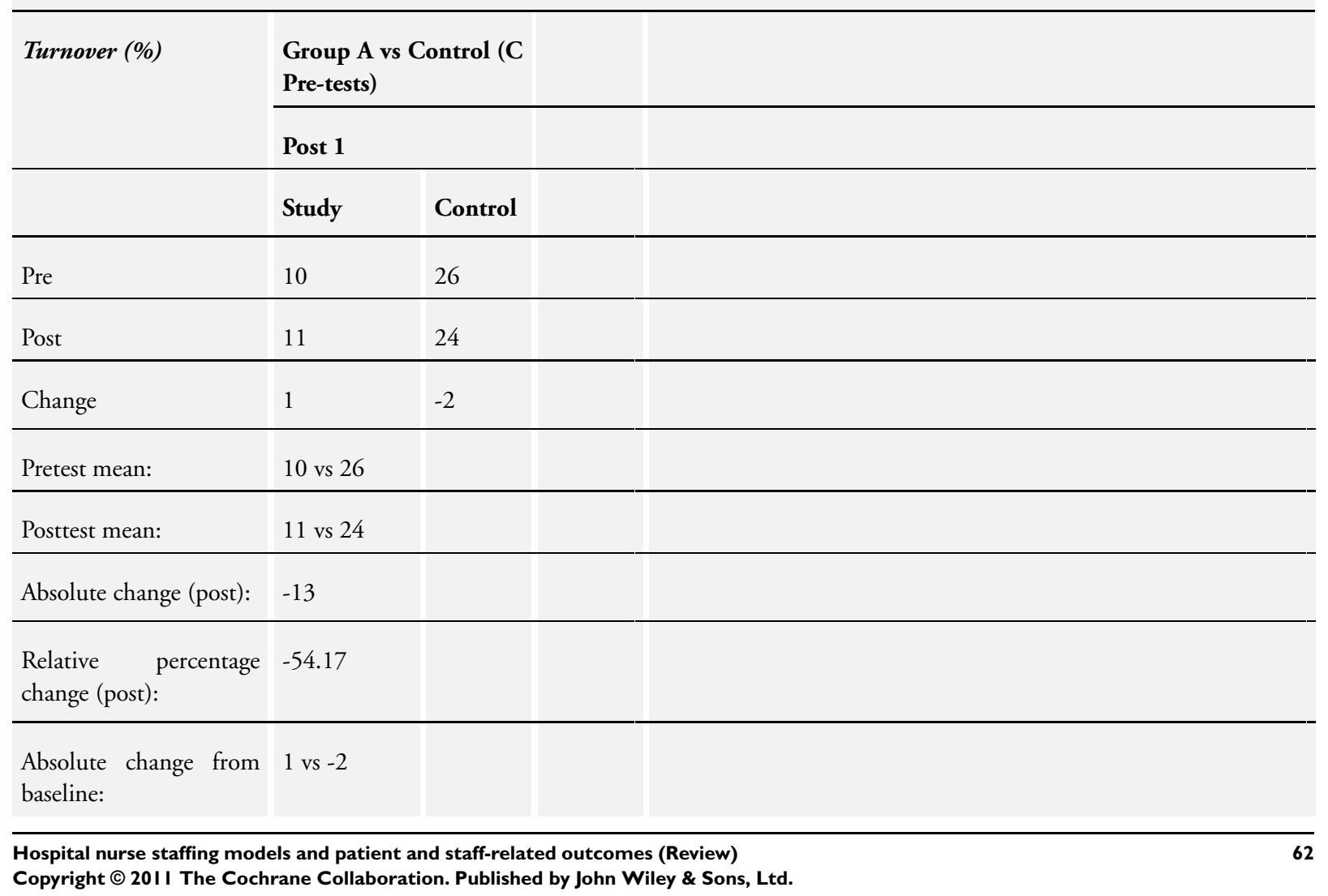


Table 5. Outcomes for self-staffing versus usual staffing models (Continued)

Difference in absolute 3

change from baseline:

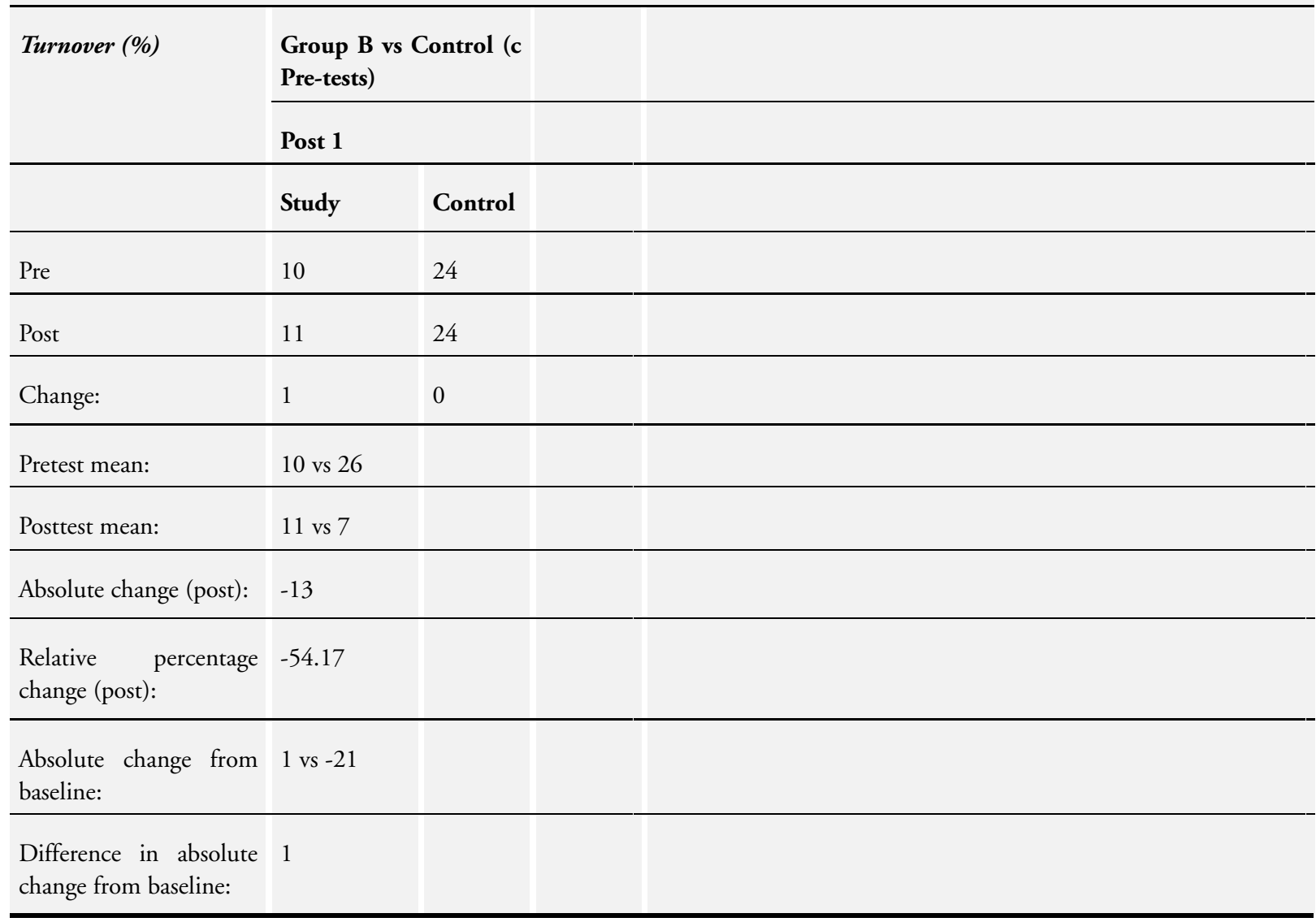

Table 6. Outcomes for primary nursing versus usual nursing model

\begin{tabular}{lllll}
\hline \multicolumn{3}{l}{ Boumans 1999} & \multicolumn{2}{l}{ Primary Nursing } \\
\hline $\begin{array}{l}\text { Absence } \\
(\text { mean })\end{array}$ & frequency & Post - Time 1 & & Post - Time 2 \\
\cline { 2 - 5 } & Study & Control & Study & Control \\
\hline Pre & 0.69 & 0.96 & 0.69 & 0.96 \\
\hline Post & 0.53 & 0.91 & 0.55 & 0.82 \\
\hline Change & -0.16 & -0.05 & -0.14 & -0.14
\end{tabular}


Table 6. Outcomes for primary nursing versus usual nursing model (Continued)

\begin{tabular}{l|l|l}
\hline Pretest mean: & 0.69 vs 0.96 & 0.69 vs 0.96 \\
\hline Posttest mean: & 0.53 vs 0.91 & 0.55 vs 0.82 \\
\hline $\begin{array}{l}\text { Absolute change (post): } \\
\text { Relative percentage } \\
\text { change (post): }\end{array}$ & -0.31 .76 & -0.27 \\
\hline $\begin{array}{l}\text { Absolute change from } \\
\text { baseline: }\end{array}$ & -0.16 vs -0.05 & -32.93 \\
\hline $\begin{array}{l}\text { Difference in absolute } \\
\text { change from baseline: }\end{array}$ & -0.11 & -0.14 vs -0.14 \\
\hline
\end{tabular}

\begin{tabular}{|c|c|c|c|c|}
\hline \multirow{2}{*}{$\begin{array}{l}\text { Absence duration } \\
\text { (mean days) }\end{array}$} & \multicolumn{2}{|l|}{ Post - Time 1} & \multicolumn{2}{|l|}{ Post - Time 2} \\
\hline & Study & Control & Study & Control \\
\hline Pre & 2.33 & 10.39 & 2.33 & 10.39 \\
\hline Post & 1.68 & 8.81 & 2.51 & 4.8 \\
\hline Change & -0.65 & -1.58 & 0.18 & -5.59 \\
\hline Pretest mean: & 2.33 vs 10.39 & & 2.33 vs 10.39 & \\
\hline Posttest mean: & 1.68 vs 8.81 & & 2.51 vs 4.8 & \\
\hline Absolute change (post): & -7.13 & & -2.29 & \\
\hline $\begin{array}{l}\text { Relative percentage } \\
\text { change (post): }\end{array}$ & -80.93 & & -47.71 & \\
\hline $\begin{array}{l}\text { Absolute change from } \\
\text { baseline: }\end{array}$ & -0.65 vs -1.58 & & 0.18 vs -5.59 & \\
\hline $\begin{array}{l}\text { Difference in absolute } \\
\text { change from baseline: }\end{array}$ & 0.93 & & 5.77 & \\
\hline
\end{tabular}

\begin{tabular}{l|l|l}
\hline Mechoir 1996 & Primary Nursing & \\
\hline Job Turnover (\%) & Study & Control \\
\hline Pre* & - \\
\hline $\begin{array}{l}\text { Hospital nurse staffing models and patient and staff-related outcomes (Review) } \\
\text { Copyright } \odot 20 \text { II The Cochrane Collaboration. Published by John Wiley \& Sons, Ltd. }\end{array}$
\end{tabular}


Table 6. Outcomes for primary nursing versus usual nursing model

\begin{tabular}{l|l|l}
\hline Post & 17.1 & 26.7 \\
\hline Change & - & \\
\hline Pretest mean: & - \\
\hline Posttest mean: & 17.1 vs 26.7 \\
\hline Absolute change (post): & percentage & -35.96 \\
\hline $\begin{array}{l}\text { Relative } \\
\text { change (post): }\end{array}$ \\
\hline $\begin{array}{l}\text { Absolute change from } \\
\text { baseline: }\end{array}$
\end{tabular}

*Turnover values before intervention (pretest) not reported

\section{A P P E N D I CES}

\section{Appendix I. Search strategies}

Appendix One: Search strategies used for MEDLINE, CINAHL, EMBASE and CAB Health

\section{Search Strategy: Ovid MEDLINE(R)}

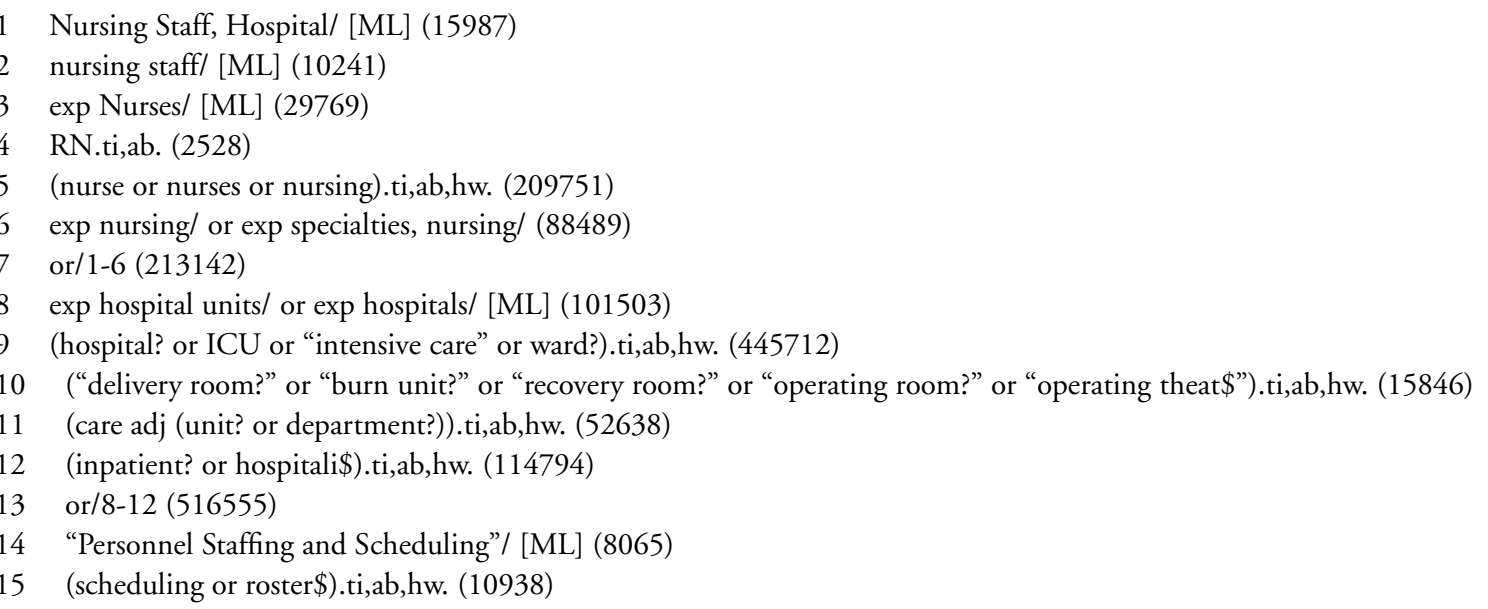



overtime) adj shift?).ti,ab. (1700)

19 (skill? adj2 mix\$).ti,ab. (369)

20 or/14-19 (35979)

$21 \quad 7$ and 13 and 20 (5238)

22 randomized controlled trial/ or controlled clinical trial/ [ML EM] (108984)

23 clinical trial/ [ML] (165107)

56 ("quasi-experiment\$” or quasiexperiment\$ or “quasi random\$” or quasirandom\$ or "quasi control\$” or quasicontrol\$ or (quasi\$ adj3 (method\$ or study or studies or trial or design\$)) ).ti,ab. (5950)

57 ("time series" adj2 interrupt\$).ti,ab,hw. (573)

58 or/52-57 (459720)

59 (outcome $\$$ or policy or policies or quality).ti,ab,hw. (1173913)

60 cost\$.ti,ab,hw. or economics.fs. (294449)

61 “organization \& administration”.fs. [ML] (214924)

62 implement\$.ti,ab,hw. (133294)

63 or/59-62 (1562076)

6421 and $63(3980)$

65 limit 64 to ed=“20070701 - 20090430” (1039)

Hospital nurse staffing models and patient and staff-related outcomes (Review) 
66 limit 65 to humans (992)

6718 or 15 or 14 (12361)

68 (Staff\$ adj2 (model? or plan\$ or structure? or improv\$)).ti,ab. (1433)

6967 or 68 (13597)

706 or 4 or 1 or 3 or 2 (122608)

71 (nursing adj2 (care or staff? or employee? or aide? or registered or practical or clinical)).ti,ab. (15818)

7270 or $71(130406)$

7369 and $72(4846)$

74 limit 73 to ed=“20070701 - 20090430” (1151)

75 limit 74 to humans (1113)

$76 \quad 69$ and 13 (5904)

77 limit 76 to humans (5199)

78 limit 77 to ed=“20070701 - 20090430” (1433)

79 or/ $66,75,78(2227)$

80 from 79 keep 1-2227 (2227)

\section{Database: CINAHL - Cumulative Index to Nursing \& Allied Health Literature Search Strategy:}

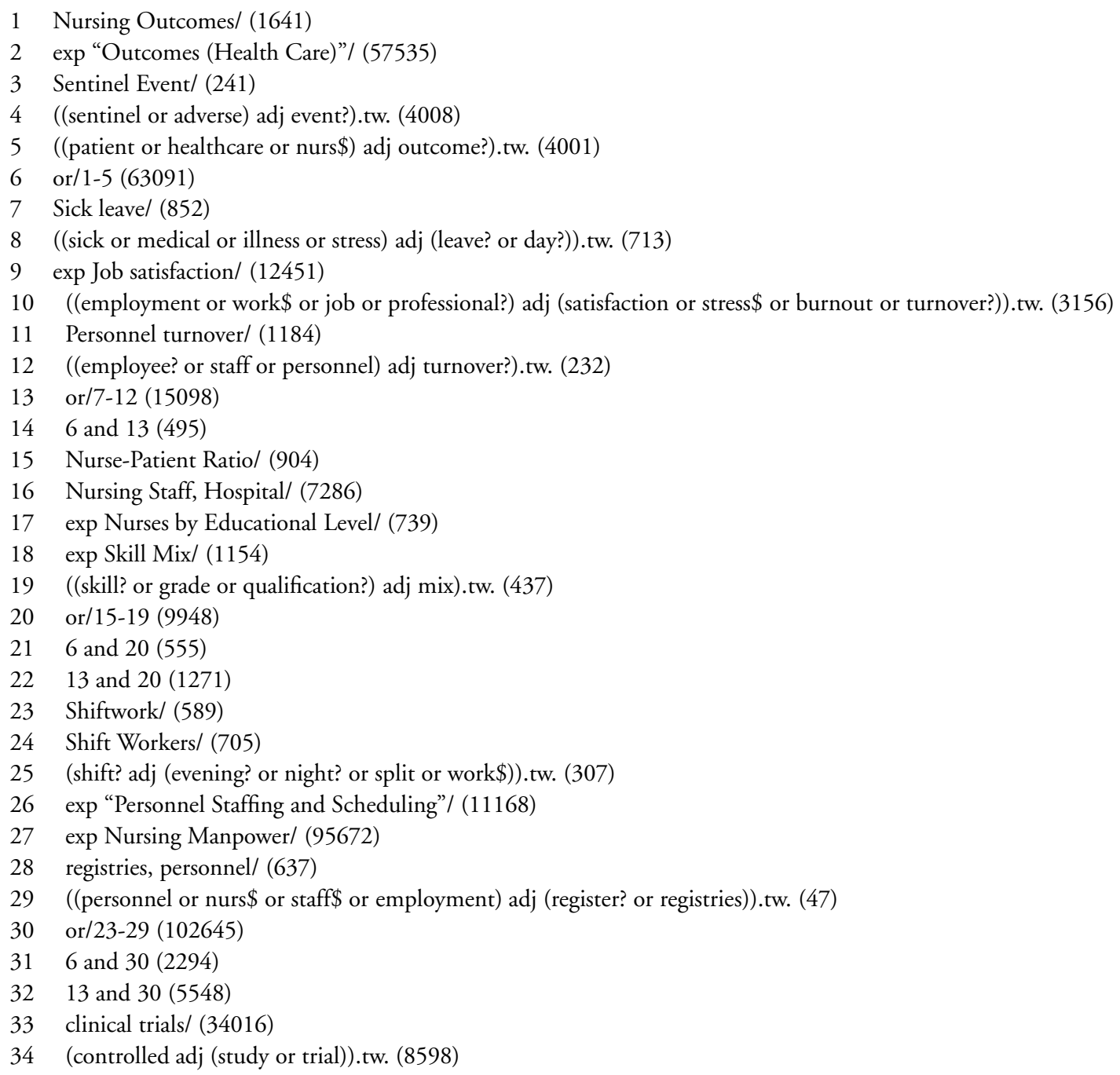

Hospital nurse staffing models and patient and staff-related outcomes (Review)

Copyright @ 201 I The Cochrane Collaboration. Published by John Wiley \& Sons, Ltd. 
(randomised or randomized).tw. (26549)

(random\$ adj1 (allocat\$ or assign\$)).tw. (6691)

exp pretest-posttest design/ (10261)

exp quasi-experimental studies/ (3727)

comparative studies/ (40478)

time series/ (671)

(time adj series).tw. (559)

experiment\$.tw. (14619)

intervention?.tw. (60951)

or/33-43 (148816)

(21 or 22 or 31 or 32$)$ and 44 (923)

nursing home?.tw. (7592)

45 not $46(881)$

\section{Search Strategy: EMBASE}

1 nursing staff/ [EM] (3021)

2 exp Nurse/ [EM] (18236)

3 exp nursing/ [EM] (15646)

RN.ti,ab. (1791)

(nurse or nurses or nursing).ti,ab,hw. (74788)

or/1-5 (76475)

7 hospital/ or community hospital/ or general hospital/ or geriatric hospital/ or non profit hospital/ or pediatric hospital/ or private hospital/ or public hospital/ or "hospital subdivisions and components"/ or delivery room/ or hospital department/ or operating room/ or recovery room/ or exp ward/ or exp mental hospital/ or exp teaching hospital/ [EM] (132314)

8 (hospital? or ICU or intensive care).ti,ab,hw. (518246)

9 ((care adj (unit? or department?)) or ward?).ti,ab,hw. (99201)

10 (inpatient? or hospitali\$).ti,ab,hw. (149253)

11 or/7-10 (615734)

12 (scheduling or roster\$).ti,ab,hw. (3618)

13 work schedule/ [EM] (2528)

14 staffing.ti,ab. (3259)

15 night work/ or working time/ [EM] (3382)

16 ( (day\$ or night\$ or work\$ or job? or rotat\$ or team \$ or interval? or "long-hour?" or alternat $\$$ or enhanc\$ or shared or group? or overtime) adj shift?).ti,ab. (1864)

17 (skill? adj2 mix\$).ti,ab. (164)

18 or/12-17 (13443)

19 randomized controlled trial/ or controlled clinical trial/ [EM] (179176)

20 controlled study/ [EM] (2877472)

21 evaluation/ or evaluation research/ or outcome assessment/ [EM] (114426)

22 clinical study/ or major clinical study/ [EM] (1298376)

23 intervention study/ [EM] (4834)

24 practice guideline/ [EM] (104043)

25 validation study/ [EM] (6624)

26 pilot study/ [EM] (14168)

27 comparative study/ [EM] (117375)

28 or/19-27 (3803218)

29 random\$.ti,ab,hw. (436937)

30 (controlled or (control\$ adj2 (group? or study or studies or trial?))).ti,ab. (478382)

31 (evaluat\$ adj (study or studies)).ti,ab. (2403)

32 intervention?.ti,ab. (261197)

33 guideline?.ti,ab. (95716)

Hospital nurse staffing models and patient and staff-related outcomes (Review)

Copyright $\odot 201$ I The Cochrane Collaboration. Published by John Wiley \& Sons, Ltd. 
34 (protocol? adj2 (practice? or adherence or adhere?)).ti,ab. (444)

35 (piloting or (pilot adj (study or project? or studies or program?))).ti,ab. (32596)

36 evidence-base?.ti,ab. (25124)

37 or/29-36 (1096535)

38 chi square test/ or monte carlo method/ or latin square design/ [EM] (13358)

39 control group/ or crossover procedure/ or experimental design/ or pretest posttest control group design/ or pretest posttest design/ or single blind procedure/ or double blind procedure/ or triple blind procedure/ [EM] (97897)

40 or/38-39 (110998)

41 (“pre test $\$$ ” or pretest $\$$ or posttest $\$$ or “post test $\$$ ”).ti,ab. (9297)

42 ((single\$ or double\$ or triple\$ or treble\$) adj (blind\$ or mask\$)).ti,ab. (93701)

43 ("chi square\$” or “monte carlo\$” or "latin square").ti,ab. (26549)

44 ((control\$ adj2 (before or after or group\$ or trial\$ or study or studies or design\$ or method\$ or clinical)) or controlled).ti,ab. (517612)

45 ("quasi-experiment\$” or quasiexperiment\$ or “quasi random\$” or quasirandom\$ or "quasi control\$” or quasicontrol\$ or (quasi\$ $\operatorname{adj} 3(\operatorname{method} \$$ or study or studies or trial or design\$))).ti,ab. (3107)

46 ("time series" adj2 interrupt\$).ti,ab,hw. (299)

47 intervention\$.ti,ab,hw. (288389)

48 or/41-47 (835632)

49 (outcome\$ or policy or policies or quality).ti,ab,hw. (1137375)

50 cost\$.ti,ab,hw. or economics.fs. (280283)

51 implement\$.ti,ab,hw. (97463)

52 or/49-51 (1379850)

53 or $28,37,40,48,52(4924618)$

$54 \quad 6$ and 11 and 18 and 53 (913)

55 limit 54 to em=“200726 - 200917” (79)

56 limit 55 to human (63)

57 or/12-13,15-17 (10415)

58 (Staff\$ adj2 (model? or plan\$ or structure? or improv\$)).ti,ab. (1150)

59 or/57-58 (11521)

60 or/1-4 (35785)

61 (nursing adj2 (care or staff? or employee? or aide? or registered or practical or clinical)).ti,ab. (7936)

62 or/60-61 (39606)

6359 and $11(2931)$

64 limit 63 to em=“200726 - 200917” (309)

65 limit 64 to human (230)

$66 \quad 59$ and 62 (958)

67 limit 66 to em=“200726 - 200917” (75)

68 limit 67 to human (59)

69 (nurs\$ adj2 (competence or education\$)).ti,ab. and 18 (33)

70 limit 69 to human (19)

71 (nurs\$ adj2 (competence or education\$ or degree? or bachelor? or master? or registered)).ti,ab. (2476)

7271 and $18(208)$

73 limit 72 to human (136)

74 limit 73 to em=“200726 - 200917” (10)

7556 or 68 or $65(281)$

76 from 75 keep 1-281 (281)

\section{Search strategy: CAB Global Health Search Strategy}

"nursing outcome?” OR "health outcome?” or "patient outcome?” OR “nursing outcome?” OR “care outcome?” OR "sentinel event? ” OR “adverse event?” OR "sentinel surveillance” OR “sick leave” OR “sick day?” OR "medical leave” OR "illness leave” OR "stress leave” OR “job satisfaction” OR “job burnout” OR “job stress” OR “job turnover” OR "professional satisfaction” OR "professional burnout" OR "professional stress" OR "personnel turnover" OR “employee turnover” OR "staff turnover"

Hospital nurse staffing models and patient and staff-related outcomes (Review)

Copyright @ 201 I The Cochrane Collaboration. Published by John Wiley \& Sons, Ltd. 
AND

shift? OR shift work* OR schedule* OR scheduling OR manpower OR staffing OR "personnel management" OR "skill mix" OR

"clinical competence" or "clinical competencies" OR qualification*

AND

nurs*

AND

random* OR control* OR intervention? OR "time series" OR experiment* OR evaluat*

\section{H I S T O R Y}

Protocol first published: Issue 1, 2008

Review first published: Issue 7, 2011

\section{CONTRIBUTIONSOFAUTHORS}

All authors have contributed to this systematic review. MB led the writing of the protocol, all other authors provided comment and feedback. For the full review: MB and EPOC librarians /UCD librarians developed the search strategy and ran the search. MB, RC, $\mathrm{PH}, \mathrm{AS}$, TS and EV screened records for eligibility. DO'M acted as local supervisor and provided valuable support and advice to the team. MB, RC, PH, AS, JD, TS and EV extracted data. MB, RC, PH, AS and JD contributed to the analysis and the interpretation of results. $\mathrm{MB}$ wrote up the review with feedback from all authors.

\section{DECLARATIONSOF INTEREST}

None

\section{SOURCES OF SUPPORT}

\section{Internal sources}

- UCD School of Nursing, Midwifery and Health Systems, Ireland.

- Dublin City University, Ireland.

- Joanna Briggs Institute, Australia.

- University of Ottawa, Canada.

\section{External sources}

- Health Research Board, Ireland. 


\section{DIFFERENCES BETWEEN PROTOCOLANDREVIEW}

None with the exception of analysis limitations.

\section{NDEX TERMS}

\section{Medical Subject Headings (MeSH)}

*Models, Nursing; Clinical Trials as Topic; Midwifery [organization \& administration]; Nursing Staff, Hospital [*organization \& administration]; Outcome Assessment (Health Care); Personnel Staffing and Scheduling [*organization \& administration]; Specialties, Nursing [organization \& administration]

\section{MeSH check words}

Humans 